\title{
Observations of hydroxyl ground state transitions in a complete sample of methanol sources ${ }^{\star, \star \star}$
}

\author{
M. Szymczak ${ }^{1}$ and E. Gérard ${ }^{2}$ \\ 1 Torun Centre for Astronomy, Nicolaus Copernicus University, Gagarina 11, 87-100 Torun, Poland \\ 2 GEPI, UMR 8111, Observatoire de Paris, 5 place J. Janssen, 92195 Meudon Cedex, France
}

Received 6 June 2003 / Accepted 1 October 2003

\begin{abstract}
High sensitivity observations of all four transitions of the ground state ${ }^{2} \Pi_{3 / 2}, J=3 / 2$ of $\mathrm{OH}$ in both senses of circular polarization have been carried out with the Nançay radio telescope. The sample was a set of 100 star forming regions detected in a recent unbiased survey of $6668 \mathrm{MHz} \mathrm{CH} \mathrm{CH}_{3} \mathrm{OH}$ masers. $\mathrm{OH}$ maser emission was found in 55 objects of which 31 were not previously catalogued. The $1665 \mathrm{MHz}$ line was seen in almost all $\mathrm{OH}$ maser sources and was accompanied by the $1667 \mathrm{MHz}$ line in about $75 \%$ of cases. Respectively $7 \%$ and $11 \%$ of $\mathrm{OH} 1665 \mathrm{MHz}$ masers were accompanied by maser lines at 1612 and $1720 \mathrm{MHz}$. These two satellite line masers never occurred simultaneously in the same source nor at the same radial velocity, suggesting mutually exclusive physical conditions as predicted by models. $\mathrm{OH}$ maser emission usually shared the same velocity range as the $6668 \mathrm{MHz} \mathrm{CH} \mathrm{CH}_{3} \mathrm{OH}$ maser. The intensity ratio of the $6668 \mathrm{MHz}$ and $1665 \mathrm{MHz}$ lines clearly divides the sample into methanol- and hydroxyl-rich sources and could be controlled by the abundance of maser molecules and the kinetic temperature. The $\mathrm{OH}$ maser emission was substantially polarized with a mean fractional circular polarization of 0.30 and Zeeman pair candidates were found in 15 targets. 36 sources were found in $\mathrm{OH}$ absorption at the main lines and 24 of them were also accompanied by $\mathrm{OH}$ maser emission. $\mathrm{OH}$ absorption features were blueshifted with regard to the related $\mathrm{OH}$ masers, indicating that they were formed in front of the central continuum sources. Absorption at $1720 \mathrm{MHz}$ was always accompanied by emission at $1612 \mathrm{MHz}$ and vice versa. The behaviour of stimulated emission and absorption in both satellite lines was thus conjugated and the $1720 \mathrm{MHz}$ emission features seem to be signatures of regions of low hydrogen density and $\mathrm{OH}$ column density. The correlation of $\mathrm{OH}$ and $\mathrm{CH}_{3} \mathrm{OH}$ flux densities with the IRAS flux densities found for our sample appears to support pumping schemes of both molecules by infrared photons. Statistics of masers in the sample appear to be consistent with the scenario that the $\mathrm{CH}_{3} \mathrm{OH}$ masers appeared earlier than the $\mathrm{OH}$ masers.
\end{abstract}

Key words. masers - surveys - stars: formation - ISM: molecules - radio lines: ISM - HII regions

\section{Introduction}

Since its discovery more than three decades ago, $\mathrm{OH}$ maser emission from the ground state transitions is a widely used tool to study the environments of ongoing or recently formed massive stars. The most extensive survey of all four $18 \mathrm{~cm} \mathrm{OH}$ lines near the Galactic plane with various sampling densities, different areas and targeted to specific objects was carried out by Turner (1979). Subsequent systematic surveys of the main line $\mathrm{OH}$ masers in the Galactic plane extended to weaker sources of the southern sky (Caswell \& Haynes 1983a, 1983b). Those surveys provided a large data set which revealed a close association of $\mathrm{OH}$ masers with other signs of star formation such

Send offprint requests to: M. Szymczak, e-mail: msz@astro.uni.torun.pl

* Figure A1 is only available in electronic form via http://www. edpsciences.org

$\star \star$ Tables 1, 2, 4 are only, and Table 3 also, available at the CDS via anonymous ftp to cdsarc.u-strasbg.fr $(130.79 .128 .5)$ or via http://cdsweb.u-strasbg.fr/cgi-bin/qcat?J/A+A/414/235 as compact HII regions, infrared objects, and masers of other species.

An efficient way to search for $\mathrm{OH}$ masers was revealed with the release of IRAS all sky data. Observations of IRAS-selected ultra compact HII region candidates were successful in obtaining a more complete set of OH masers (Cohen et al.1988; Moore et al. 1988; Slysh et al. 1994, 1997) and supported a far infrared pumping scheme of the main lines.

The detection of a very strong and widespread $\mathrm{CH}_{3} \mathrm{OH}$ maser line at $6668 \mathrm{MHz}$ (Menten 1991) has allowed more efficient investigation of star formation sites. The data sets resulting from various surveys of the $6668 \mathrm{MHz}$ masers offered more complete samples of targets for $\mathrm{OH}$ maser studies (Gaylard et al. 1994; Szymczak \& Kus 2000). Caswell (1997) suggested that $\mathrm{CH}_{3} \mathrm{OH}$ masers probe the environment of young stars in a somewhat earlier phase than $\mathrm{OH}$ masers, so it follows that observations of $\mathrm{OH}$ lines arising from $\mathrm{CH}_{3} \mathrm{OH}$ sources can be important for building a more general picture of maser properties and hosting sites. 
Unbiased surveys of the $6668 \mathrm{MHz} \mathrm{CH}_{3} \mathrm{OH}$ masers (Caswell 1996; Ellingsen et al. 1996; Szymczak et al. 2002) significantly improved statistics on sites of star formation, providing excellent lists of targets for further observations. In this paper we report on the $\mathrm{OH}$ survey of a sample of $\mathrm{CH}_{3} \mathrm{OH}$ masers detected in a blind survey of a $21 \mathrm{deg}^{2}$ region in the Galactic plane (Szymczak et al.2002). Our aims are to derive the detection rate and to depict properties of all four ground state $\mathrm{OH}$ transitions. The $\mathrm{OH}$ data obtained allow us to diagnose the physical conditions in the environments of the target sites. Additionally this study provides some constraints for pumping schemes proposed for $\mathrm{CH}_{3} \mathrm{OH}$, notably the recent model by Cragg et al. (2002, hereafter CSG02). This investigates the conditions under which $\mathrm{CH}_{3} \mathrm{OH}$ and $\mathrm{OH}$ masers can arise together from the same region, and the implications if only certain combinations of the possible lines are seen.

\section{Observations}

The measurements were carried out using the upgraded Nançay radio telescope (van Driel et al. 1996) from October 2001 to March 2002. At $18 \mathrm{~cm}$ the instrument had a half-power beamwidth of 3.5 in the E-W direction and $19^{\prime}$ in the N-S direction. The beam efficiency was 0.65 , the point source efficiency at $\delta=0^{\circ}$ was $1.4 \mathrm{~K} \mathrm{Jy}^{-1}$ and the system temperature was about $35 \mathrm{~K}$. All four transitions of the ground $\mathrm{OH}$ state $\left({ }^{2} \Pi_{3 / 2}, J=3 / 2\right)$ were observed simultaneously in both orientations of circular polarization using a 8192 channel autocorrelator configured into eight banks of 1024 channels. Each bank had a bandwidth of $1.5625 \mathrm{MHz}$ yielding velocity resolutions of $0.284,0.275,0.274$ and $0.266 \mathrm{~km} \mathrm{~s}^{-1}$ at $1612,1665,1667$ and $1720 \mathrm{MHz}$, respectively. The total useful velocity coverage was about $\pm 140 \mathrm{~km} \mathrm{~s}^{-1}$. The radial velocities were measured with respect to the local standard of rest. The spectral bandwidth was centred at the middle velocity of the $6668 \mathrm{MHz}$ $\mathrm{CH}_{3} \mathrm{OH}$ emission range of each target. Spectra of each source were taken in the frequency switching mode with an integration time of about $18 \mathrm{~min}$. A typical $1 \sigma$ noise level for a single polarization was about $40 \mathrm{mJy}$. The data were calibrated by comparison observations of $\mathrm{W} 12$ and $\mathrm{W} 3 \mathrm{OH}$ and the absolute flux density was determined with an accuracy better than $10 \%$.

The sample of targets was a set of $100 \mathrm{CH}_{3} \mathrm{OH}$ sources found by Szymczak et al. (2002) in an unbiased survey for $6668 \mathrm{MHz}$ maser emission. That survey was restricted to the Galactic plane between $20^{\circ} \leq l \leq 40^{\circ}$ and $|b| \leq 0.52$, providing a large complete sample of young star forming regions.

\section{Results}

Tables 1 and 2 list the sources detected in the main and satellite $\mathrm{OH}$ lines, respectively. These tables and further discussion only refer to those features that appeared at velocities that differ by less than $5 \mathrm{~km} \mathrm{~s}^{-1}$ from the velocity range of $6668 \mathrm{MHz}$ $\mathrm{CH}_{3} \mathrm{OH}$ maser emission (Szymczak et al. 2002). This criterion results from observations; the typical velocity extent of previously known $\mathrm{OH}$ and $\mathrm{CH}_{3} \mathrm{OH}$ masers in star forming regions is about $10 \mathrm{~km} \mathrm{~s}^{-1}$ (Caswell et al. 1995). OH emission and absorption of those objects in our sample which do not meet this criterion appear to come from objects unrelated to the $\mathrm{CH}_{3} \mathrm{OH}$ sources. The first two columns of Tables 1 and 2 give the source name and date of observation. The line properties derived from the $I$ Stokes parameter spectra are the velocity interval at zero intensity $\Delta V$ (all velocities in $\mathrm{km} \mathrm{s}^{-1}$ ) over which $\mathrm{OH}$ emission was detected, the centre $V_{\mathrm{c}}$ of this interval, the velocity $V_{\mathrm{p}}$ and the flux density $S_{\mathrm{p}}$ (in Jy) of the strongest feature and the integrated flux density $S_{\mathrm{i}}$ (in Jy km s${ }^{-1}$ ). The $3 \sigma$ noise level is given when no line was detected. A rich variety in the polarization characteristics of $\mathrm{OH}$ emission can be seen in the spectra themselves, while only the degree of circular polarization $m_{\mathrm{c}}=\left(S_{\mathrm{i}}(R)-S_{\mathrm{i}}(L)\right) /\left(S_{\mathrm{i}}(R)+S_{\mathrm{i}}(L)\right)$ is given in Tables 1 and 2. Here $S_{\mathrm{i}}(L)$ and $S_{\mathrm{i}}(R)$ is the integrated flux density in left and right circular polarization, respectively. The degree of polarization is omitted for absorption and/or quasi-thermal emission features as they are unpolarized within the noise limits. The known OH sources are labelled to show where they were published. The spectra of most known sources, taken about twenty years ago, were published by Caswell \& Haynes (1983b) and usually look very different from ours. Thus, we make the complete set of $\mathrm{OH}$ spectra available in electronic form (Fig. A1) in the whole velocity range observed. The spectra are the lefthanded and right-handed circular polarization at 1612, 1665, 1667 and $1720 \mathrm{MHz}$, respectively, from top to bottom. Note that along the lines of sight towards several target sources there are several absorption and likely quasi-thermal emission features as well as the characteristic $\mathrm{OH} / \mathrm{IR}$ star profiles seen at $1612 \mathrm{MHz}$ (e.g. the source G20.08-0.14 in Fig. A1) unrelated to the $\mathrm{CH}_{3} \mathrm{OH}$ sources. For the features related to the $\mathrm{CH}_{3} \mathrm{OH}$ sources the velocity centroid of the Gaussian fitted line profile was measured rather than $V_{\mathrm{p}}$ determined for the $\mathrm{OH}$ maser emission. $V_{\mathrm{p}}$ is equal to $V_{\mathrm{c}}$ for almost all the non-maser lines. About $73 \%$ of entries in Table 1 and possibly all entries in Table 2 were not previously catalogued.

\subsection{Variety of spectra}

The spectra of representative sources are shown in Fig. 1. The source $24.79+0.09$ shows the $\mathrm{OH}$ maser emission at both main lines superimposed on the broad and weak absorption feature centred near $109 \mathrm{~km} \mathrm{~s}^{-1}$. At a similar velocity the satellite lines at 1612 and $1720 \mathrm{MHz}$ show emission and absorption, respectively. There are 13 sources in our sample that exhibit such a morphology of $\mathrm{OH}$ emission and similarly 4 other sources but with absorption and emission at 1612 and $1720 \mathrm{MHz}$, respectively. In the group of sources typified by $24.79+0.09$ the $6668 \mathrm{MHz} \mathrm{CH}_{3} \mathrm{OH}$ maser coincides in velocity with the $\mathrm{OH}$ maser and quasi-thermal profiles.

The source 30.76-0.05 is typical of a group of 6 sources in the sample where the $\mathrm{OH}$ main line masers are superimposed on a deep and broad absorption profile (Fig. 1). The two satellite lines show conjugate behaviour. The $1612 \mathrm{MHz}$ line shows absorption at velocities slightly blueshifted from the main line masers, while the $1720 \mathrm{MHz}$ line shows emission. At redshifted velocities with respect to the absorption peak at main lines, the $1612 \mathrm{MHz}$ line is seen in emission, while the $1720 \mathrm{MHz}$ line in absorption. Generally, the two satellite lines have different 


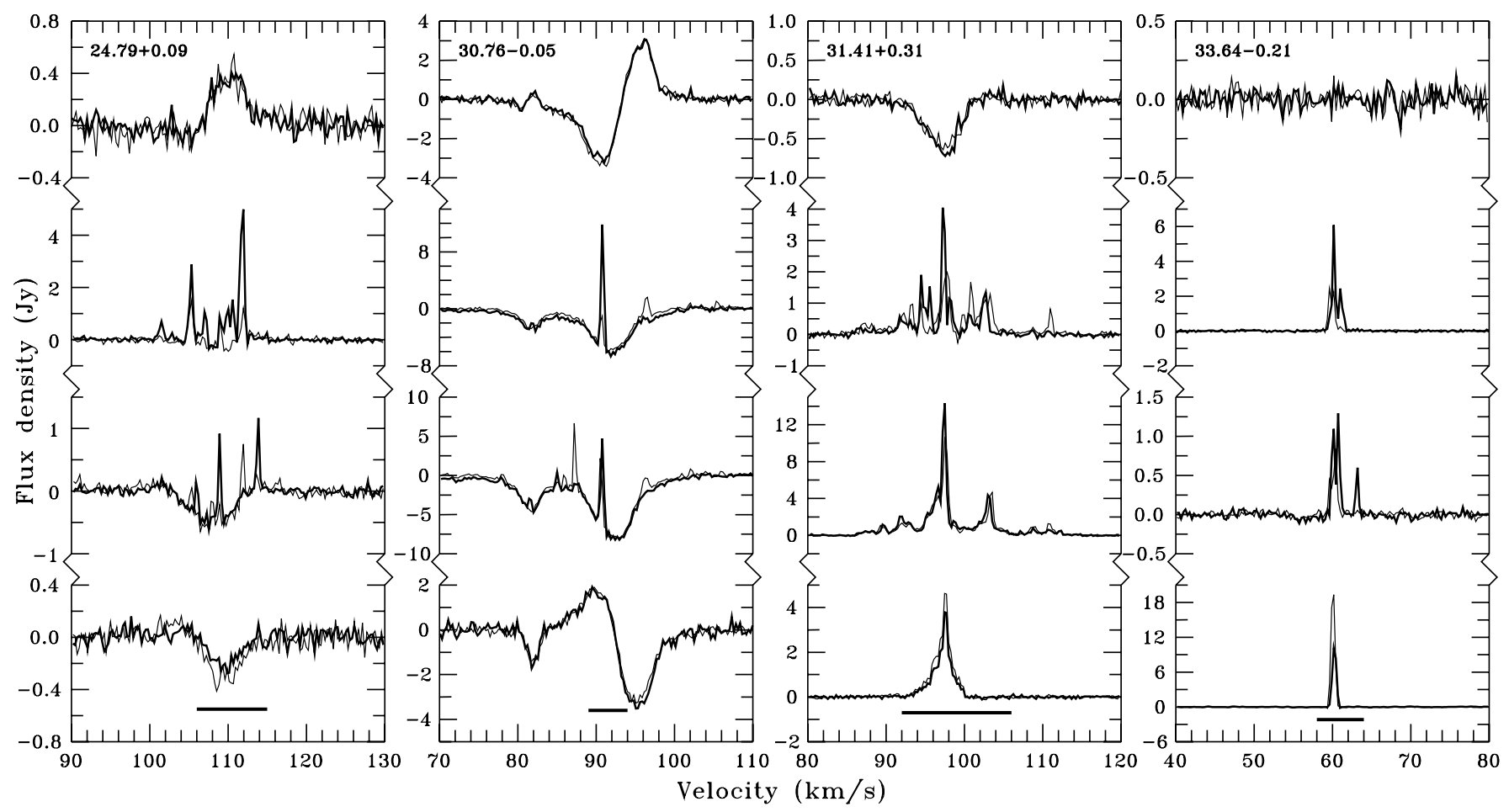

Fig. 1. OH spectra of the four selected sources $24.79+0.09,30.76-0.05,31.41+0.31$ and $33.64-0.21$. The ground state transitions at 1612 , 1665,1667 and $1720 \mathrm{MHz}$ are shown from top to bottom. Light lines indicate left circularly polarized emission and heavy lines right circularly polarized emission. Horizontal bars above the velocity axis mark the ranges of the $\mathrm{CH}_{3} \mathrm{OH} 6668 \mathrm{MHz}$ maser emission as observed by Szymczak et al. (2002).

absolute intensities. The $6668 \mathrm{MHz} \mathrm{CH}_{3} \mathrm{OH}$ maser emission is commonly centred at a transition velocity from $1720 \mathrm{MHz}$ to $1612 \mathrm{MHz}$ emission.

The $1612 \mathrm{MHz}$ line of the source $31.41+0.31$ is seen in absorption (Fig. 1). The $1720 \mathrm{MHz}$ profile appears to be a superposition of narrow maser emission and broad quasi-thermal emission coinciding in velocity with the $1612 \mathrm{MHz}$ absorption profile. Broad multi-feature spectra are observed in both $\mathrm{OH}$ main lines without any obvious absorption feature. The $\mathrm{CH}_{3} \mathrm{OH}$ maser at $6668 \mathrm{MHz}$ coincides well in velocity with the $\mathrm{OH}$ profiles.

The source 33.64-0.21 is typical for objects without the $1612 \mathrm{MHz}$ line and without the absorption features at the $\mathrm{OH}$ main lines (Fig. 1). Strongly circularly polarized maser emission occurs at the main lines and $1720 \mathrm{MHz}$. The velocity interval of the $6668 \mathrm{MHz}$ maser is the same as for the $\mathrm{OH}$ lines.

\subsection{Detection rates}

$\mathrm{OH}$ ground state masers were found at 55 of the $100 \mathrm{CH}_{3} \mathrm{OH}$ maser sites. $31 \mathrm{OH}$ masers were found for the first time. A summary of the occurrence of maser lines is given in Table 3. The $1665 \mathrm{MHz}$ maser occurs almost always (96\%) in all $\mathrm{OH}$ sources studied and is accompanied at nearly $74 \%$ of sites by the $1667 \mathrm{MHz}$ maser. Masers at $1720 \mathrm{MHz}$ are detectable in $11 \%$ of $1665 \mathrm{MHz}$ maser objects and occur only where both 1665 and $1667 \mathrm{MHz}$ lines are also seen. The $1612 \mathrm{MHz}$ masers are observed in $9 \%$ of $\mathrm{OH}$ sources and are usually accompanied by the main line masers. No objects are found with
Table 3. Number of maser sources in the sample depending on the presence $(+)$ and absence $(-)$ of four $\mathrm{OH}$ transitions.

\begin{tabular}{cccccccc}
\hline \hline 1612 & + & + & + & - & - & - & - \\
1665 & - & + & + & + & + & - & + \\
1667 & - & - & + & - & + & + & + \\
1720 & - & - & - & - & - & - & + \\
\hline Frequency & 1 & 3 & 1 & 11 & 32 & 1 & 6 \\
$(\mathrm{MHz})$ & \multicolumn{7}{c}{ Number of sources } \\
\hline
\end{tabular}

simultaneous maser emission or absorption at both satellite lines at the same velocity.

36 objects were detected in absorption in the main lines and 24 of them were also accompanied by maser emission (Table 1). 30 objects were detected in absorption in either satellite line and only 5 of them were possibly accompanied by maser emission (Table 2). No OH maser emission nor absorption and quasi-thermal emission features were detected towards 31 targets (Table 4).

\subsection{Characteristics of $\mathrm{OH}$ maser lines}

The $\mathrm{OH}$ maser velocity extent ranges from 1 to $26 \mathrm{~km} \mathrm{~s}^{-1}$ with the median values of 8.3 and $8.8 \mathrm{~km} \mathrm{~s}^{-1}$ at 1665 and $1667 \mathrm{MHz}$, respectively. On average the velocity range of both satellite $\mathrm{OH}$ maser lines is about a factor of four narrower than that for the main maser lines. The $6668 \mathrm{MHz} \mathrm{CH}_{3} \mathrm{OH}$ maser emission in the sample studied extends from 1 to $20 \mathrm{~km} \mathrm{~s}^{-1}$ 
(Szymczak et al. 2002) and the median velocity interval of $8.0 \mathrm{~km} \mathrm{~s}^{-1}$ is comparable to that observed for $\mathrm{OH}$ main lines.

On average, for 53 maser sources found in the $1665 \mathrm{MHz}$ line, $V_{\mathrm{c}}$ differs from that at $6668 \mathrm{MHz}$ only by $-0.5 \pm$ $4.1 \mathrm{~km} \mathrm{~s}^{-1}$. The largest differences in $V_{\mathrm{c}}$ of both species are seen for sources $23.19-0.38\left(-10.8 \mathrm{~km} \mathrm{~s}^{-1}\right)$ and $32.74-0.08$ $\left(+11.2 \mathrm{~km} \mathrm{~s}^{-1}\right)$.

The brightest source in our sample is $34.25+0.16$ with $S_{\mathrm{p}}$ equal to 75 and $95 \mathrm{Jy}$ at 1665 and $1667 \mathrm{MHz}$, respectively. The weakest source visible at both main lines is $23.49+0.08$ ( 0.35 and $0.20 \mathrm{Jy}$ respectively). The median peak flux density of 53 objects detected in $1665 \mathrm{MHz}$ is $1.2 \mathrm{Jy}$, while that of 40 sources of $1667 \mathrm{MHz}$ maser is $0.7 \mathrm{Jy}$. The latter value is very similar to the median $S_{\mathrm{p}}$ of the $1720 \mathrm{MHz}$ masers. The $1612 \mathrm{MHz}$ masers of median $S_{\mathrm{p}}=0.4 \mathrm{Jy}$ belong to the group of the weakest $\mathrm{OH}$ sources in the sample. The integrated flux densities follow the above described trends.

The great majority of the masers have the $1667 \mathrm{MHz}$ emission weaker than the $1665 \mathrm{MHz}$ emission. The median ratio of $S_{\mathrm{i}}$ of $1667 \mathrm{MHz}$ and $1665 \mathrm{MHz}$ is 0.45 for the 39 sources. The quartiles are at 1.0 and 0.23 , i.e. there are $9(25 \%)$ objects for which $S_{\mathrm{i}}$ at $1667 \mathrm{MHz}$ is greater than that at $1665 \mathrm{MHz}$, and $10(25 \%)$ objects with the $1667 \mathrm{MHz}$ flux density weaker than 0.23 times the $1667 \mathrm{MHz}$ flux density. The extreme low and high ratios are $0.016(35.02+0.35)$ and $3.50(31.41+0.31)$.

In order to estimate the intensity ratio of methanol and hydroxyl we have used the $6668 \mathrm{MHz} \mathrm{CH} \mathrm{CH}_{3} \mathrm{OH}$ data (Szymczak et al. 2002) obtained about half a year before the $\mathrm{OH}$ data presented here. The sum of $S_{\mathrm{i}}$ in all $\mathrm{OH}$ lines is taken into ratio $S_{\mathrm{i}}\left(\mathrm{CH}_{3} \mathrm{OH}\right) / S_{\mathrm{i}}(\mathrm{OH})$. For the sample of 55 sources with both $\mathrm{CH}_{3} \mathrm{OH}$ and $\mathrm{OH}$ detected the median ratio is 10.7 with the quartiles at 34.2 and 4.6. This ratio is greater than 100 and lower than 1 for 7 and 6 sources, respectively. The source $36.11+0.55$ belongs to the first group of methanol-rich sources and has the highest ratio 730 . The source $20.08-0.14$ is a member of the second group of hydroxyl-rich objects having the extremely low ratio 0.05 . We notice that our estimate of the median intensity ratio of $\mathrm{CH}_{3} \mathrm{OH}$ and $\mathrm{OH}$ is about 2 times higher than that obtained by Caswell et al. (1995). A plausible cause is a difference in sensitivity limits of $\mathrm{OH}$ and $\mathrm{CH}_{3} \mathrm{OH}$ surveys. $\mathrm{OH}$ observations reported here are about one order of magnitude more sensitive than the $6668 \mathrm{MHz} \mathrm{CH}_{3} \mathrm{OH}$ unbiased survey (Szymczak et al.2002). Indeed, when we restrict the sample to the $28 \mathrm{OH}$ sources with a peak flux density greater than $1.6 \mathrm{Jy}$, which corresponds to a $3 \sigma$ detection level in the unbiased $\mathrm{CH}_{3} \mathrm{OH}$ survey, then the median value of $S_{\mathrm{i}}\left(\mathrm{CH}_{3} \mathrm{OH}\right) / S_{\mathrm{i}}(\mathrm{OH})$ is 5.2. This agrees well with Caswell's et al. estimate.

\subsection{Polarization properties}

In the sample studied there are several $\mathrm{OH}$ masers which show considerable circular polarization (Tables 1 and 2). At $1667 \mathrm{MHz}$ the degree of circular polarization $m_{\mathrm{c}}$ increases with a decrease in $S_{\mathrm{i}}$. In contrast, at $1665 \mathrm{MHz}$ no obvious relation between $m_{\mathrm{c}}$ and $S_{\mathrm{i}}$ is seen. Therefore, one can expect that at this frequency a statistical analysis of the polarization
Table 5. Possible Zeeman patterns.

\begin{tabular}{cccc}
\hline \hline Sources & $\begin{array}{c}\text { Line } \\
(\mathrm{MHz})\end{array}$ & $\begin{array}{c}V_{\mathrm{c}} \\
\left(\mathrm{km} \mathrm{s}^{-1}\right)\end{array}$ & $\begin{array}{c}\text { Field } \\
(\mathrm{mG})\end{array}$ \\
\hline $20.08-0.14$ & 1667 & 41.76 & -4.3 \\
& & 46.70 & -4.1 \\
$20.24+0.07$ & 1665 & 71.83 & -0.5 \\
& & 73.23 & -0.5 \\
& & 75.31 & -1.2 \\
$21.87+0.01$ & 1665 & 20.95 & +2.9 \\
$22.34-0.16$ & 1665 & 25.15 & +0.3 \\
$22.35+0.06$ & 1667 & 78.39 & +0.6 \\
$23.01-0.41$ & 1667 & 74.31 & -0.2 \\
$23.26-0.24$ & 1665 & 57.22 & +3.8 \\
$30.76-0.05$ & 1665 & 90.84 & -0.3 \\
& 1667 & 90.79 & -0.8 \\
$30.89+0.17$ & 1667 & 107.18 & +0.8 \\
$32.05+0.06$ & 1665 & 92.10 & -0.6 \\
& 1667 & 92.43 & -0.6 \\
$32.74-0.08$ & 1720 & 36.38 & -1.3 \\
$32.98+0.04$ & 1665 & 79.48 & +0.3 \\
$33.64-0.21$ & 1720 & 60.23 & -1.0 \\
$34.25+0.16$ & 1667 & 58.33 & +0.6 \\
$35.79-0.17$ & 1665 & 59.41 & -4.2 \\
& 1667 & 59.45 & -3.7 \\
\hline
\end{tabular}

degree is not strongly biased by that effect. The median value of $\left|m_{\mathrm{c}}\right|$ is 0.30 for $531665 \mathrm{MHz}$ sources. The quartiles are at 0.51 and 0.17 . There are 13 objects with $\left|m_{\mathrm{c}}\right| \geq 0.55$. Two sources 23.44-0.18 and 31.27-0.08 exhibit high fractional circular polarization $\left(\left|m_{\mathrm{c}}\right|>0.8\right)$ being relatively strong emitters with $S_{\mathrm{i}}$ of 3.9 and $9.7 \mathrm{Jy} \mathrm{km} \mathrm{s}^{-1}$, respectively.

In our data we found sources with left and right circularly polarized features well separated in velocity. It is possible that some of those are Zeeman pairs. If features of opposite polarization come from the same spatial location then the velocity separation provides a direct measure of the component of the magnetic field in the maser region parallel to the line of sight. Table 5 lists the maser sources with possible Zeeman patterns and the field intensity estimates assuming that a $1 \mathrm{mG}$ magnetic field produces velocity splittings of $0.59,0.35$, and $0.23 \mathrm{~km} \mathrm{~s}^{-1}$ at 1665,1667 , and $1720 \mathrm{MHz}$, respectively (see Davis 1974). The absolute field intensity along the line of sight ranges from 0.3 to $4.3 \mathrm{mG}$. The latter value is typical for the Galactic star forming regions (Reid \& Silverstein 1990). The source $23.26-0.24$ is a prominent example of object with the magnetic field of $3.8 \mathrm{mG}$ and large fractional polarization of 0.55 at $1665 \mathrm{MHz}$. In the group of 15 objects there is neither a preference for the field direction towards nor away from the observer. Our candidate Zeeman pairs need to be confirmed by high angular resolution observations to check whether opposite circularly polarized components spatially coincide. Single telescope data (Table 5) can be a guide to select suitable targets for detailed studies. 


\section{5. $\mathrm{OH}$ absorption}

44 sources in the sample are accompanied by absorption at main and/or satellite $\mathrm{OH}$ transitions at a velocity differing from the central velocity of the $6668 \mathrm{MHz} \mathrm{CH}_{3} \mathrm{OH}$ maser emission by less than $5 \mathrm{~km} \mathrm{~s}^{-1}$. The main $\mathrm{OH}$ lines dominate in absorption sources; 28 sources are seen in both main lines and 8 sources only in the $1667 \mathrm{MHz}$ line. There are 30 objects accompanied by absorption at one of the satellite lines, 5 of them are only seen at one satellite line. We note that the satellite lines 1612 and $1720 \mathrm{MHz}$ always behave complementarily to each other; if one shows emission the other is seen in absorption.

24 out of 36 absorption main line objects exhibit maser emission. The average width of absorption features at $1665 \mathrm{MHz}$ of $14.3 \pm 1.8 \mathrm{~km} \mathrm{~s}^{-1}$ is by $5.8 \mathrm{~km} \mathrm{~s}^{-1}$ larger than the average velocity interval of maser emission. The central velocity of absorption features are blueshifted with regard to that of the maser emission by $2.0 \pm 1.2 \mathrm{~km} \mathrm{~s}^{-1}$ at $1665 \mathrm{MHz}$ and by $3.8 \pm 1.1 \mathrm{~km} \mathrm{~s}^{-1}$ at $1667 \mathrm{MHz}$.

In some of our sources, especially those with noisy spectra, the ratio of absorption depth at 1667 and $1665 \mathrm{MHz}, R_{\mathrm{m}}$, depends on whether the flux density or the integrated flux density is used. In the analysis below we discuss the ratio taken as the mean of both values. This ratio ranges from 0.82 to 2.36 with the average value of $1.30 \pm 0.09$ for 20 objects with absorption at main and satellite lines. Only the source $31.06+0.09$ has $R_{\mathrm{m}}$ close to 1.78 together with the intensity ratios $1665 / 1612$ and $1667 / 1612$ close to 6.3 and 10.2 , respectively. These ratios are close to those expected for thermally excited optically thin $\mathrm{OH}$ transitions. In this case one can use the intensity ratios to derive the $\mathrm{OH}$ column density $N_{\mathrm{OH}}$ (Magnani et al.1988, and reference therein). For the width of absorption feature at half intensity 3.6 and $3.2 \mathrm{~km} \mathrm{~s}^{-1}$ at 1665 and $1667 \mathrm{MHz}$ respectively, we obtained $N_{\mathrm{OH}}=1.2 \times 10^{15} \mathrm{~cm}^{-2}$. This value is similar to, or even slightly higher than, typical $\mathrm{OH}$ column densities estimated towards molecular clouds with continuum sources (Colgan et al. 1989).

In our sample there are two further sources, 23.19-0.38 and 23.44-0.18, with $R_{\mathrm{m}}$ equal to 1.32 and 1.50 respectively, and with the ratios of the main line to the satellite line deviating only by a factor of 2-3 from those expected for thermal excitation. However, the satellite lines exhibit conjugate $S$ shaped patterns with emission/absorption and it is unlikely that these are thermally excited $\mathrm{OH}$ lines. For the remaining sources in the sample the ratios of absorption depths are very different from the LTE value. We conclude that most (about 90\%) $\mathrm{CH}_{3} \mathrm{OH}$ sources at $6668 \mathrm{MHz}$ accompanied by absorption features are possibly embedded in clouds where $\mathrm{OH}$ molecules are non thermally excited and the estimation of $N_{\mathrm{OH}}$ from the main line ratios can no longer be applied.

\section{Properties of target sites}

\subsection{Location of $\mathrm{OH}$ and $\mathrm{CH}_{3} \mathrm{OH}$ masers}

As shown in Sect. 3.3 the $\mathrm{OH}$ and $\mathrm{CH}_{3} \mathrm{OH}$ maser spectra in the sample are confined to a very similar velocity interval. It is therefore likely that both masers arise in close proximity, even if they do not arise in exactly the same volume of gas surrounding the newly formed star. This appears to be consistent with results of VLBI observations of the archetypical ultra compact HII region $\mathrm{W} 3(\mathrm{OH})$ which showed that the general distribution of the $6668 \mathrm{MHz}$ masers closely resembles that of the $1665 \mathrm{MHz}$ masers (Menten et al. 1992). Caswell (1996) also reported the position coincidence of the $\mathrm{CH}_{3} \mathrm{OH}$ and $\mathrm{OH}$ masers for about $80 \%$ of sources in his sample resulting from a blind search for $6668 \mathrm{MHz}$ emission.

21 sources in our sample were observed in the CS (2-1) line by Bronfman et al. (1996). This thermal emission, being a tracer of high density gas, usually associated with embedded ultra compact HII regions, provides a reliable estimate of the systemic velocity. For 17 out of 21 sources the central velocity of the $\mathrm{CH}_{3} \mathrm{OH}$ maser emission (11 sources are also $\mathrm{OH}$ masers) is confined to less than $4 \mathrm{~km} \mathrm{~s}^{-1}$ around the velocity of the CS peak, while for the remaining 4 sources: $30.82+0.27,32.98+0.04,35.02+0.35$ and $38.12-0.24$ it is as different as $10 \mathrm{~km} \mathrm{~s}^{-1}$. This suggests that most $\mathrm{CH}_{3} \mathrm{OH}$ and $\mathrm{OH}$ masers probably originate from the inner part of the cloud surrounding a central star. For a minority of the sources the maser emission of both molecules can arise in outflows. However, given a large uncertainty of position of the maser sources of about $30^{\prime \prime}$ we cannot exclude, for these four objects, the possibility that the masers arise from objects different from those observed in the CS line.

\subsection{Physical parameters}

There are few objects in the sample that were observed in the CS lines (e.g. Olmi \& Cesaroni 1999; Beuther et al. 2002) and their properties are discussed here in order to constrain the CSG02 model. This model deals with the origin of masers in $\mathrm{OH}$ and $\mathrm{CH}_{3} \mathrm{OH}$ under identical conditions in regions of highmass star formation.

Sources $29.95-0.02,31.41+0.31$ and $34.25+0.16$ are common to Olmi \& Cesaroni's sample and ours. For these targets they derived the density of molecular hydrogen gas $n_{\mathrm{H}_{2}}$ of $0.6-1.1 \times 10^{6} \mathrm{~cm}^{-3}$ (their Table 6) and the hydrogen column density of about $10^{24} \mathrm{~cm}^{-2}$ (their Table 7). These estimates generally agree with values derived for sources $22.35+0.06$ and 32.98+0.04 (Beuther et al. 2002, their Table 3) assuming a CS abundance relative to hydrogen of $10^{-8}-10^{-9}$. We note that $n_{\mathrm{H}_{2}}$ derived from CS data falls in the lower limit of the gas density range required in the $\mathrm{CSG} 02$ model for the $6668 \mathrm{MHz} \mathrm{CH} 3 \mathrm{OH}$ and $1665 \mathrm{MHz} \mathrm{OH}$ masers.

Our estimate of $N_{\mathrm{OH}}$ from the absorption depth ratio at 1665 and $1667 \mathrm{MHz}$ for source $31.06+0.09$ (Sect. 3.5) of $1.2 \times 10^{15} \mathrm{~cm}^{-2}$, if typical for our sample, implies a fractional abundance of $\mathrm{OH}$ molecules of $10^{-8}-10^{-9}$. This agrees well with the minimum value of fractional abundance of $10^{-8.5}$ for $\mathrm{OH}$ which leads to an $\mathrm{OH}$ maser with a brightness temperature $T_{\mathrm{b}}>10^{4} \mathrm{~K}(\mathrm{CSG} 02)$. In the CSG02 model the brightest $\mathrm{OH}$ masers $\left(T_{\mathrm{b}}=10^{11} \mathrm{~K}\right)$ require an $\mathrm{OH}$ fractional abundance of $10^{-5}-10^{-6}$. Such high values can be easily reached due to evaporation of icy grain mantles (Hartquist et al. 1995).

There are six sources in our sample identified with IRAS counterparts that are also included in a sample of high-mass 


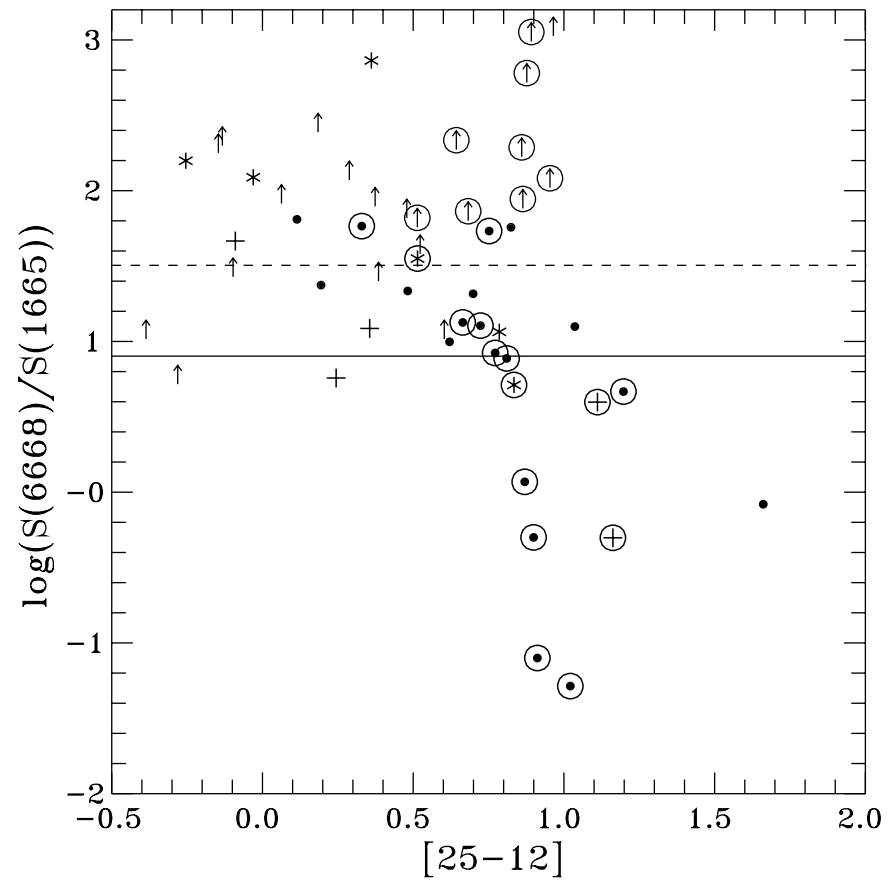

Fig. 2. Ratio of the integrated flux density for $\mathrm{CH}_{3} \mathrm{OH} 6668 \mathrm{MHz}$ and $\mathrm{OH} 1665 \mathrm{MHz}$ lines versus [25-12] IRAS colour. The sources with $1720 \mathrm{MHz}$ (crosses), 1665 and $1667 \mathrm{MHz}$ (dots), only with $1665 \mathrm{MHz}$ (stars) are shown. Upper limits for the ratio for sources with only the $\mathrm{CH}_{3} \mathrm{OH}$ emission are marked by arrows. Circled symbols represent objects with well determined colour. The masers above the dashed line are methanol-rich, while those below the solid line are hydroxyl-rich.

protostellar candidates studied by Sridharan et al. (2002). They showed that the IRAS data supplemented by the $1.2 \mathrm{~mm}$ dust observation can be well reproduced by two component grey bodies. The temperature of the cold dust component which can represent a less evolved outer environment of young stars ranges from 23 to $65 \mathrm{~K}$. The hot dust component which possibly represents a more evolved inner environment of the central object has a temperature ranging from 123 to $204 \mathrm{~K}$.

The hot dust temperature estimate essentially relies on the flux densities at 12 and $25 \mu \mathrm{m}$. Figure 2 shows the ratio of the maser intensity versus [25-12] colour ${ }^{1}$ for all 52 sources (22 sources without the $\mathrm{OH}$ maser emission) in the sample with IRAS counterparts within a radius of less than $58^{\prime \prime}$. Note that there are 23 sources with high quality IRAS measurements (flags 3 and 2) at 12 and $25 \mu \mathrm{m}$, so that their colour can be well determined and we only consider those in the following discussion. The ratio $R_{\mathrm{m}}$ of the integrated flux density at 6668 and $1665 \mathrm{MHz}$ maser transitions slightly increases with colour. For $9 \mathrm{OH}$ objects called hydroxyl-rich with $R_{\mathrm{m}}<8$ (Caswell et al. 1995; CSG02) the mean colour is $0.98 \pm 0.05$, while for $6 \mathrm{OH}$ objects with intermediate and methanol-rich $\left(R_{\mathrm{m}}>32\right)$ ratios the mean colour is $0.62 \pm 0.07$. For $8 \mathrm{CH}_{3} \mathrm{OH}$ sources without $\mathrm{OH}$ masers the mean colour is $0.78 \pm 0.05$ being intermediate between those of the two groups of $\mathrm{OH}$ masers discussed. A significant increase of $R_{\mathrm{m}}$ with the dust temperature is generally predicted in the CSG02 model for the high kinetic

\footnotetext{
${ }^{1}$ Colour is defined as $\left[\lambda_{i}-\lambda_{j}\right]=\log \left(S\left(\lambda_{i}\right) / S\left(\lambda_{j}\right)\right)$, where $S\left(\lambda_{i}\right)$ and $S\left(\lambda_{j}\right)$ are the IRAS flux densities at wavelengths $\lambda_{i}$ and $\lambda_{j}$.
}

temperature $T_{\mathrm{k}}$ regime. The appearance of either maser at 1665 , 1667 and $1720 \mathrm{MHz}$, or the $1665 \mathrm{MHz}$ alone, in a similar range of dust temperatures, can be explained by differences in $T_{\mathrm{k}}$. For the three sources from the Olmi \& Cesaroni (1999) sample, $T_{\mathrm{k}}$ shows a large scatter from 100 to $250 \mathrm{~K}$ (Kurtz et al. (2000).

\section{Discussion}

\subsection{Maser occurrence and flux ratios}

The present observations show that $55 \%$ of $\mathrm{CH}_{3} \mathrm{OH}$ maser sites in the sample are accompanied by $\mathrm{OH}$ masers. This detection rate is broadly consistent with a $44 \%$ rate inferred by Caswell (1996) for southern hemisphere sources. However, our detection rate is biased by a sensitivity effect; the $\mathrm{OH}$ survey reported here is about one order of magnitude more sensitive than the $6668 \mathrm{MHz} \mathrm{CH} \mathrm{CH}_{3} \mathrm{OH}$ blind survey (Szymczak et al.2002). The number of $\mathrm{OH}$ detections would then decrease to 28 sources if we apply a poorer common sensitivity limit of about $1.6 \mathrm{Jy}$ for the surveys of both maser species. Furthermore, due to the low angular resolution of both surveys it is possible that in some sources the coincidence of the $\mathrm{CH}_{3} \mathrm{OH}$ and $\mathrm{OH}$ masers is subject to position uncertainties up to $30^{\prime \prime}$.

The prevalence of the $1665 \mathrm{MHz}$ line in the sample documented here agrees well with findings by Caswell (1998). The occurrence of the $1667 \mathrm{MHz}$ line in nearly $74 \%$ of the $1665 \mathrm{MHz}$ sources is less frequent than in Caswell (1998). Furthermore, in our sample the median ratio of the 1665 and $1667 \mathrm{MHz}$ flux density of 1.8 (Fig. 3) is about a factor of two higher than Caswell's ratio. Our detection rate of the $1720 \mathrm{MHz}$ maser emission is nearly a factor of two higher than his rate. We suggest that these differences can be due to the selection of the samples; Caswell's sample is essentially based on an $\mathrm{OH}$ survey, while ours is taken from an unbiased search for the $6668 \mathrm{MHz} \mathrm{CH}_{3} \mathrm{OH}$ emission.

The present study clearly shows that the 1612 and $1720 \mathrm{MHz}$ masers behave complementarily to each other; no $1612 \mathrm{MHz}$ maser line was found in the $1720 \mathrm{MHz}$ maser source at the same velocity and vice versa. This observational finding is well explained with the CSG02 model where the $1612 \mathrm{MHz}$ line needs $N_{\mathrm{OH}}>10^{14} \mathrm{~cm}^{-2}$ and $T_{\mathrm{k}}>100 \mathrm{~K}$, whereas the $1720 \mathrm{MHz}$ line arises in regions with $N_{\mathrm{OH}}$ about 1.5 orders of magnitude lower for similar $T_{\mathrm{k}}$. The scarcity of satellite $\mathrm{OH}$ masers strongly suggests that these conditions are less common.

The median ratio of the flux density of the $6668 \mathrm{MHz}$ and $1665 \mathrm{MHz}$ masers is 13.3 (Fig. 3) and is close to the typical value of 16 (Caswell 1996) that is expected if the $\mathrm{CH}_{3} \mathrm{OH}$ and $\mathrm{OH}$ maser components are comparable in size and the ratio of the brightness temperatures of components at 6668 and $1665 \mathrm{MHz}$ equals unity (CSG02). The average values of the $6668 / 1665$ flux ratio for the sources with only $1665 \mathrm{MHz}$ emission and with $1665 / 1667 \mathrm{MHz}$ emission are $124.3 \pm 56.1$ and $33.1 \pm 10.1$ respectively. This difference is statistically significant at the $98.3 \%$ confidence level (t-test) and can be a result of differences in $T_{\mathrm{k}}$ at which the maser transitions are quenched. The CSG02 model predicts such a trend since the $1667 \mathrm{MHz}$ transition is quenched at $T_{\mathrm{k}}>80 \mathrm{~K}$, the $1665 \mathrm{MHz}$ transition 


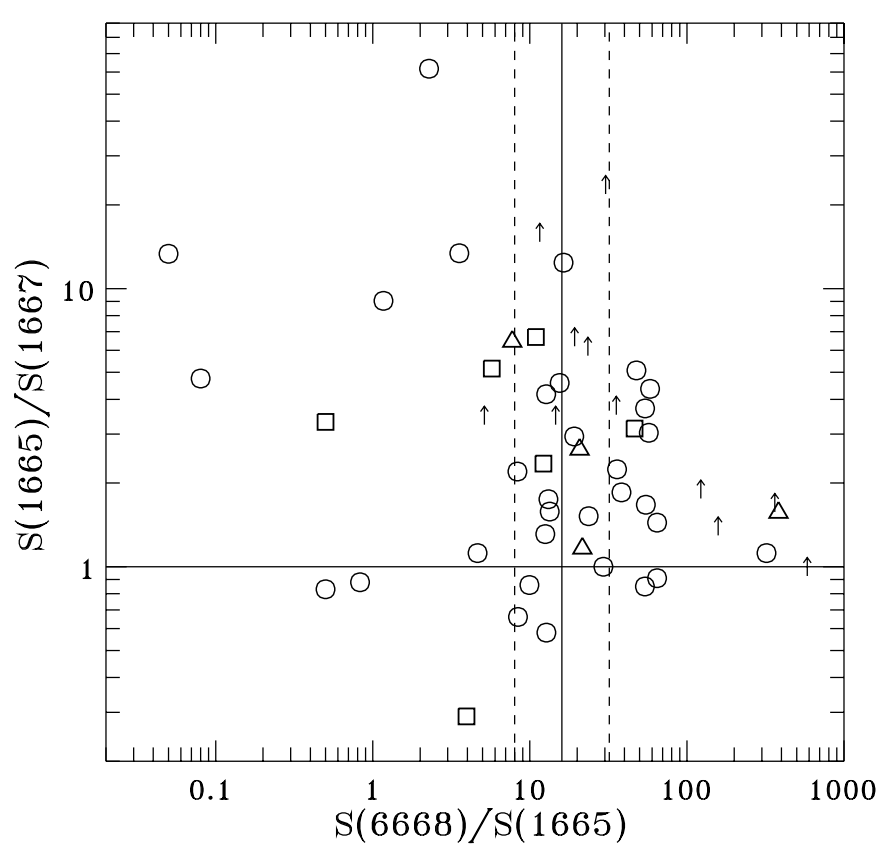

Fig. 3. Diagram of the ratios of the integrated flux density for $\mathrm{OH} 1665$ and $1667 \mathrm{MHz}$ and $\mathrm{CH}_{3} \mathrm{OH} 6668 \mathrm{MHz}$ masers. The objects with the maser emission at 1665 and $1667 \mathrm{MHz}$ (circles), $1720 \mathrm{MHz}$ (squares), $1612 \mathrm{MHz}$ (triangles), only $1665 \mathrm{MHz}$ (arrows) are shown. Note that arrows indicate only the upper limit to the $1665 / 1667$ ratio as the $1667 \mathrm{MHz}$ emission is not detected. The solid horizontal line marks the $1665 / 1667$ ratio equals to unity. The solid vertical line marks the ratio $6668 / 1665$ equals to 16 , while the dashed vertical lines mark that ratio of 8 and 32 .

is quenched at $T_{\mathrm{k}}>125 \mathrm{~K}$, while the $6668 \mathrm{MHz}$ maser is still strong at $T_{\mathrm{k}}$ up to $200 \mathrm{~K}$. There are no statistically significant differences in the flux density ratios (Fig. 3) for other groups of maser objects.

\subsection{Abundances and timescales}

Our study shows that 30 out of a total of 39 satellite sources listed in Table 2 exhibit absorption and/or quasi-thermal emission. The satellite lines show exclusively complementary behaviour, as they do in maser emission. Emission at $1612 \mathrm{MHz}$ and absorption at $1720 \mathrm{MHz}$ are seen in 5 objects, while the reverse case is observed in 18 sources. The remaining 6 objects exhibit a change from absorption to emission across the $1612 \mathrm{MHz}$ profile and a change from emission to absorption across the $1720 \mathrm{MHz}$ profile. This behaviour was predicted by the OH pumping model with non-local overlap (Lucas 1980). Absorption at $1612 \mathrm{MHz}$ and emission at $1720 \mathrm{MHz}$ is a signature of low column density of $\mathrm{OH}$ molecules $\left(<10^{15} \mathrm{~cm}^{-2}\right)$ and is seen for the blueshifted part of the profile, while the inverse case occurs for the redshifted part of the profile and marks the region of higher density (Elitzur 1992). The prevalence of emission at $1612 \mathrm{MHz}$ and absorption at $1720 \mathrm{MHz}$ suggests that the majority of sources have $n_{\mathrm{H}_{2}} \geq 10^{7} \mathrm{~cm}^{-3}$. More than $80 \%$ of sources with conjugate behaviour of satellite lines are associated with $\mathrm{OH}$ masers. This implies higher $N_{\mathrm{OH}}$ in $\mathrm{CH}_{3} \mathrm{OH} / \mathrm{OH}$ than in $\mathrm{CH}_{3} \mathrm{OH}$ maser sources.
The main line absorption appears in more than one third of the sample sources. The absorption features are clearly blueshifted relative to the corresponding maser lines (Sect. 3.5). This can suggest that absorption forms in front of the central radio continuum source in expanding layers of molecular clouds. The depth ratio of the main line absorption profiles is almost always different to the LTE value, suggesting non-thermal excitation of $\mathrm{OH}$ molecules. The main line absorption features are preferentially associated with sources also supporting $\mathrm{OH}$ masers, but about $30 \%$ of them are seen in objects with only $\mathrm{CH}_{3} \mathrm{OH}$ masers.

Our finding that no $\mathrm{OH}$ masers are observed towards many strong $\mathrm{CH}_{3} \mathrm{OH}$ sources can be explained by $\mathrm{N}_{\mathrm{CH}_{3} \mathrm{OH}}$ of about an order of magnitude higher than $N_{\mathrm{OH}}$ (CSG02). A large $\mathrm{CH}_{3} \mathrm{OH}$ column density can easily be reached in star forming regions due to a high abundance of methanol ice on grain mantles (Dartois et al. 1999). The detection of OH absorption in $\mathrm{CH}_{3} \mathrm{OH}$ objects without $\mathrm{OH}$ masers supports the scenario in which both molecules enrich circumstellar gas due to injection from grain mantles (Hartquist et al. 1995) but, in those objects, the $\mathrm{OH}$ column density is insufficient to sustain maser emission. This appears to be consistent with the chemical models (Charnley et al. 1992, 1995) that predict a maximum of methanol abundance before a peak of $\mathrm{OH}$ abundance. If these models are proven, then in our sample the $\mathrm{CH}_{3} \mathrm{OH}$ sources without $\mathrm{OH}$ absorption and $\mathrm{OH}$ masers could be at earlier phases of evolution than $\mathrm{OH}$-rich sources. These chemical models predict a rapid drop of $\mathrm{CH}_{3} \mathrm{OH}$ abundance between $10^{5}$ and $10^{6} \mathrm{yr}$ as the $\mathrm{CH}_{3} \mathrm{OH}$ is used up, while an abrupt drop of $\mathrm{OH}$ abundance occurs at a later time. In this phase a large dispersion of $\mathrm{CH}_{3} \mathrm{OH}$ abundance is likely to occur from one source to another. We conclude that, under similar physical conditions (CSG02), the abundances and column densities of $\mathrm{CH}_{3} \mathrm{OH}$ and $\mathrm{OH}$ control the occurrence of both maser species and their intensity ratios.

\subsection{Maser pumping}

Most theoretical models assume that IR pumping can account for both the $\mathrm{OH}$ and $\mathrm{CH}_{3} \mathrm{OH}$ masers (e.g. CSG02, and references therein). However, there is no convincing observational evidence for correlation between the $6668 \mathrm{MHz}$ maser and IR flux densities (van der Walt et al. 1995). IR pumping of the $\mathrm{OH}$ main line masers was found to be a feasible mechanism (Moore et al. 1988). The present study provides a new insight into the pumping problem. The correlation coefficient between the $\mathrm{OH}$ integrated flux density and IRAS $60 \mu \mathrm{m}$ flux density is 0.72 for the objects with good quality IRAS measurements (Fig. 4). The ratio of the $\mathrm{OH}$ and $60 \mu \mathrm{m}$ flux densities is lower than 0.025 for all but one object and higher than 0.0025. A similar correlation but with $r=0.65$ is seen for the $100 \mu$ m IRAS band. This result confirms the correlation found for IRAS selected $\mathrm{OH}$ masers (Moore et al. 1988).

The $\mathrm{CH}_{3} \mathrm{OH}$ maser and IRAS flux densities are also well correlated. The best correlation with $r=0.68$ is seen for the $25 \mu \mathrm{m}$ band (Fig. 4). The average ratio of the $6668 \mathrm{MHz}$ and $25 \mu \mathrm{m}$ flux densities is 0.04 . We found that these correlations 

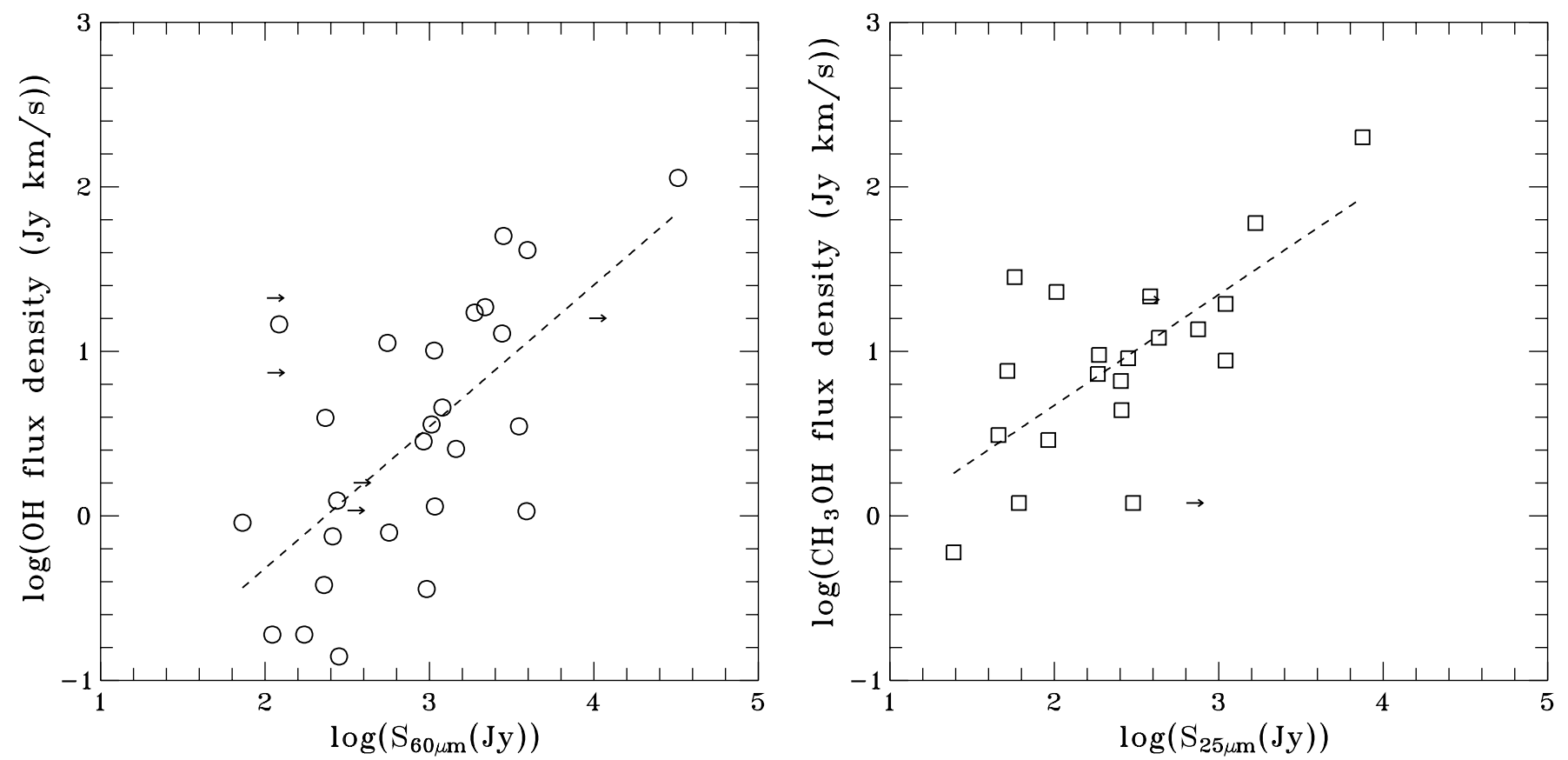

Fig. 4. Left: diagram of the $\mathrm{OH}$ integrated flux density versus IRAS $60 \mu \mathrm{m}$ flux density for the sources with the $\mathrm{OH}$ maser emission. Right: diagram of the $\mathrm{CH}_{3} \mathrm{OH}$ integrated flux density versus IRAS $25 \mu \mathrm{m}$ flux density for the sources with only $6668 \mathrm{MHz}$ maser line. The horizontal arrows indicate the upper limit for the IRAS flux densities. The dashed lines are the best least square fits for the sources represented by open symbols. Note that within noise, the regression lines are compatible with a slope of 1.

disappear when objects with $\mathrm{OH}$ maser emission are included and no other correlation between $\mathrm{CH}_{3} \mathrm{OH}$ and IRAS flux densities are seen in objects showing maser emission of both species. This suggests an intrinsic difference between objects with just the $\mathrm{CH}_{3} \mathrm{OH}$ maser and these with $\mathrm{OH}$ masers also. A plausible factor is a difference in $\mathrm{CH}_{3} \mathrm{OH}$ abundance, with the abundances falling during the lifetimes of objects such as $\mathrm{OH}$ maser sources. This is discussed in Sect. 5.2. The issue of maser - IR flux correlation needs further study with much better positional accuracy to avoid mismatching of masers and IR sources.

\section{Conclusions}

We have made $\mathrm{OH}$ observations of a complete sample of $100 \mathrm{CH}_{3} \mathrm{OH}$ maser sources. The 1665 and $1667 \mathrm{MHz}$ are dominant lines while the satellite lines at 1612 and $1720 \mathrm{MHz}$, almost always associated with the main line emission, are scarce and occur in different objects or in the same object but at different velocities. A large dispersion of the kinetic temperature $(100-250 \mathrm{~K})$ is deduced for the $\mathrm{OH}$ sources. The $1612 \mathrm{MHz}$ $\mathrm{OH}$ line probes regions of $T_{\mathrm{k}}>150 \mathrm{~K}$, while the $1720 \mathrm{MHz}$ line occurs in regions of $n_{\mathrm{H}_{2}}<10^{7} \mathrm{~cm}^{-3}$. A substantial degree of circular polarization of $\mathrm{OH}$ maser emission is observed and Zeeman pair candidates identified in several sources, which deserve further investigation, imply the strength of the magnetic field in the line of sight to be up to $4 \mathrm{mG}$. About half of the targets show $\mathrm{OH}$ absorption and quasi-thermal emission. The conjugate behaviour of the satellite line absorption/emission features is related to the gas density and $\mathrm{OH}$ column density; the absorption at $1612 \mathrm{MHz}$ and emission at $1720 \mathrm{MHz}$ seen for the blueshifted part of the profile marks regions of
$N_{\mathrm{OH}}<10^{15} \mathrm{~cm}^{-2}$. The absorption features are blueshifted by $2-4 \mathrm{~km} \mathrm{~s}^{-1}$ relative to the maser profiles, indicating that absorption forms in slowly expanding layers of gas in front of the central continuum source.

The physical conditions inferred for methanol- and hydroxyl-rich sources appear to be very similar. The maser amplification of both molecular species can occur in common regions with $n_{\mathrm{H}_{2}}<10^{5-8} \mathrm{~cm}^{-3}, N_{\mathrm{OH}} \approx N_{\mathrm{CH}_{3} \mathrm{OH}}=10^{14-16} \mathrm{~cm}^{-2}$ as predicted by the $\mathrm{CSG} 02$ model. We found evidence that the $\mathrm{OH}$ main lines and the $6668 \mathrm{MHz} \mathrm{CH}_{3} \mathrm{OH}$ line can be efficiently pumped by infrared photons.

The two groups of objects: (1) without any $\mathrm{OH}$ emission and absorption, (2) without $\mathrm{OH}$ masers but accompanied by $\mathrm{OH}$ absorption can represent less evolved environments of young stars. There is evidence that the $\mathrm{CH}_{3} \mathrm{OH}$ maser appears earlier than the $\mathrm{OH}$ maser. The studies of extreme $\mathrm{CH}_{3} \mathrm{OH}$ and $\mathrm{OH}$ sources can provide more information about possible evolutionary scenarios of young central stars and their environments.

Acknowledgements. The Nançay Radio Observatory is operated by the Unite Scientifique de Nançay of the Observatoire de Paris, associated with the CNRS. This work was supported by the KBN grant 2P03D01122.

\section{References}

Argon, A. L., Reid, M. J., \& Menten, K. M. 2000, ApJS, 129, 159

Beuther, H., Schilke, P., Menten, K. M., et al. 2002, ApJ, 566, 945

Braz, M. A., \& Epchtein, N. 1983, A\&AS, 54, 167

Bronfman, L., Nyman, L. A., \& May, J. 1996, A\&AS, 115, 81

Caswell, J. L. 1996, MNRAS, 279, 79 
Caswell, J. L. 1997, MNRAS, 289, 203

Caswell, J. L. 1998, MNRAS, 297, 215

Caswell, J. L., \& Haynes, R. F. 1983a, Aust. J. Phys., 36, 361

Caswell, J. L., \& Haynes R. F. 1983b, Aust. J. Phys., 36, 417

Caswell, J. L., Vaile, R. A., Ellingsen, S. P., Whiteoak, J. B., \& Norris, R. P. 1995, MNRAS, 272, 96

Charnley, S. B., Tielens, A. G. G. M., \& Millar, T. J. 1992, ApJ, 399, L71

Charnley, S. B., Kress, M. E., Tielens A. G. G. M., \& Millar, T. J. 1995, ApJ, 448, 232

Cohen, R. J., Baart, E. E., \& Jonas, J. L. 1988, MNRAS, 231, 205

Colgan, S. W. J., Salpeter, E. E., \& Terzian, Y. 1989, ApJ, 336, 231

Cragg, D. M., Sobolev, A. M., \& Godfrey, P. D. 2002, MNRAS, 331, 521 (CSG02)

Dartois, E., Schutte, W., Geballe, T. R., et al. 1999, A\&A, 342, L32

Davis, R. D. 1974, in Galactic Radio Astronomy, ed. E. J. Kerr \& S. C. Simonson (Dordrecht: Reidel), 275

Elitzur, M. 1992, in Astronomical Masers (Kluwer Publishers), 234

Ellingsen, S. P., von Bibra, M. L., McCulloch, P. M., et al. 1996, MNRAS, 280, 378

Gaylard, M. J., MacLeod, G. C., \& van der Walt, D. J. 1994, MNRAS, 269,257

Hartquist, T. W., Menten, K. M., Lepp, S., \& Dalgarno A. 1995, MNRAS, 272, 184

Hughes, V. A., \& MacLeod, G. C. 1989, AJ, 97, 786

Kurtz, S., Cesaroni, R., Churchwell, E., Hofner, P., \& Walmsley, C. M. 2000, in Protostars and Planets IV, ed. V. Mannings, A. P. Boss, \& S. S. Russell (Univ. of Arizona Press), 299
Lucas, R. 1980, A\&A, 84, 36

Magnani, L., Blitz, L., \& Wouterloot, J. G. A. 1988, ApJ, 326, 909

Menten, K. M. 1991, ApJ, 380, L75

Menten, K. M., Reid, M. J., Pratap, P., Moran, J. M., \& Wilson, T. L. 1992, ApJ, 401, L39

Moore, T. J. T., Cohen, R. J., \& Mountain, C. M. 1988, MNRAS, 231, 887

Olmi, L., \& Cesaroni, R. 1999, A\&A, 352, 266

Reid, M. J., \& Silverstein, E. M. 1990, ApJ, 361, 483

Sridharan, T. K., Beuther, H., Schilke, P., Menten, K. M., \& Wyrowski, F. 2002, ApJ, 566, 931

Slysh, V. I., Dzura, A. M., Val'tts, I. E., \& Gérard, E. 1994, A\&AS, 106, 87

Slysh, V. I., Dzura, A. M., Val'tts, I. E., \& Gérard, E. 1997, A\&AS, 124,85

Szymczak, M., \& Kus, A. J. 2000, A\&AS, 147, 181

Szymczak, M., Kus, A. J., Hrynek, G., Kepa, A., \& Pazderski, E. 2002, A\&A, 392, 277

Turner, B. E. 1979, A\&AS, 37, 1

van Driel, W., Pezzani, J., \& Gérard, E. 1996, in High Sensitivity Radio Astronomy, ed. N. Jackson, \& R. J. Davis (Cambridge Univ. Press), 229

van der Walt, D. J., Gaylard, M. J., \& MacLeod, G. C. 1995, A\&AS, 110,81

Wood, D. O. S., \& Churchwell, E. 1989, ApJ, 340, 265 
M. Szymczak and E. Gérard: Hydroxyl ground state transitions in methanol sources, Online Material p 1

\section{Online Material}


M. Szymczak and E. Gérard: Hydroxyl ground state transitions in methanol sources, Online Material p 2
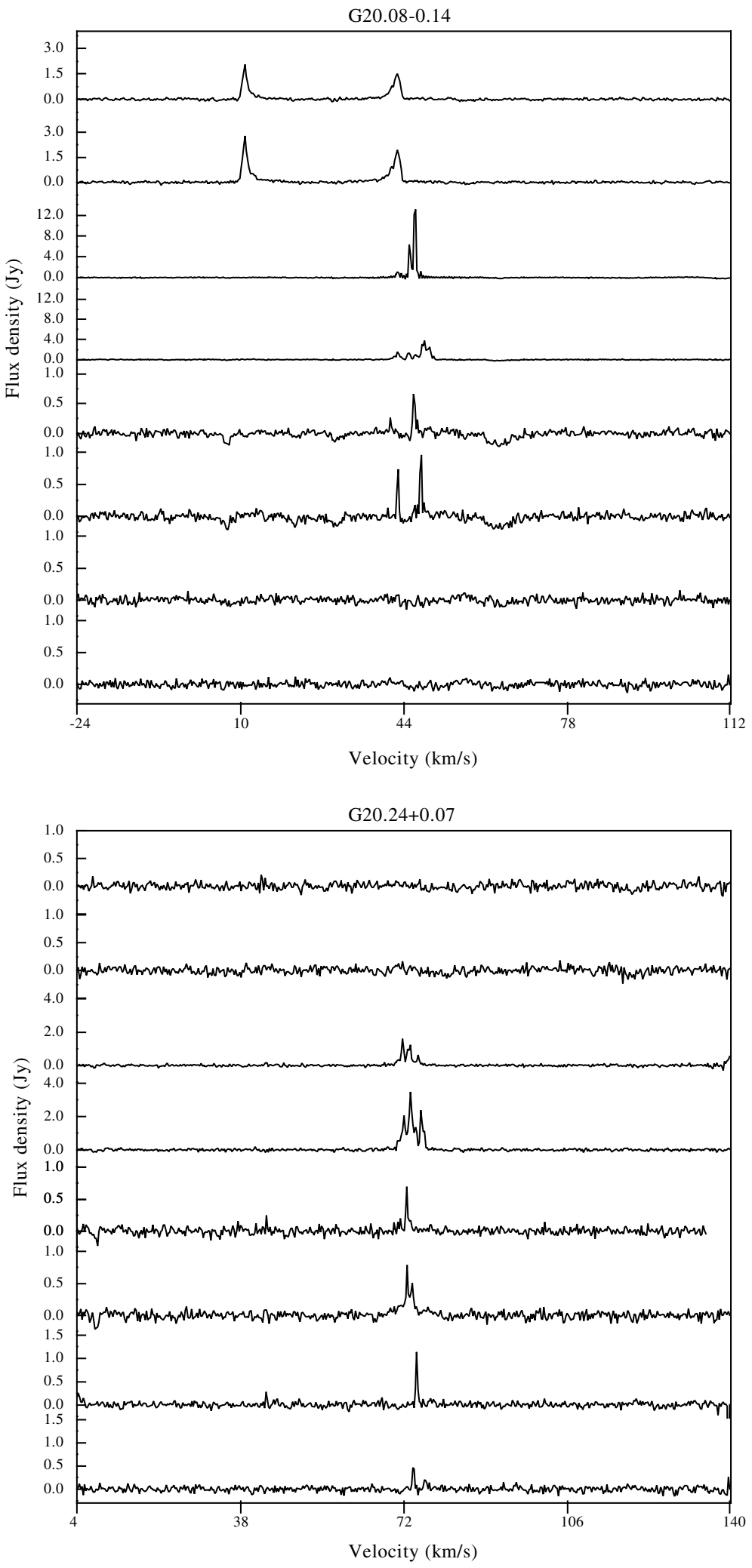

Fig. A.1. The OH spectra of the sources observed. The left and right circular polarization at 1612, 1665, 1667 and $1720 \mathrm{MHz}$ are shown from top to bottom. 
M. Szymczak and E. Gérard: Hydroxyl ground state transitions in methanol sources, Online Material p 3
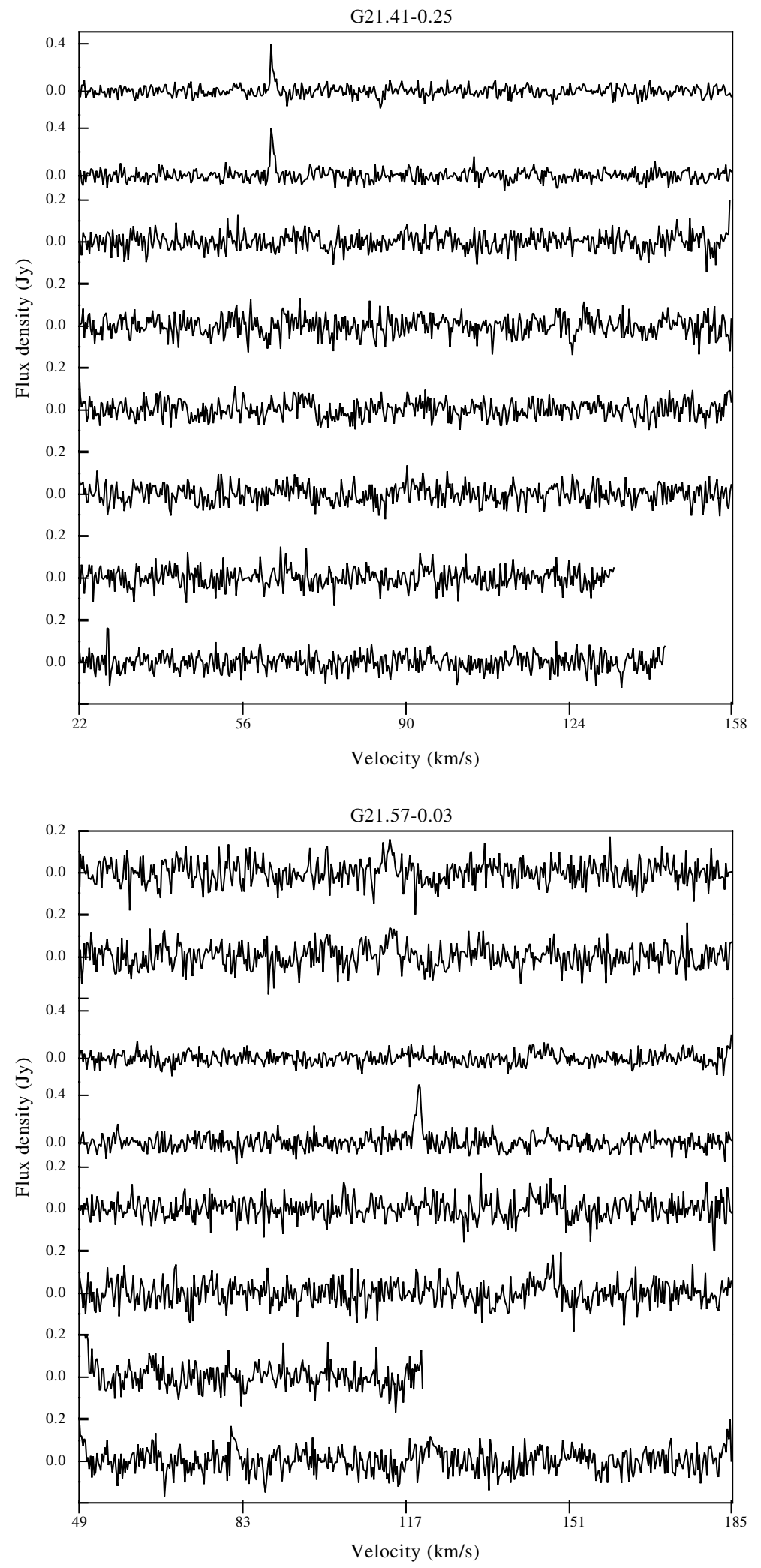

Fig. A.1. continued. 
M. Szymczak and E. Gérard: Hydroxyl ground state transitions in methanol sources, Online Material p 4
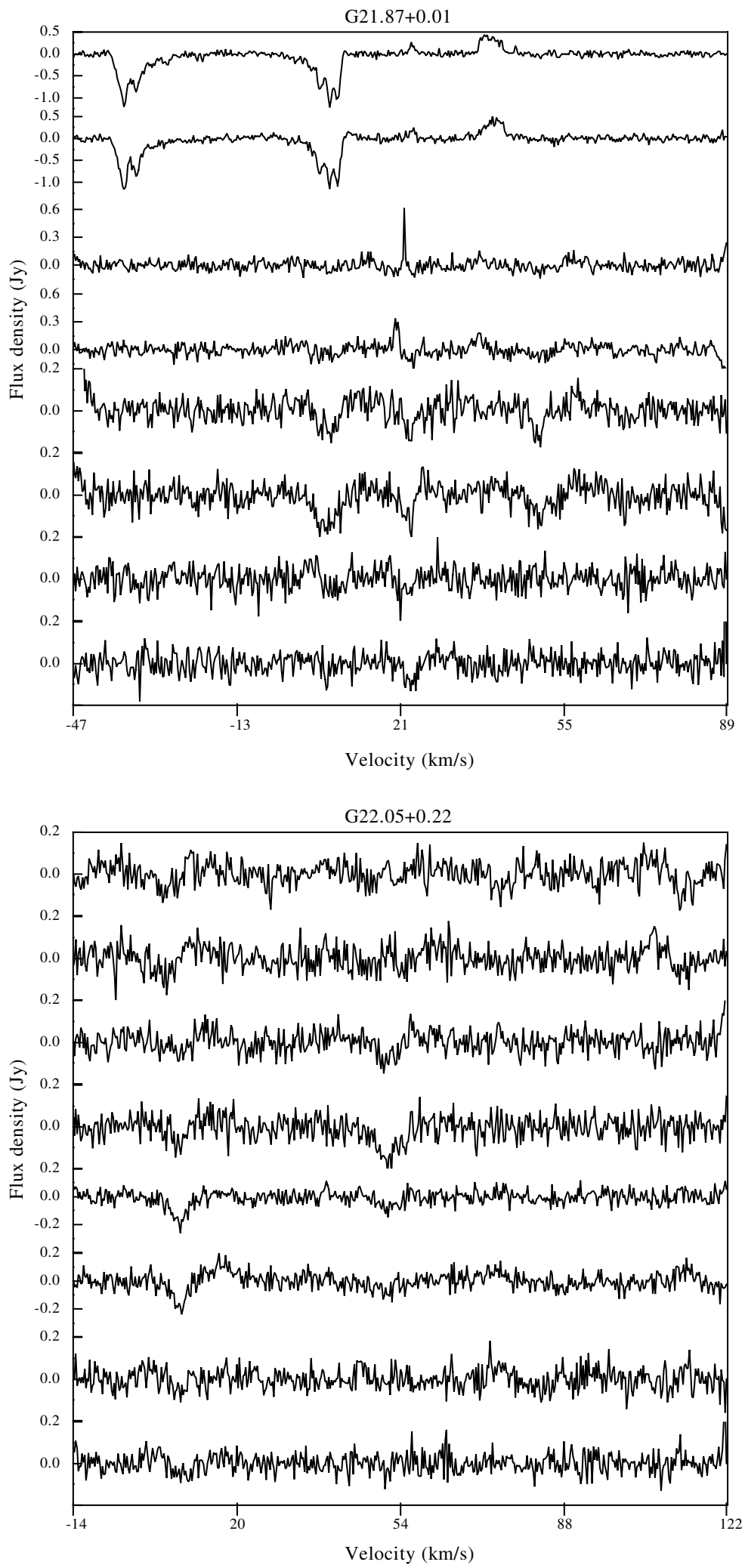

Fig. A.1. continued. 
M. Szymczak and E. Gérard: Hydroxyl ground state transitions in methanol sources, Online Material p 5
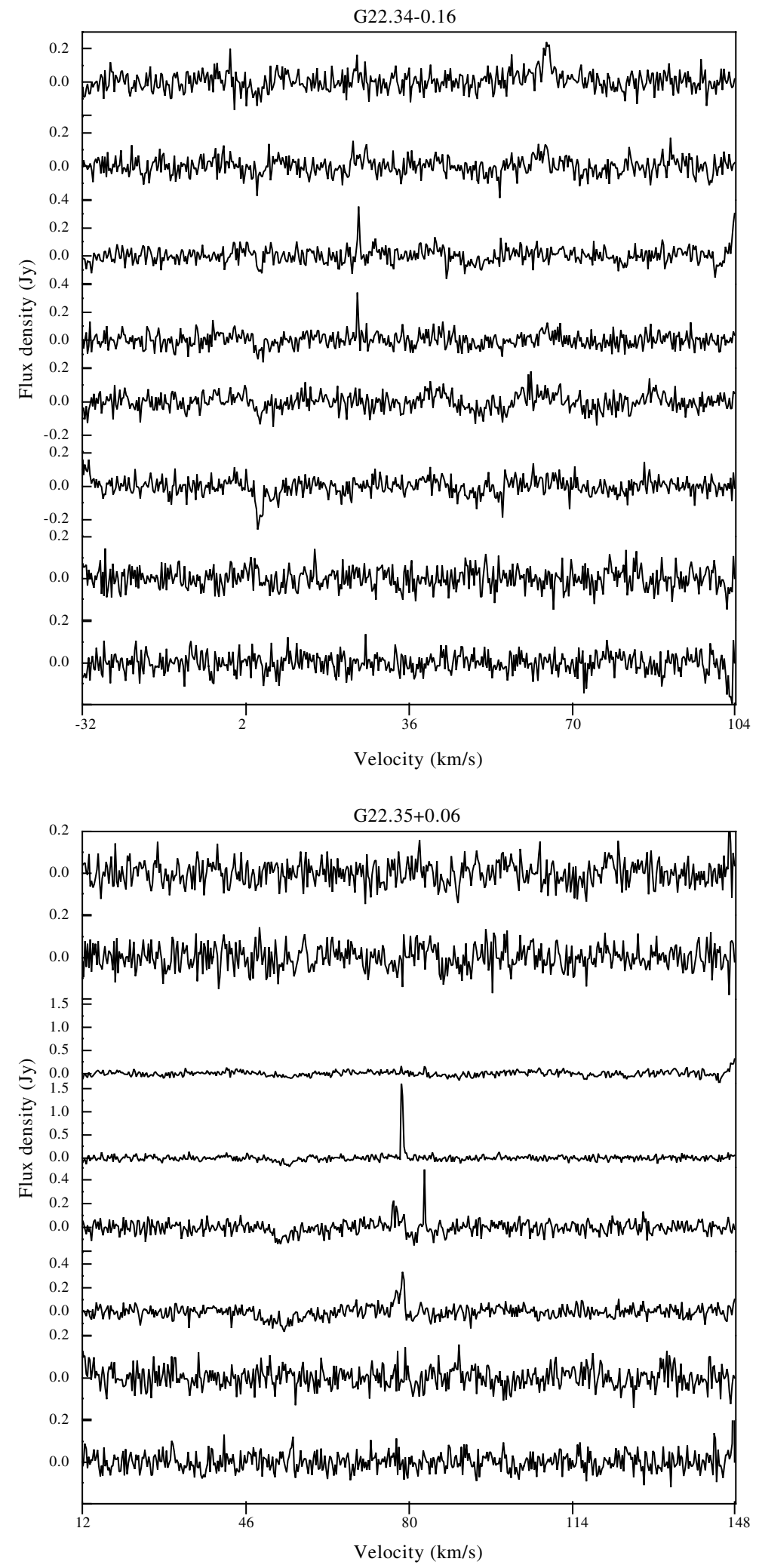

Fig. A.1. continued. 
M. Szymczak and E. Gérard: Hydroxyl ground state transitions in methanol sources, Online Material p 6
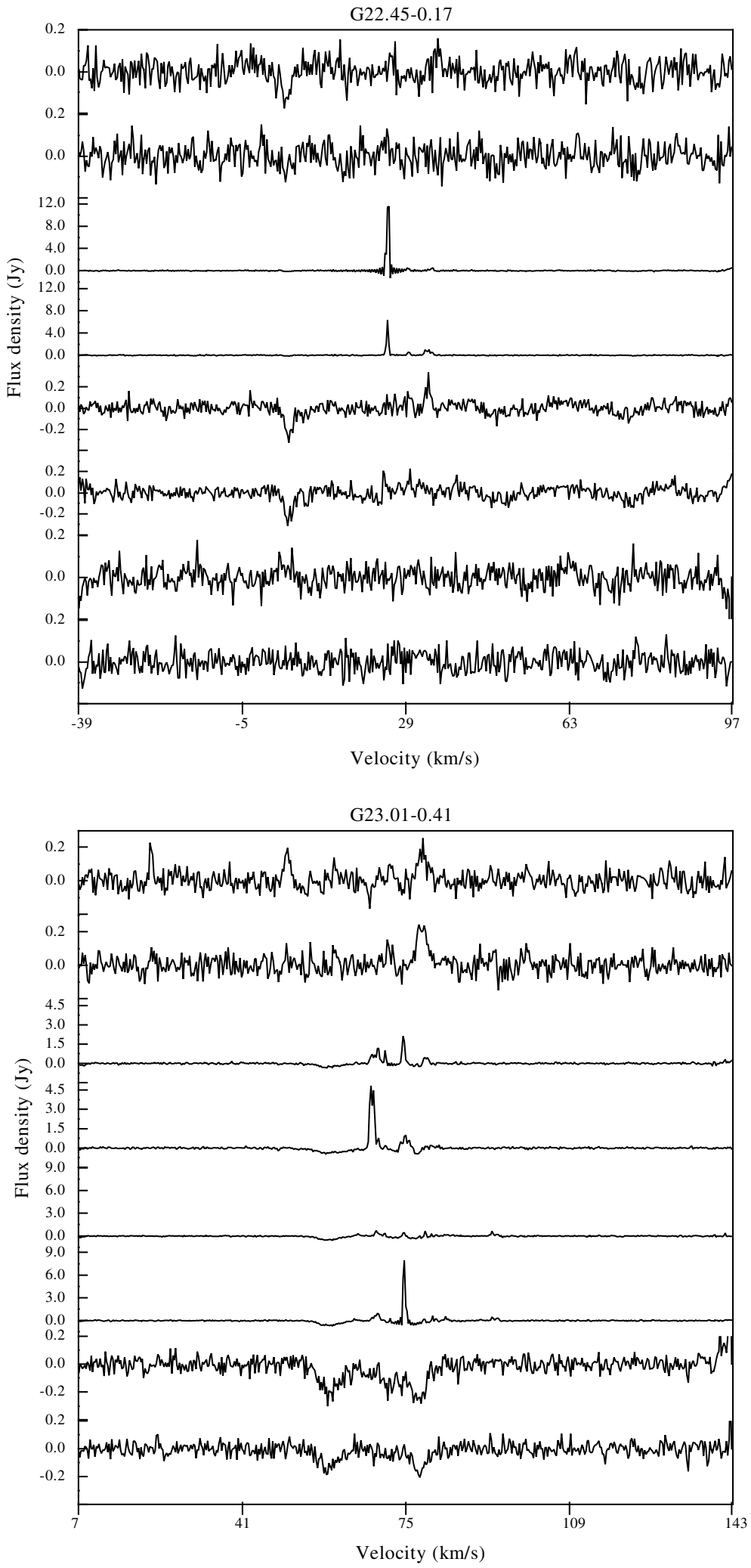

Fig. A.1. continued. 
M. Szymczak and E. Gérard: Hydroxyl ground state transitions in methanol sources, Online Material p 7
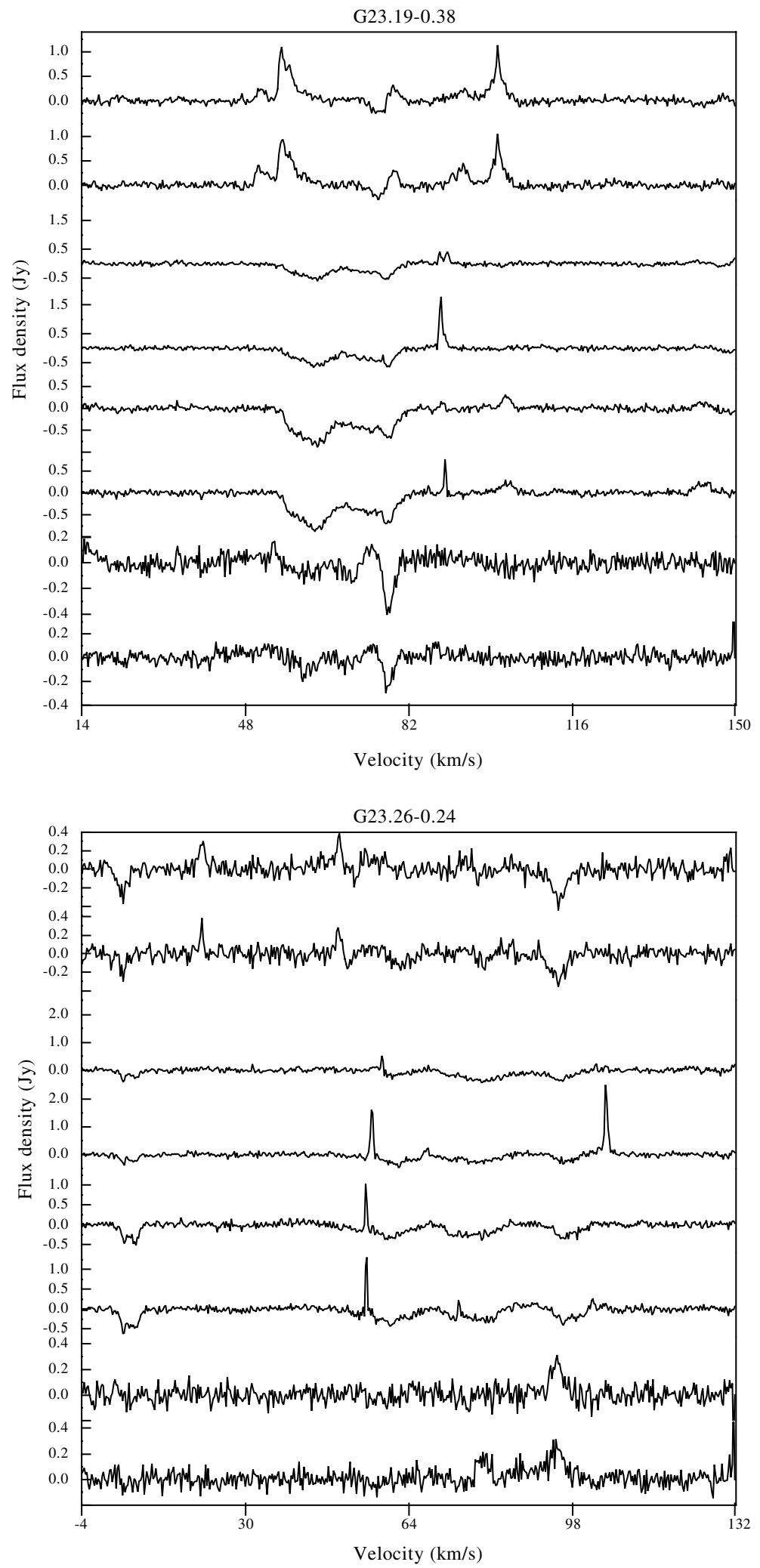

Fig. A.1. continued. 
M. Szymczak and E. Gérard: Hydroxyl ground state transitions in methanol sources, Online Material p 8
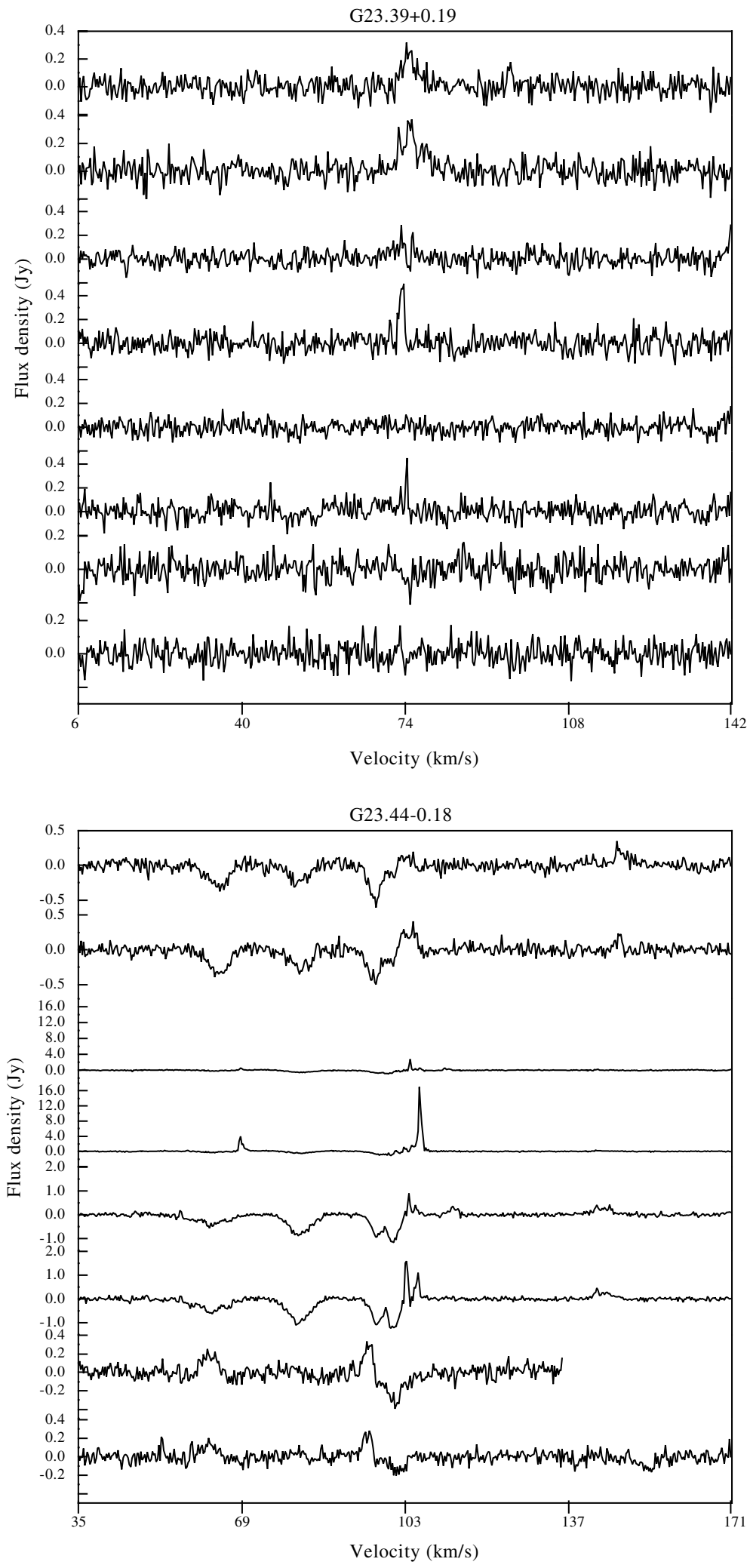

Fig. A.1. continued. 
M. Szymczak and E. Gérard: Hydroxyl ground state transitions in methanol sources, Online Material p 9
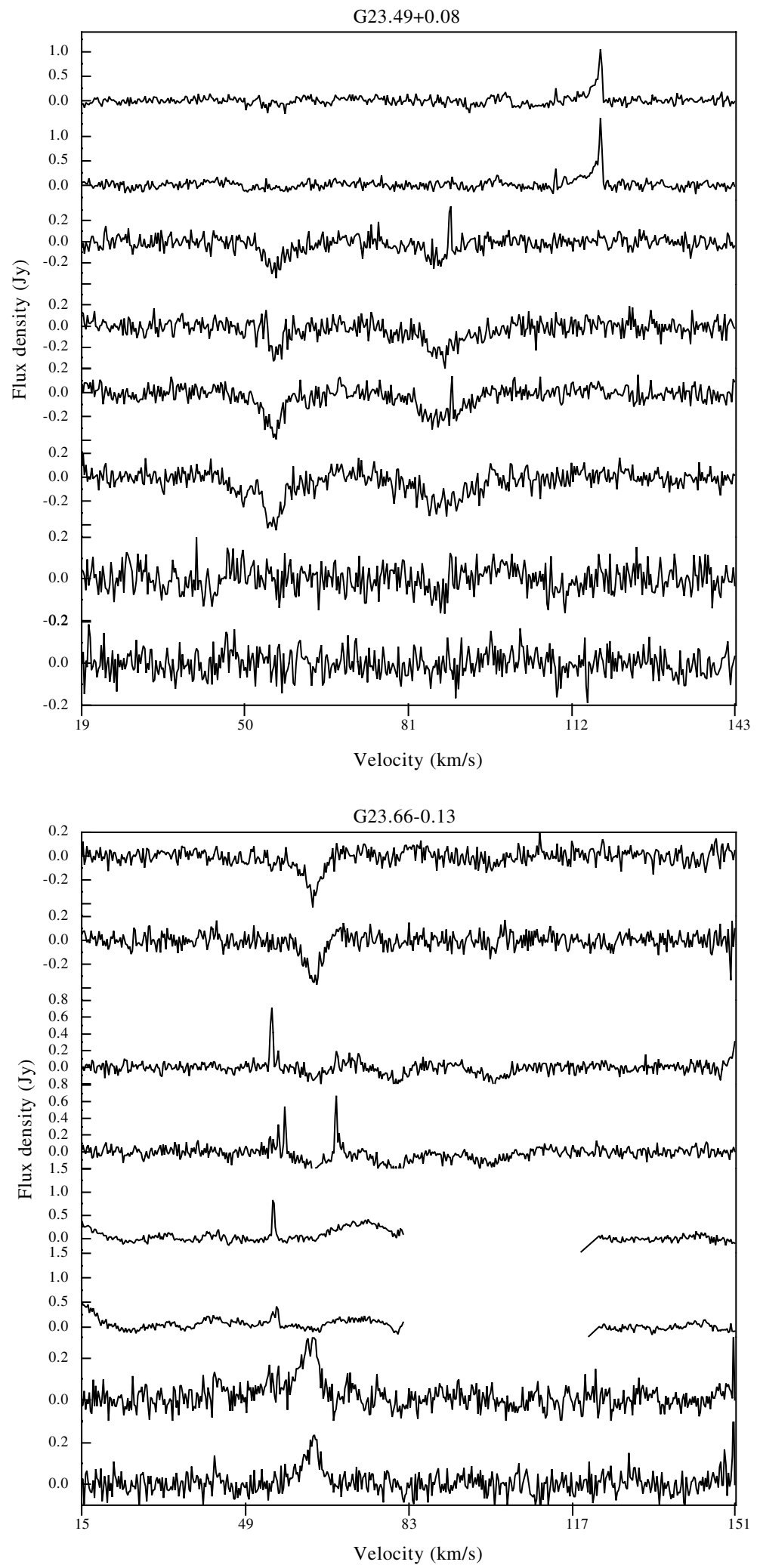

Fig. A.1. continued. 
M. Szymczak and E. Gérard: Hydroxyl ground state transitions in methanol sources, Online Material p 10

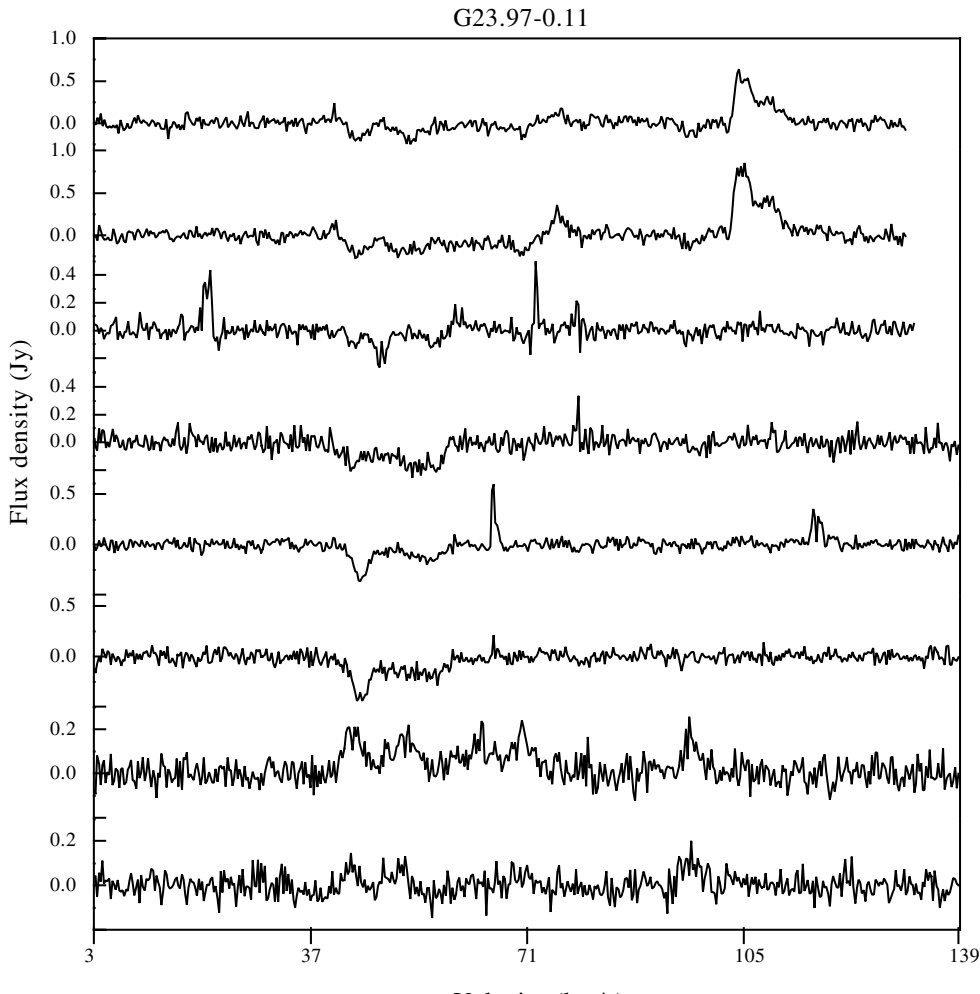

$$
\text { Velocity }(\mathrm{km} / \mathrm{s})
$$

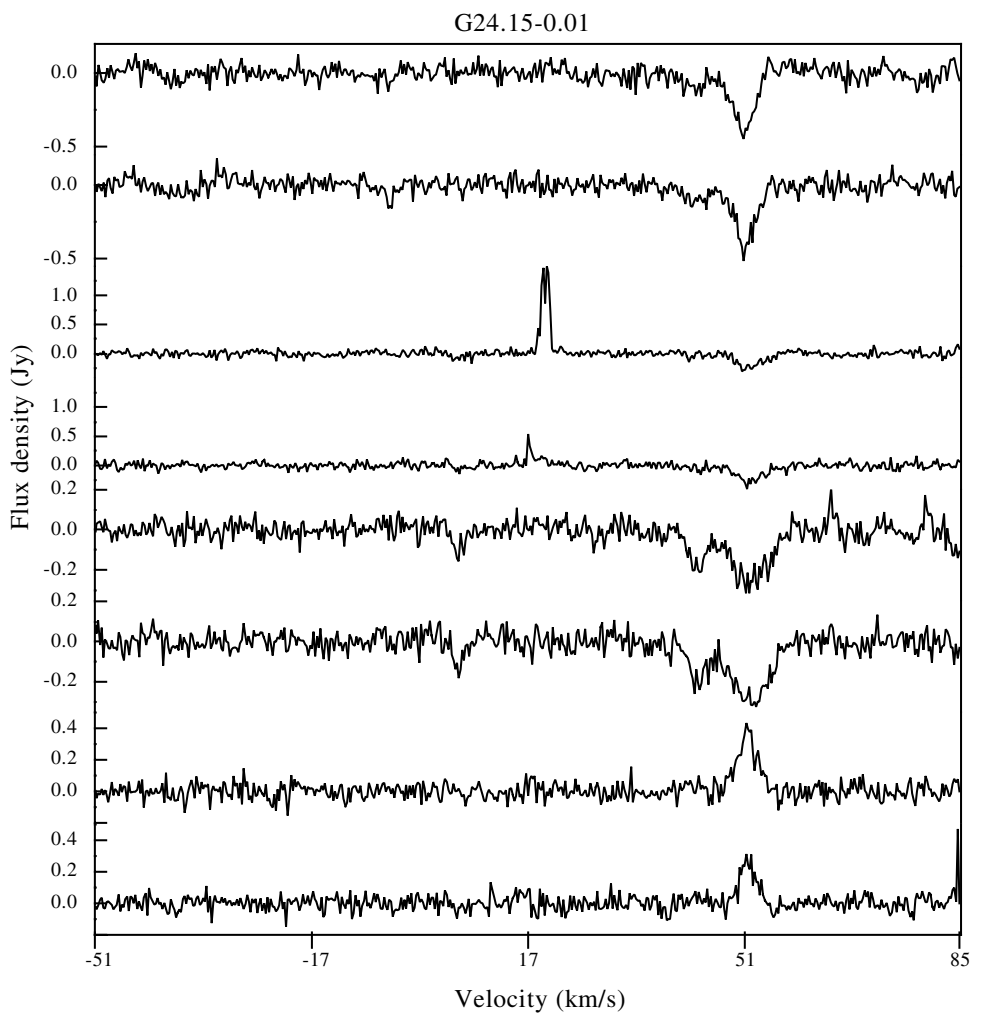

Fig. A.1. continued. 
M. Szymczak and E. Gérard: Hydroxyl ground state transitions in methanol sources, Online Material p 11
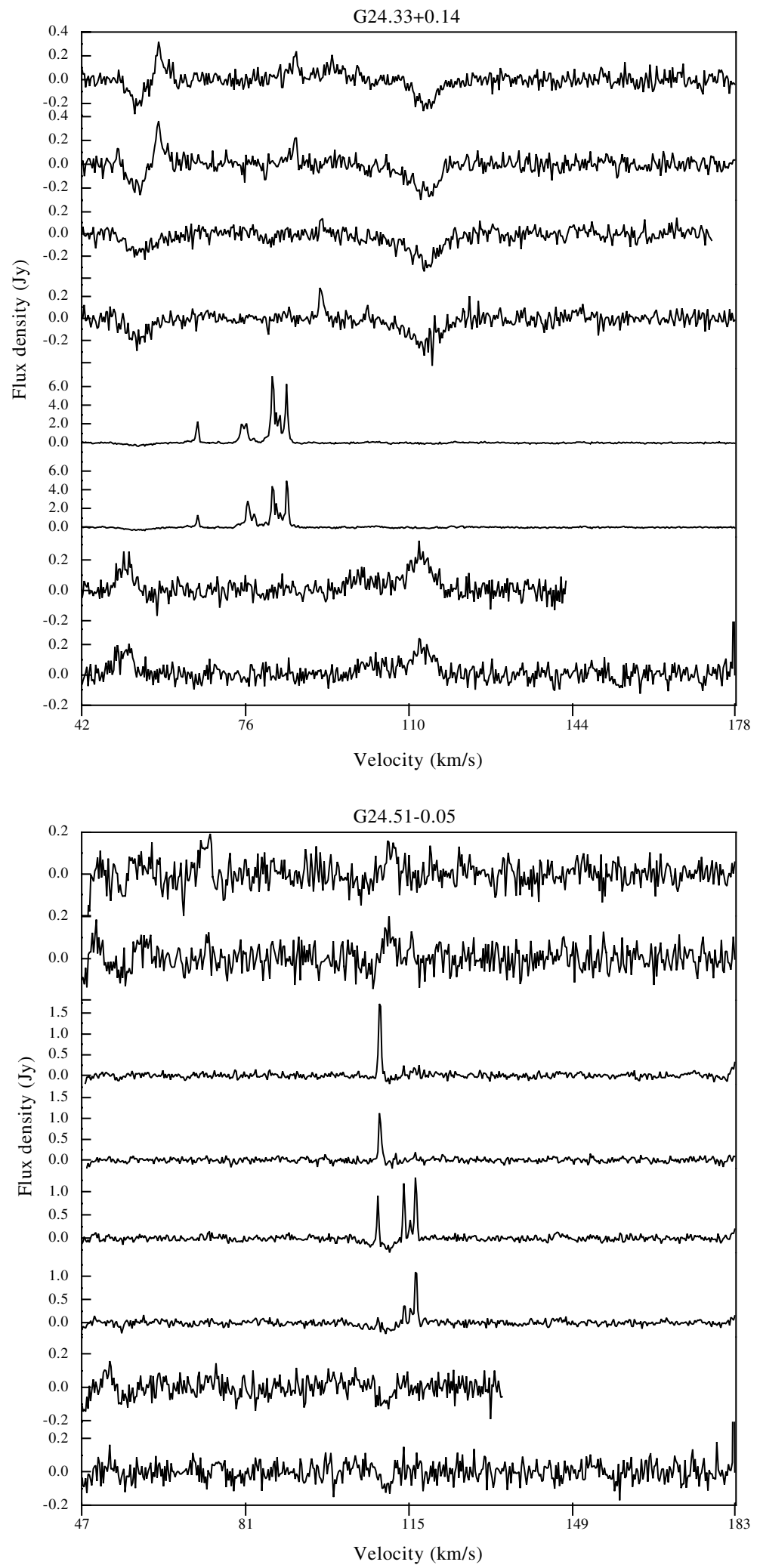

Fig. A.1. continued. 
M. Szymczak and E. Gérard: Hydroxyl ground state transitions in methanol sources, Online Material p 12
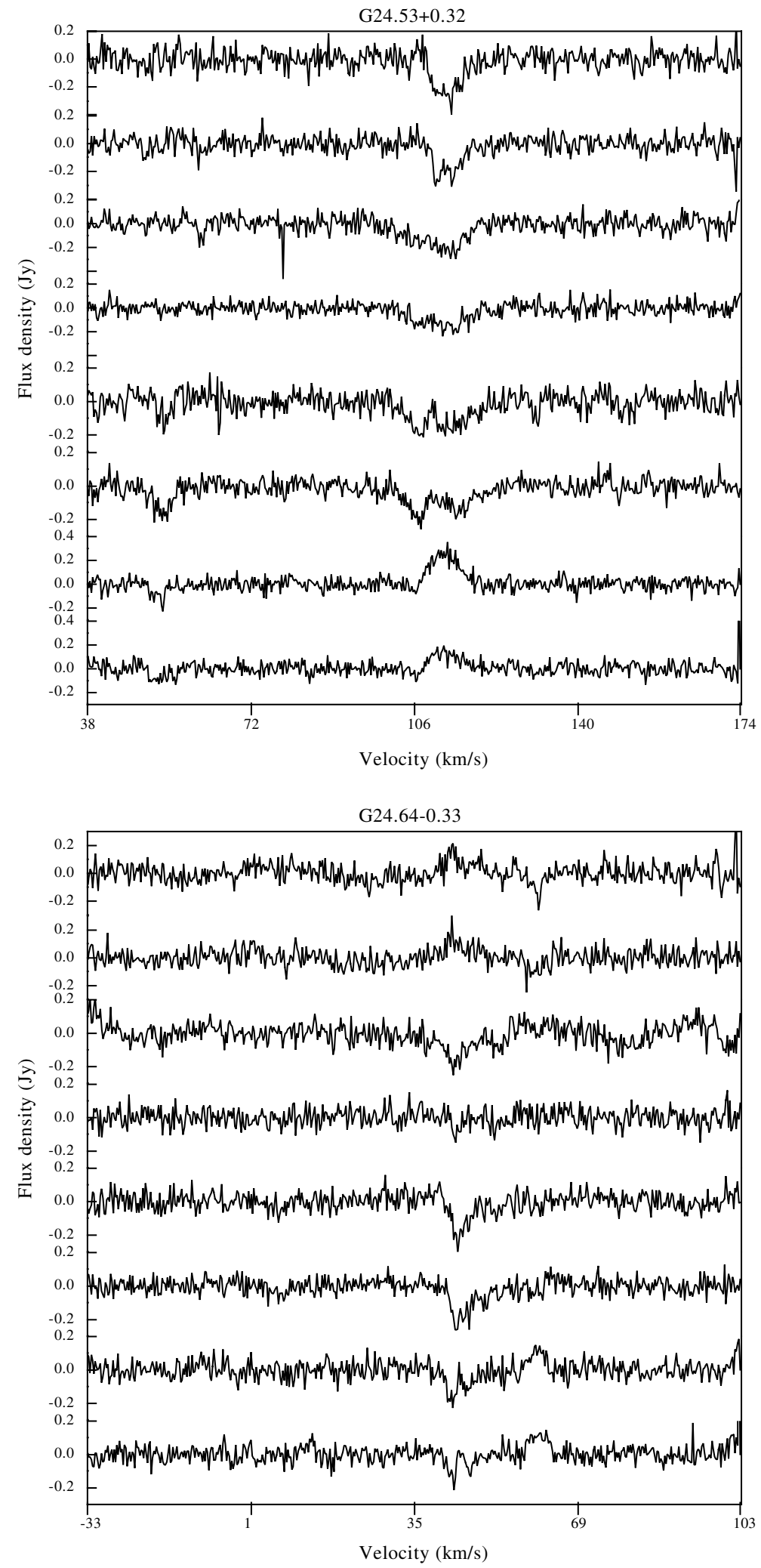

Fig. A.1. continued. 
M. Szymczak and E. Gérard: Hydroxyl ground state transitions in methanol sources, Online Material p 13
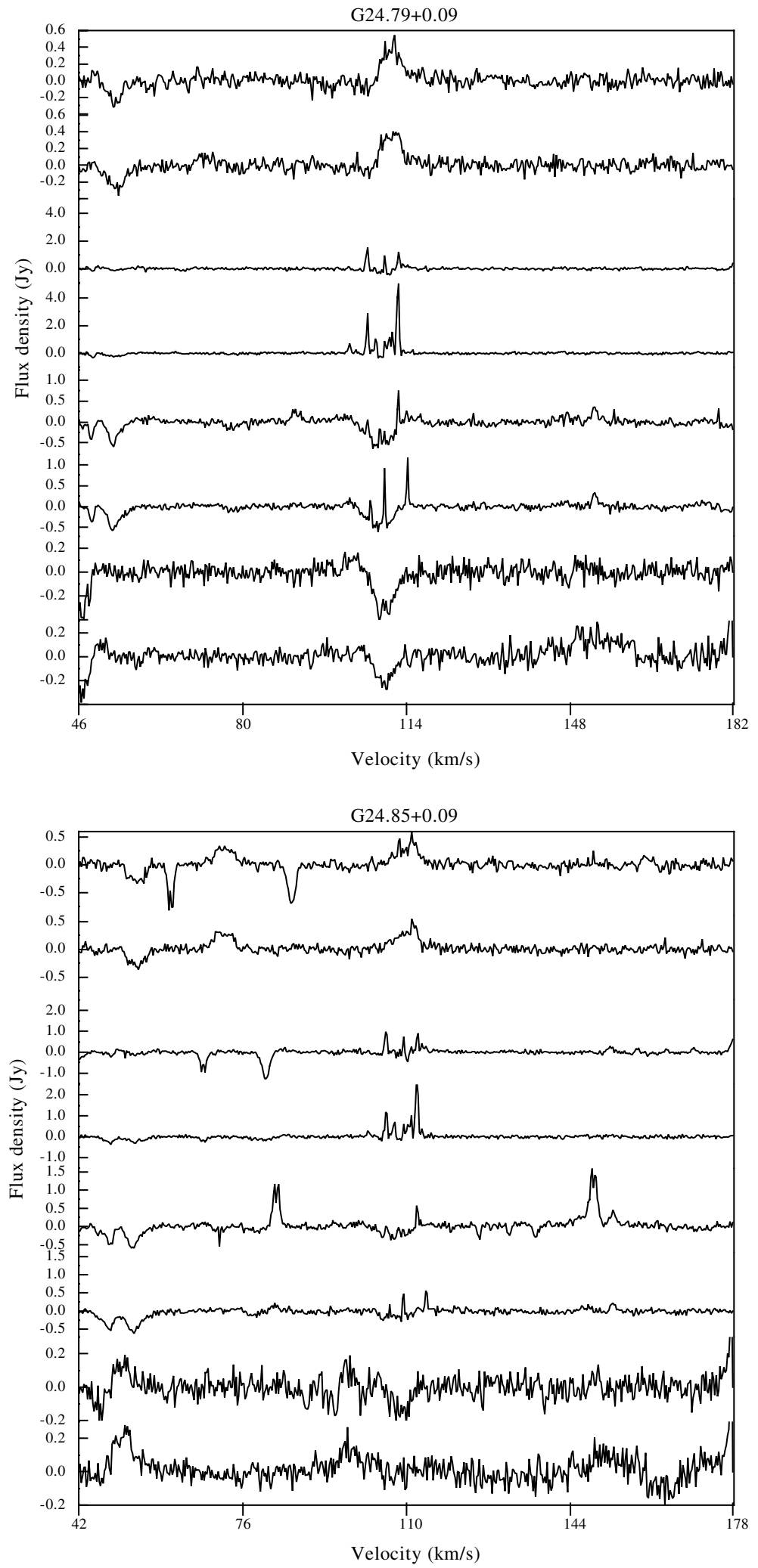

Fig. A.1. continued. 
M. Szymczak and E. Gérard: Hydroxyl ground state transitions in methanol sources, Online Material p 14
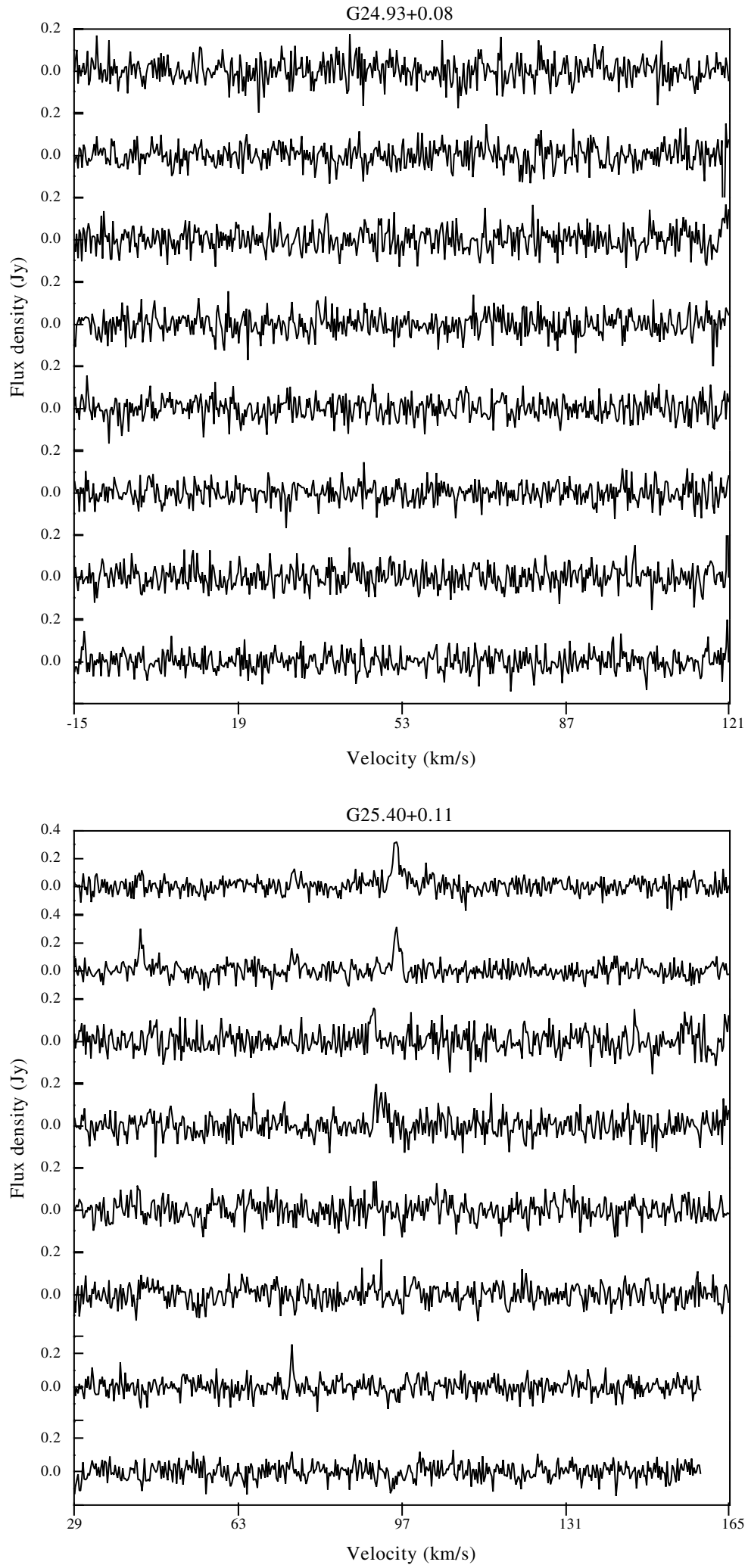

Fig. A.1. continued. 
M. Szymczak and E. Gérard: Hydroxyl ground state transitions in methanol sources, Online Material p 15
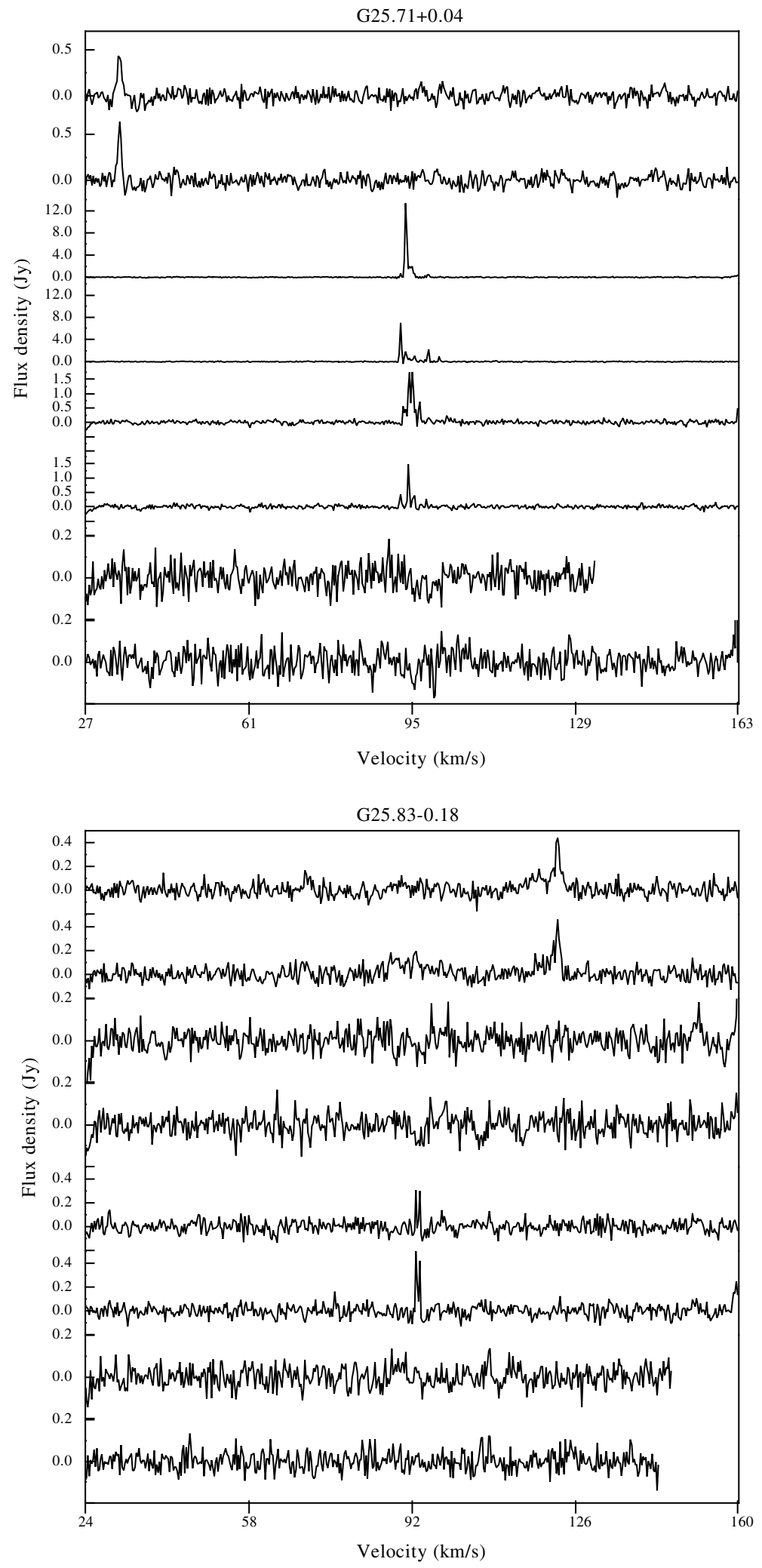

Fig. A.1. continued. 
M. Szymczak and E. Gérard: Hydroxyl ground state transitions in methanol sources, Online Material p 16
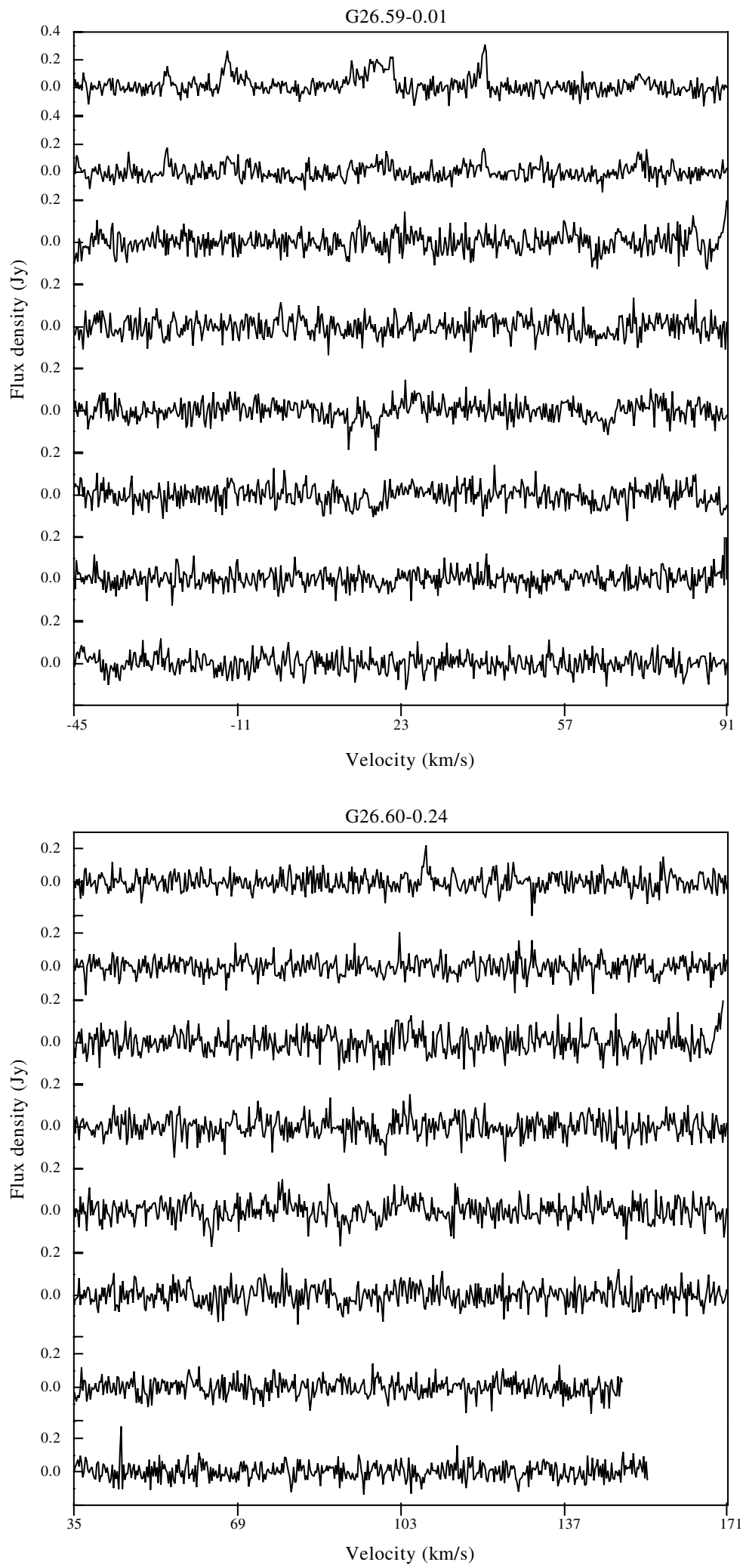

Fig. A.1. continued. 
M. Szymczak and E. Gérard: Hydroxyl ground state transitions in methanol sources, Online Material p 17
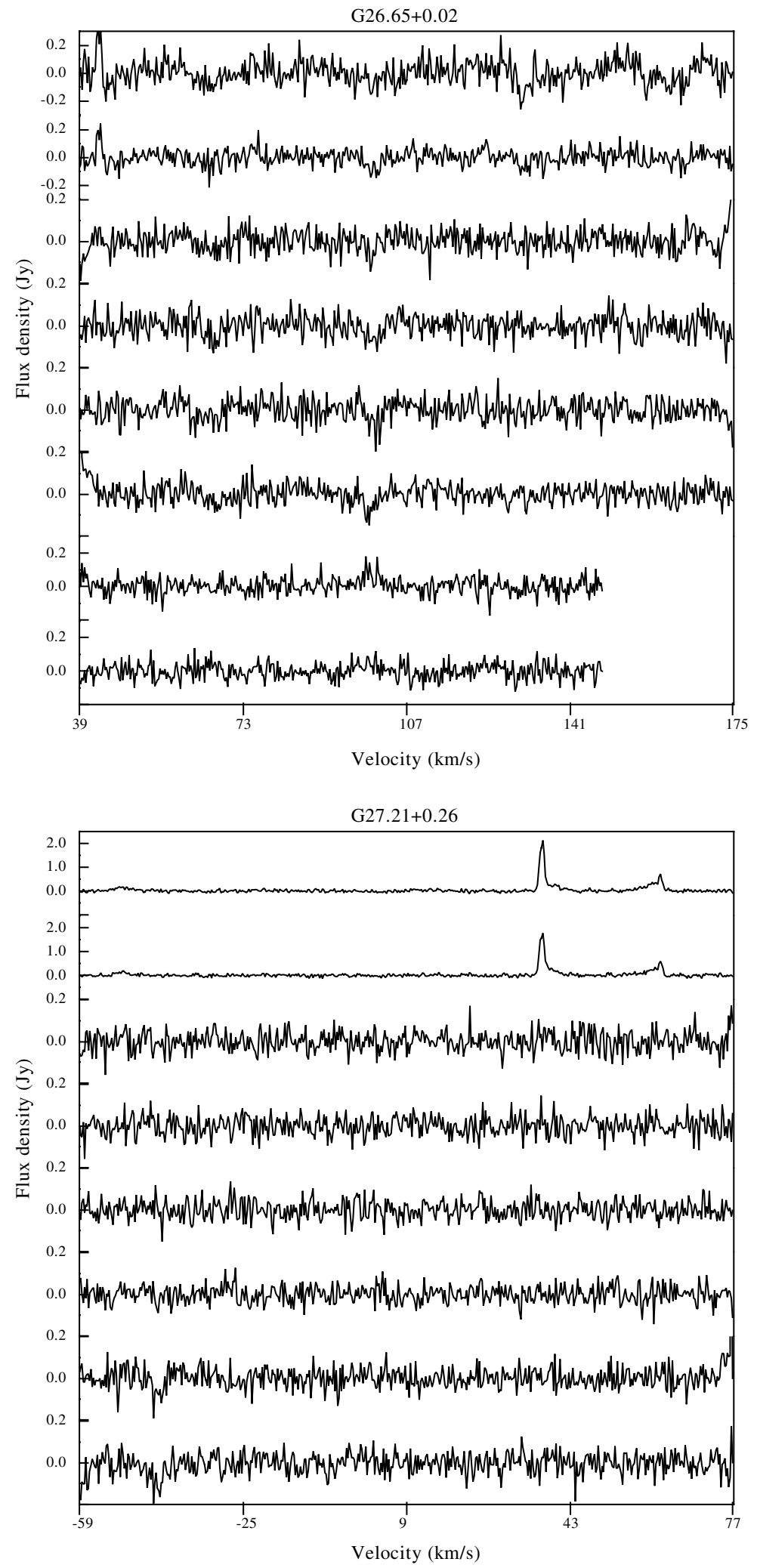

Fig. A.1. continued. 
M. Szymczak and E. Gérard: Hydroxyl ground state transitions in methanol sources, Online Material p 18
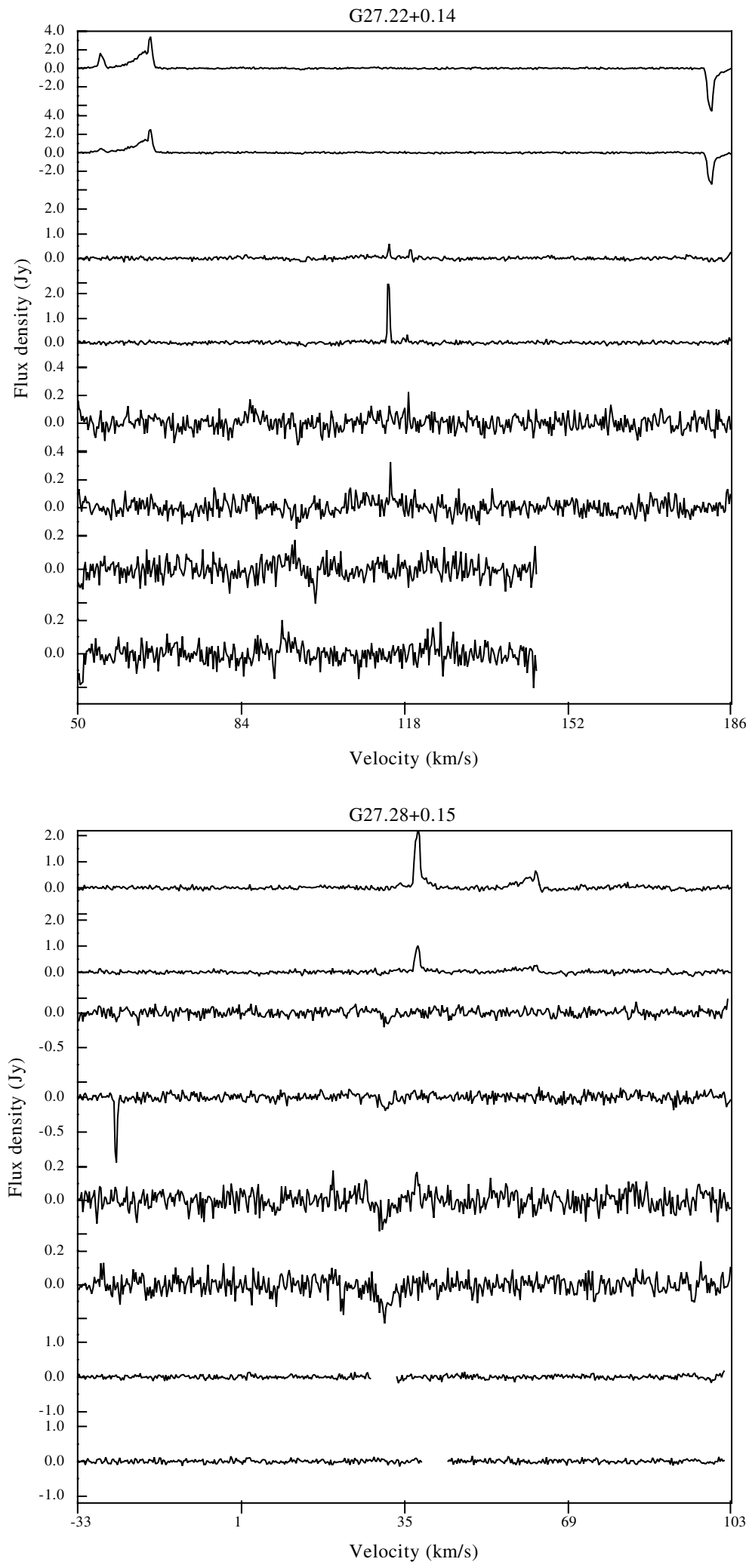

Fig. A.1. continued. 
M. Szymczak and E. Gérard: Hydroxyl ground state transitions in methanol sources, Online Material p 19
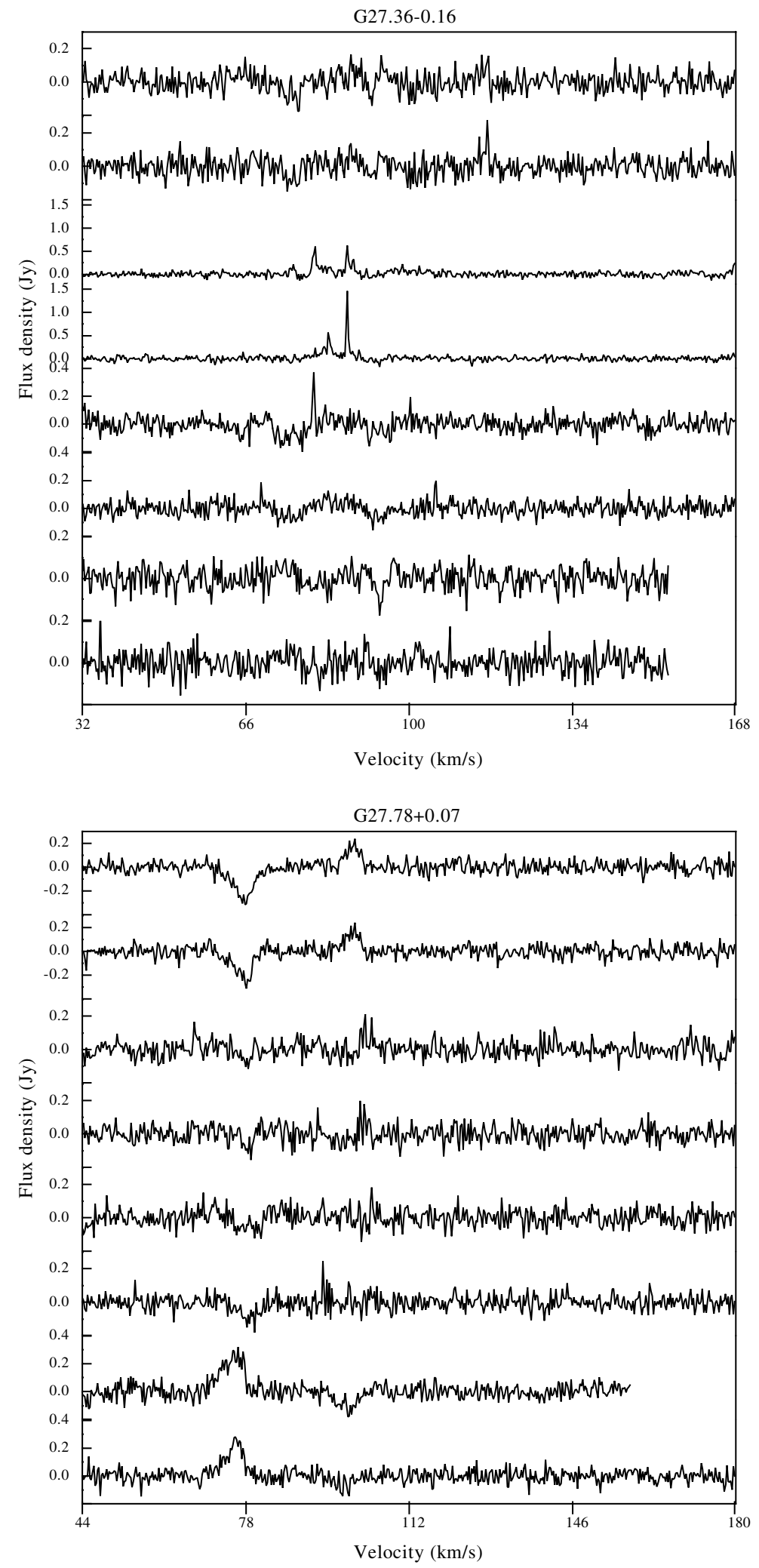

Fig. A.1. continued. 
M. Szymczak and E. Gérard: Hydroxyl ground state transitions in methanol sources, Online Material p 20
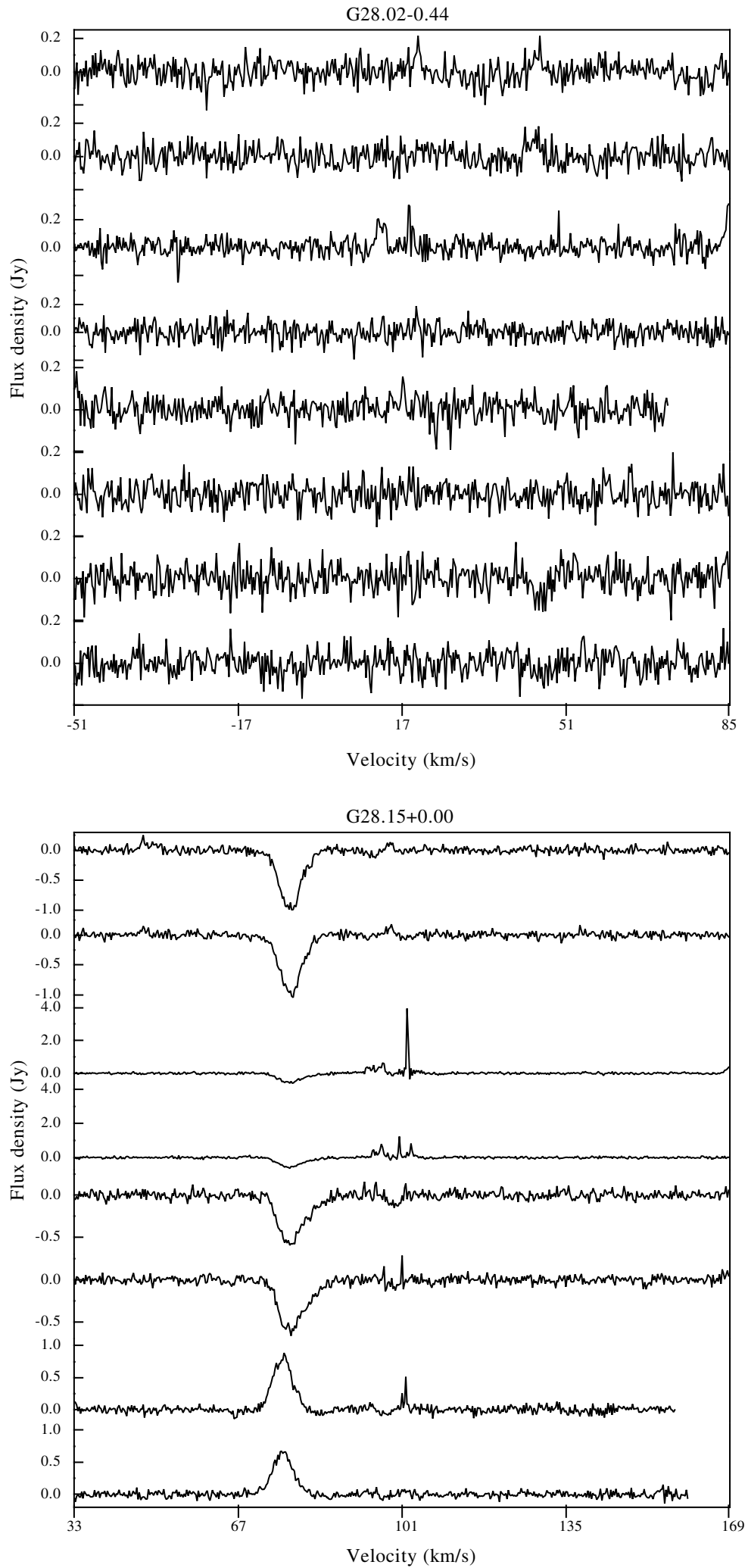

Fig. A.1. continued. 
M. Szymczak and E. Gérard: Hydroxyl ground state transitions in methanol sources, Online Material p 21
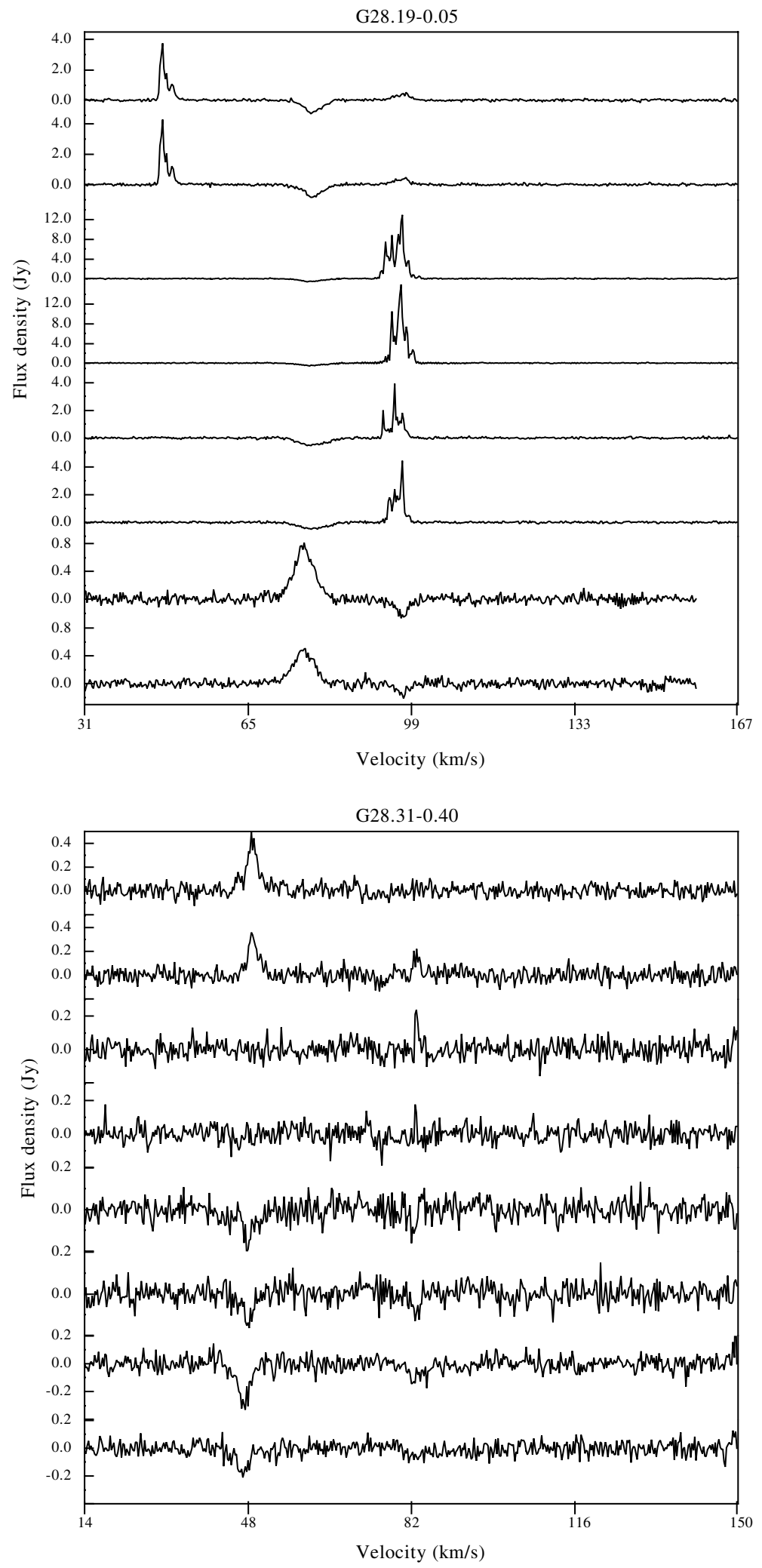

Fig. A.1. continued. 
M. Szymczak and E. Gérard: Hydroxyl ground state transitions in methanol sources, Online Material p 22

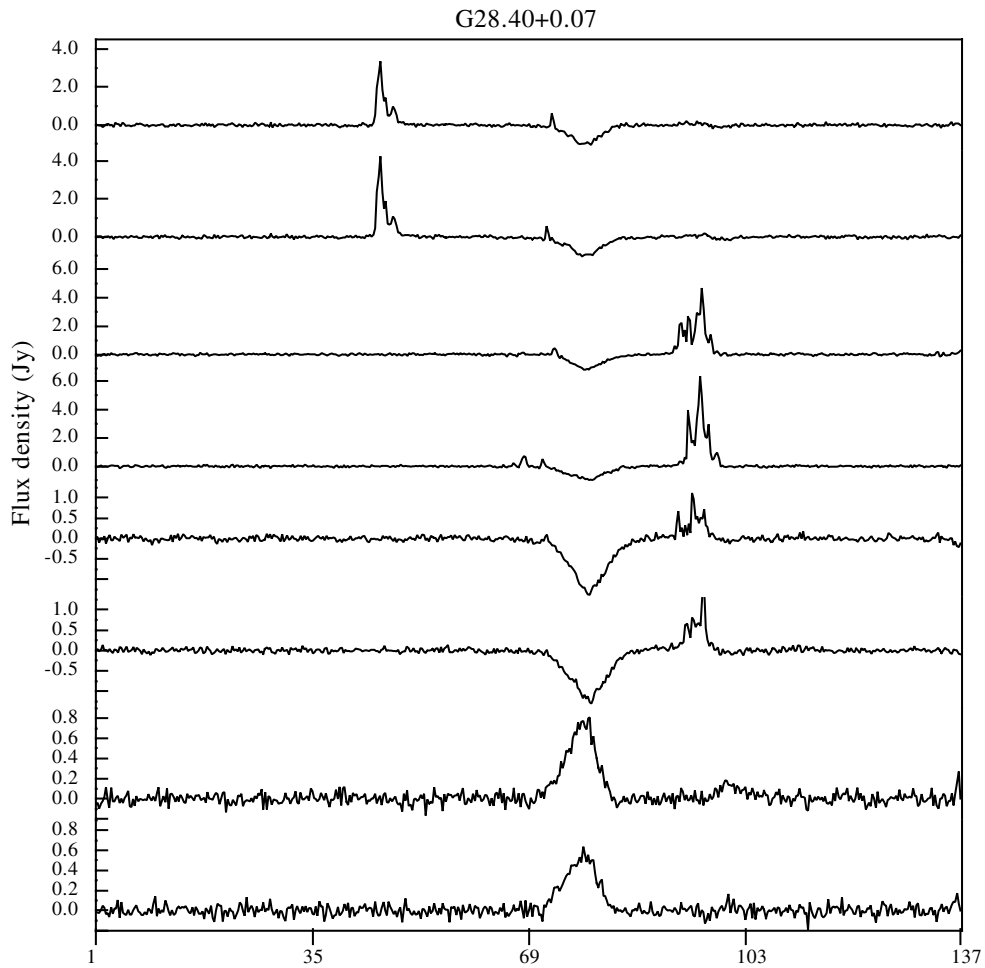

Velocity $(\mathrm{km} / \mathrm{s})$

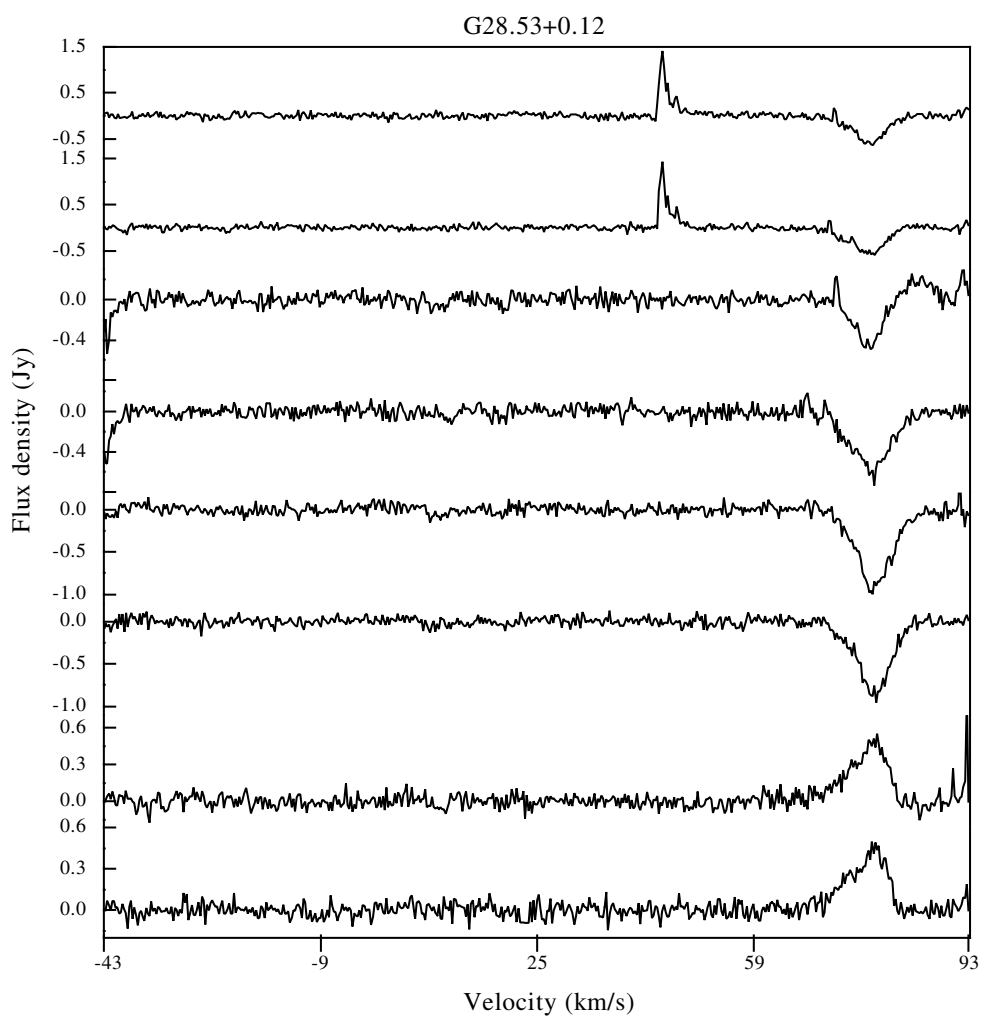

Fig. A.1. continued. 
M. Szymczak and E. Gérard: Hydroxyl ground state transitions in methanol sources, Online Material p 23
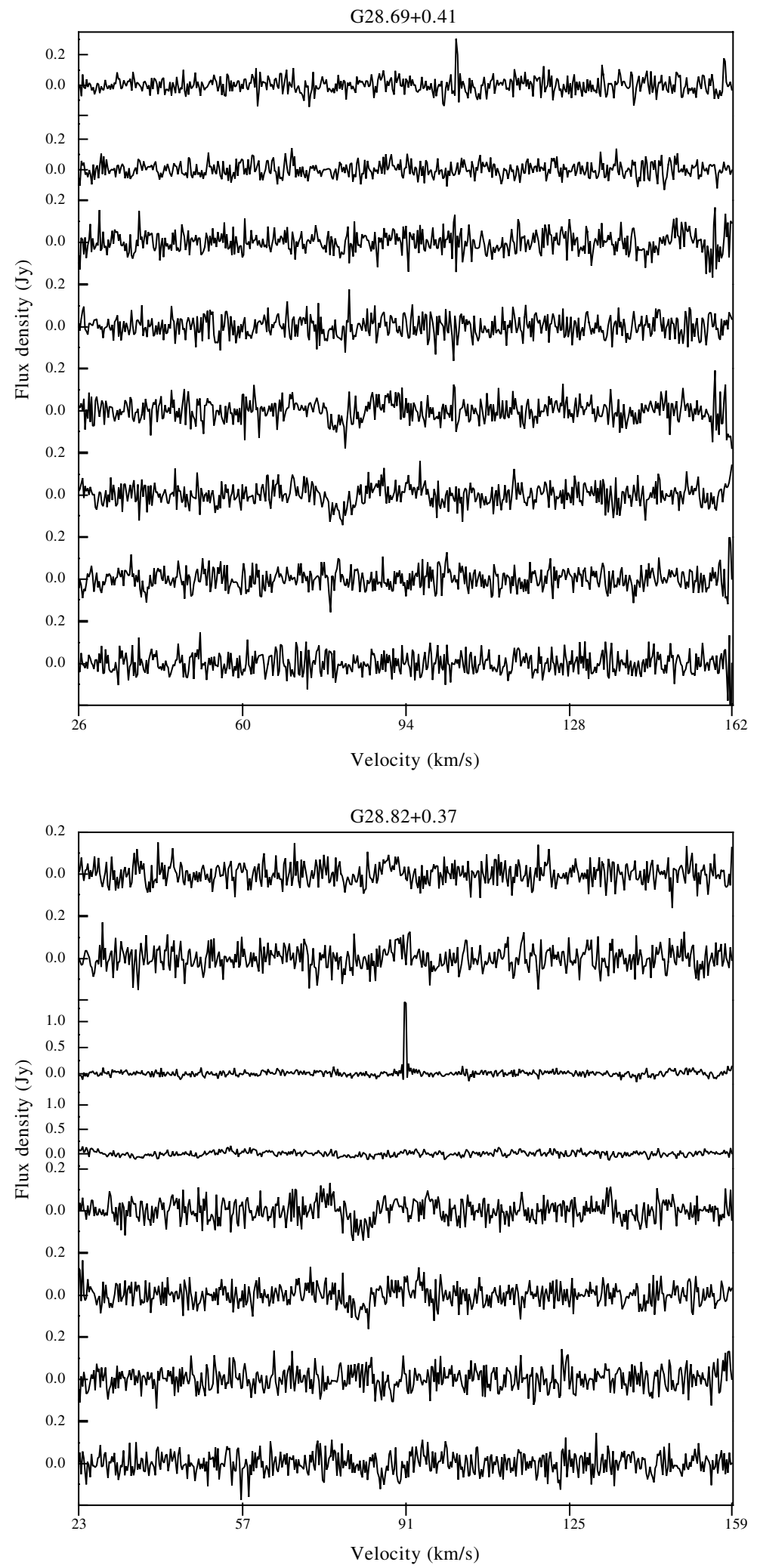

Fig. A.1. continued. 
M. Szymczak and E. Gérard: Hydroxyl ground state transitions in methanol sources, Online Material p 24
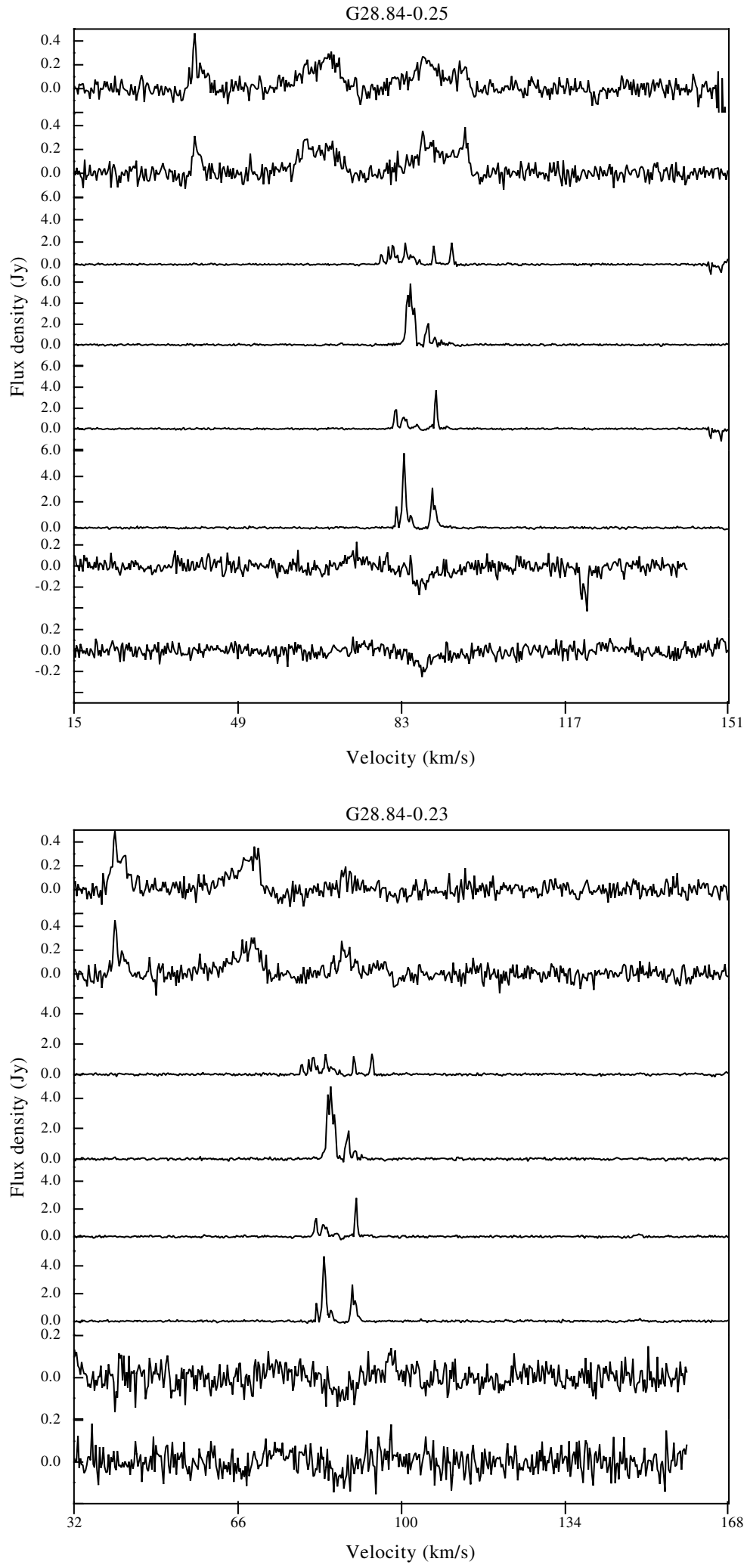

Fig. A.1. continued. 
M. Szymczak and E. Gérard: Hydroxyl ground state transitions in methanol sources, Online Material p 25

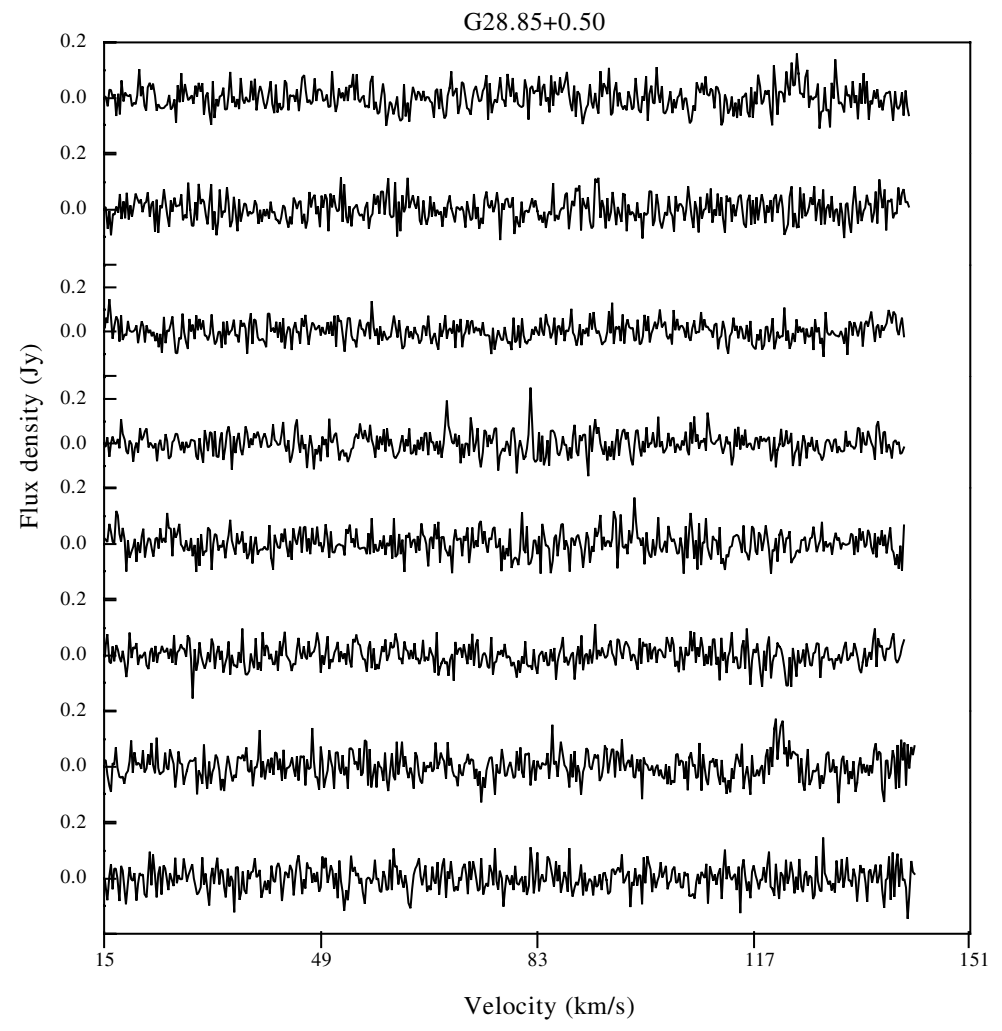

Fig. A.1. continued. 
M. Szymczak and E. Gérard: Hydroxyl ground state transitions in methanol sources, Online Material p 26
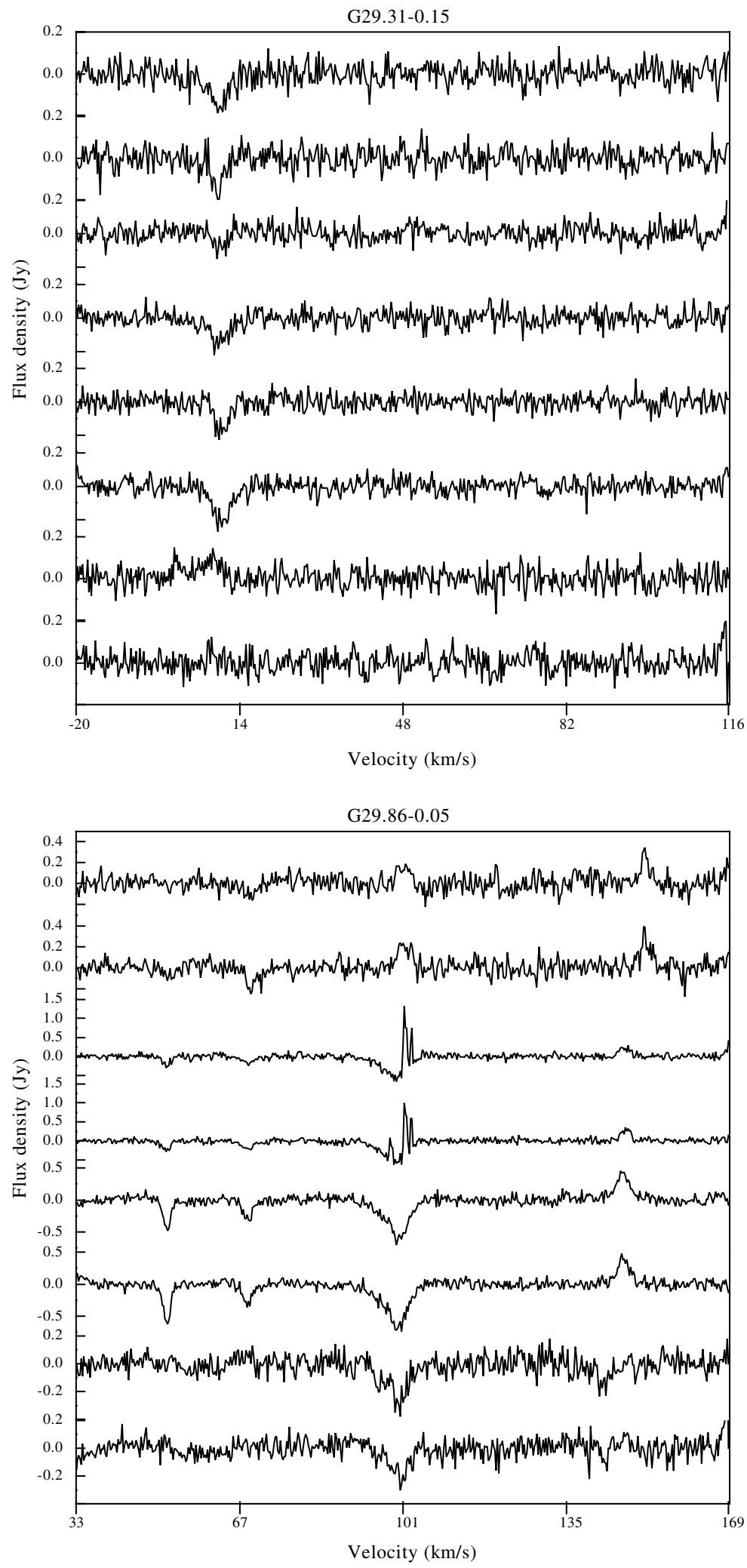

Fig. A.1. continued. 
M. Szymczak and E. Gérard: Hydroxyl ground state transitions in methanol sources, Online Material p 27
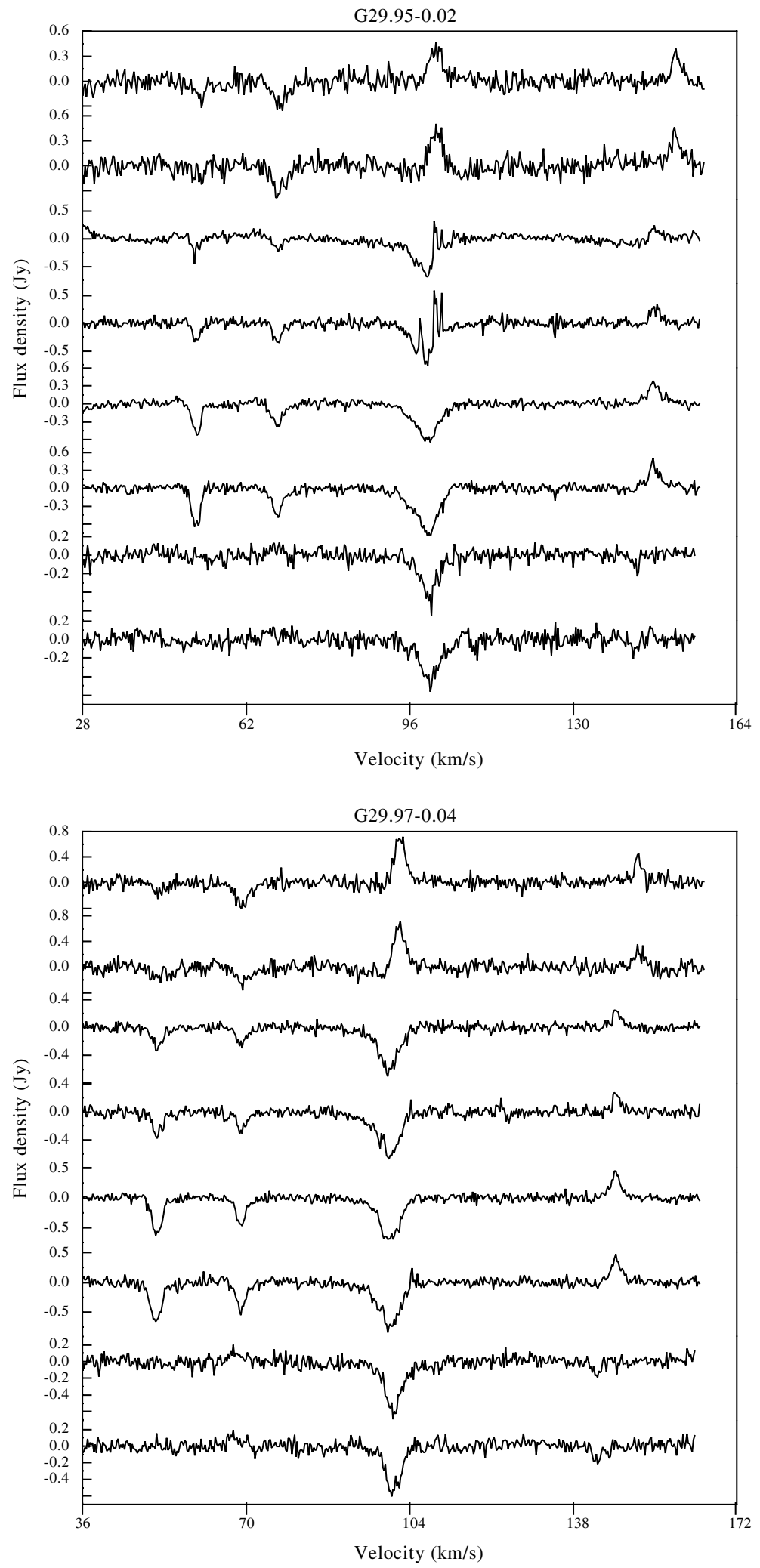

Fig. A.1. continued. 
M. Szymczak and E. Gérard: Hydroxyl ground state transitions in methanol sources, Online Material p 28
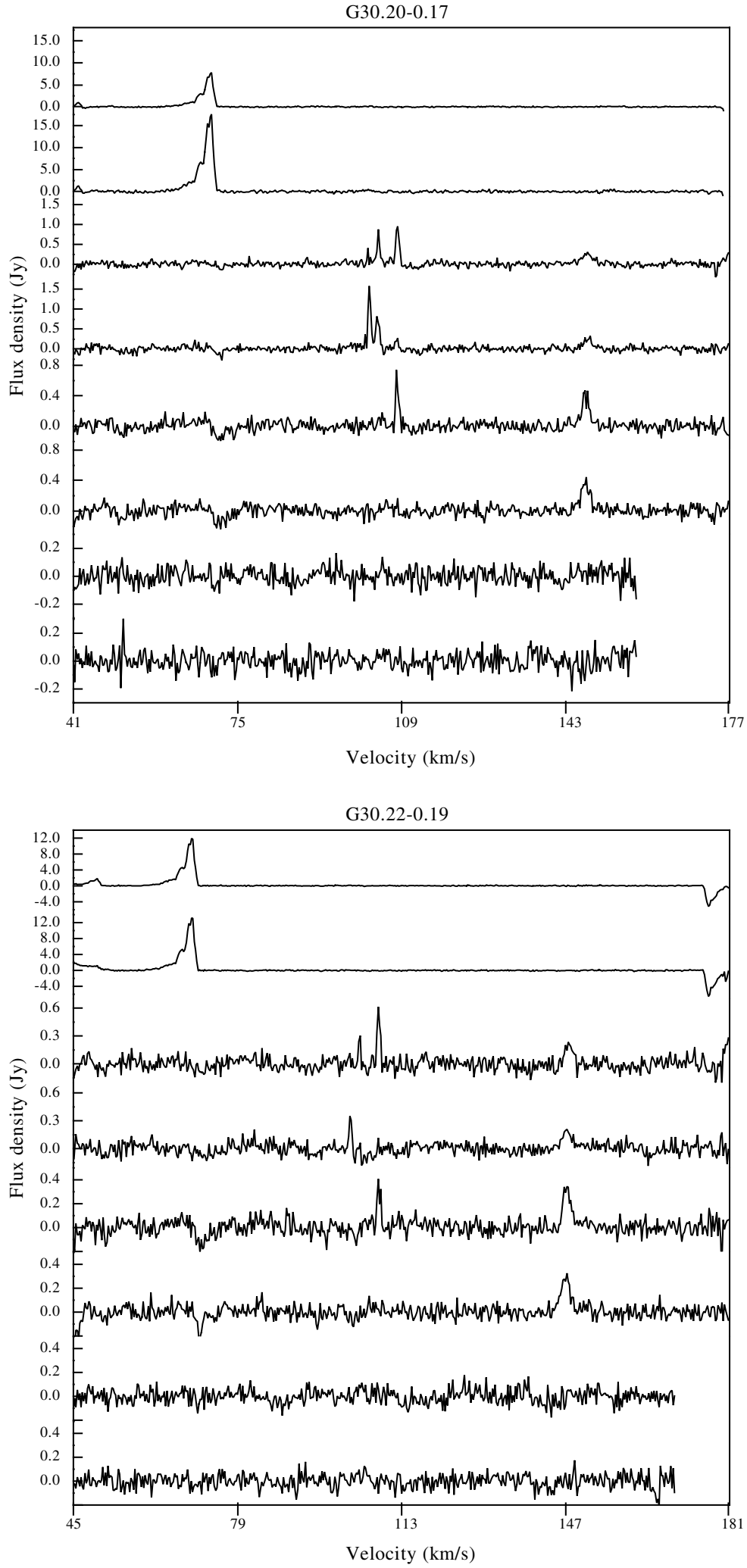

Fig. A.1. continued. 
M. Szymczak and E. Gérard: Hydroxyl ground state transitions in methanol sources, Online Material p 29
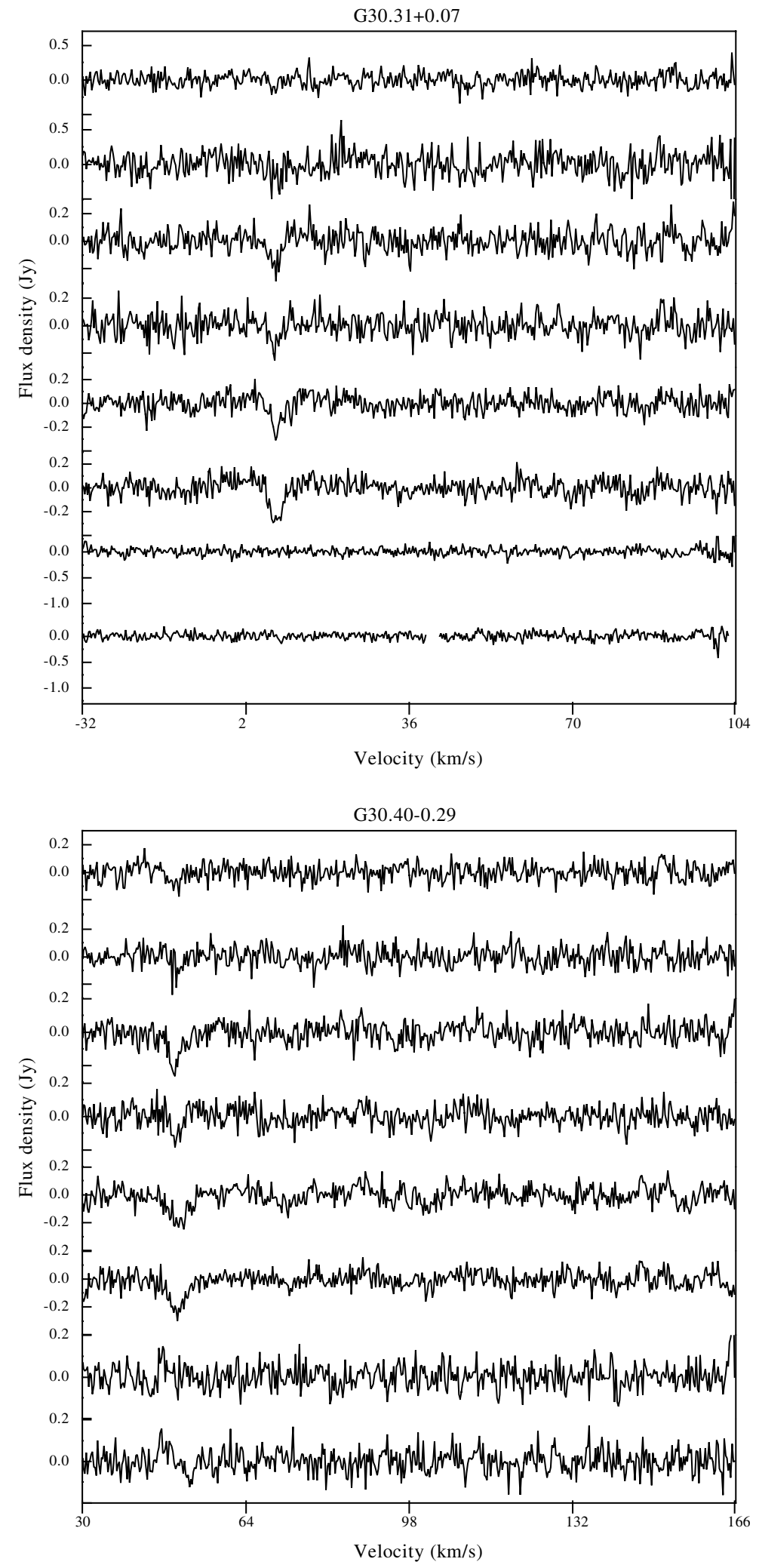

Fig. A.1. continued. 
M. Szymczak and E. Gérard: Hydroxyl ground state transitions in methanol sources, Online Material p 30
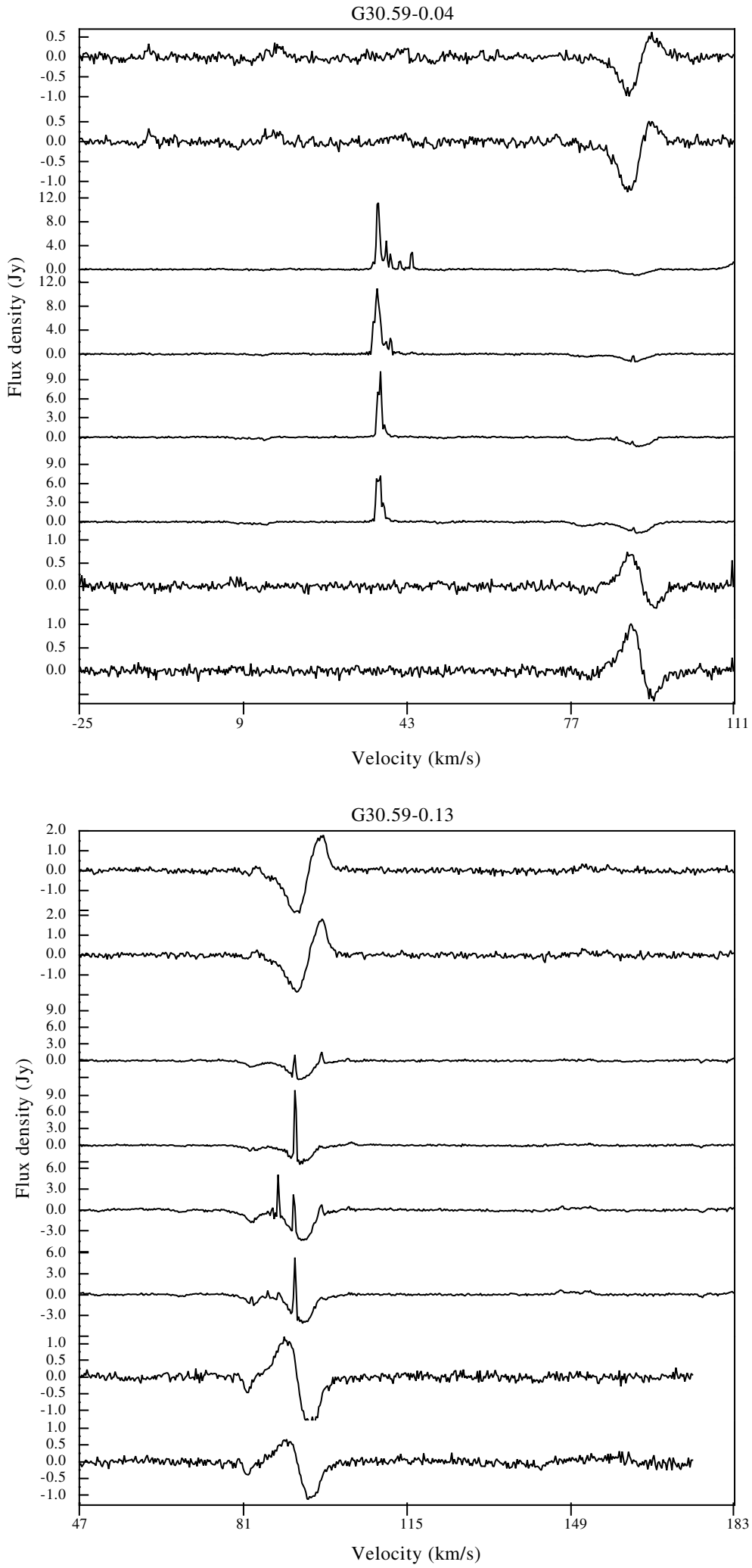

Fig. A.1. continued. 
M. Szymczak and E. Gérard: Hydroxyl ground state transitions in methanol sources, Online Material p 31
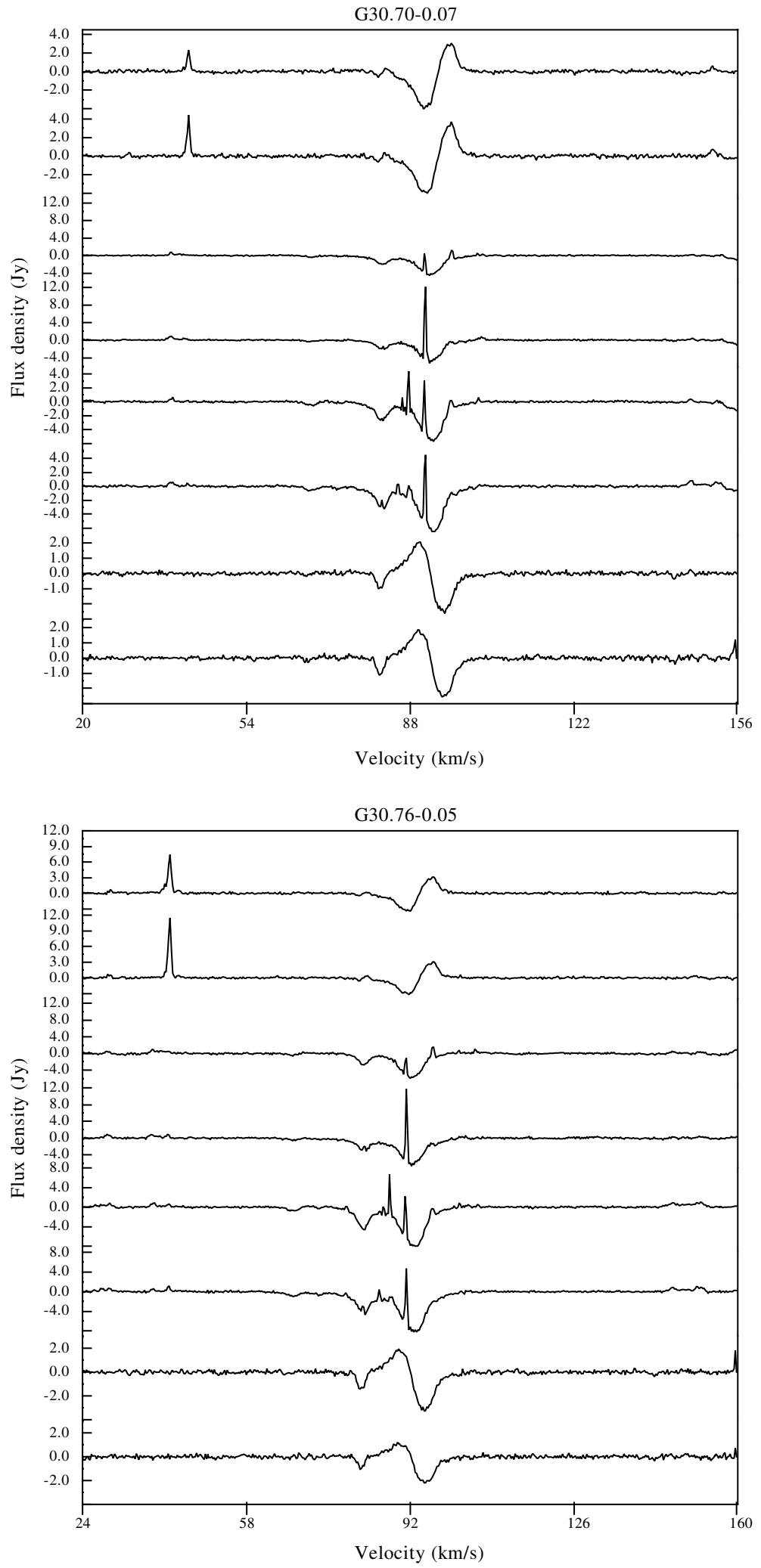

Fig. A.1. continued. 
M. Szymczak and E. Gérard: Hydroxyl ground state transitions in methanol sources, Online Material p 32
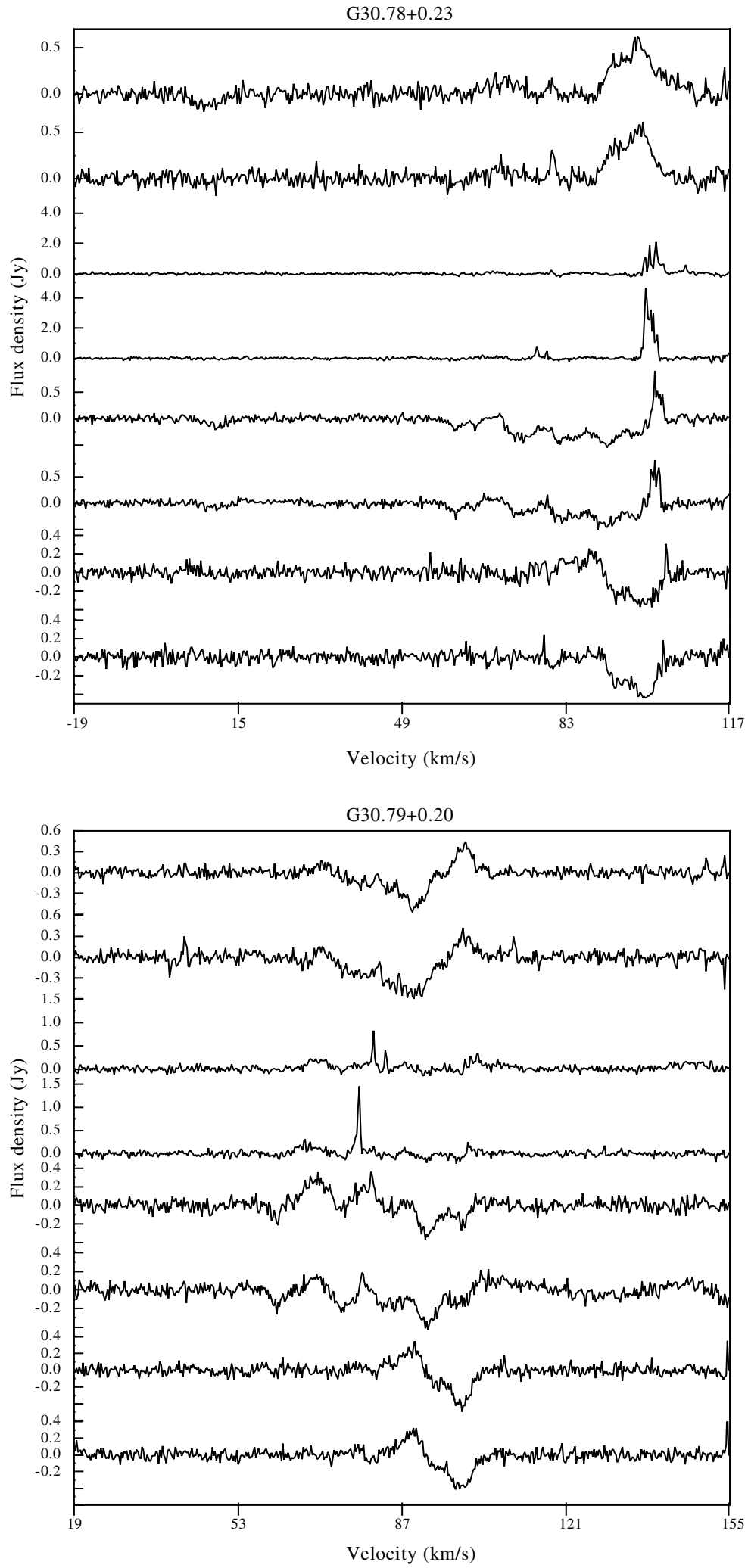

Fig. A.1. continued. 
M. Szymczak and E. Gérard: Hydroxyl ground state transitions in methanol sources, Online Material p 33
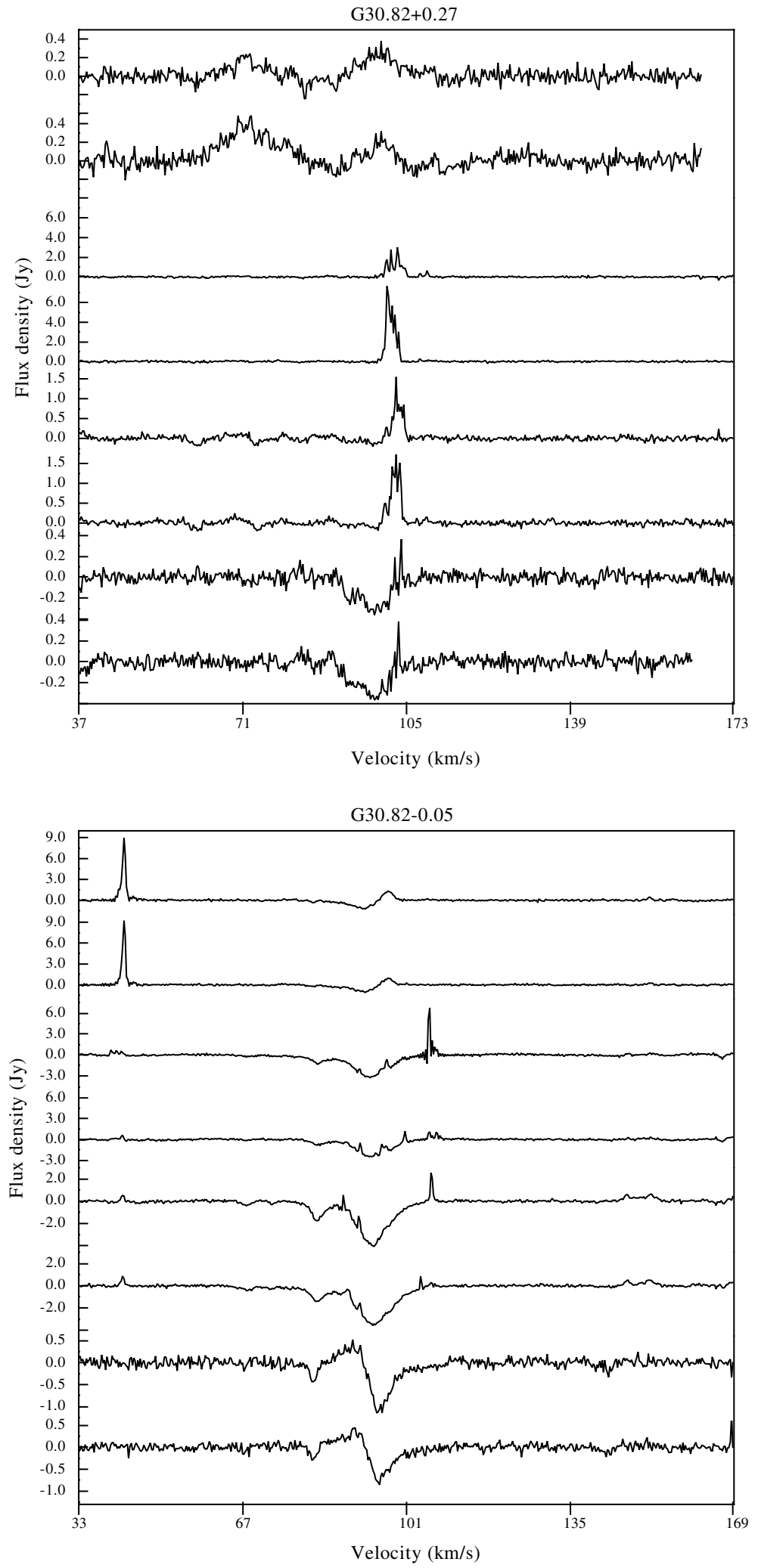

Fig. A.1. continued. 
M. Szymczak and E. Gérard: Hydroxyl ground state transitions in methanol sources, Online Material p 34
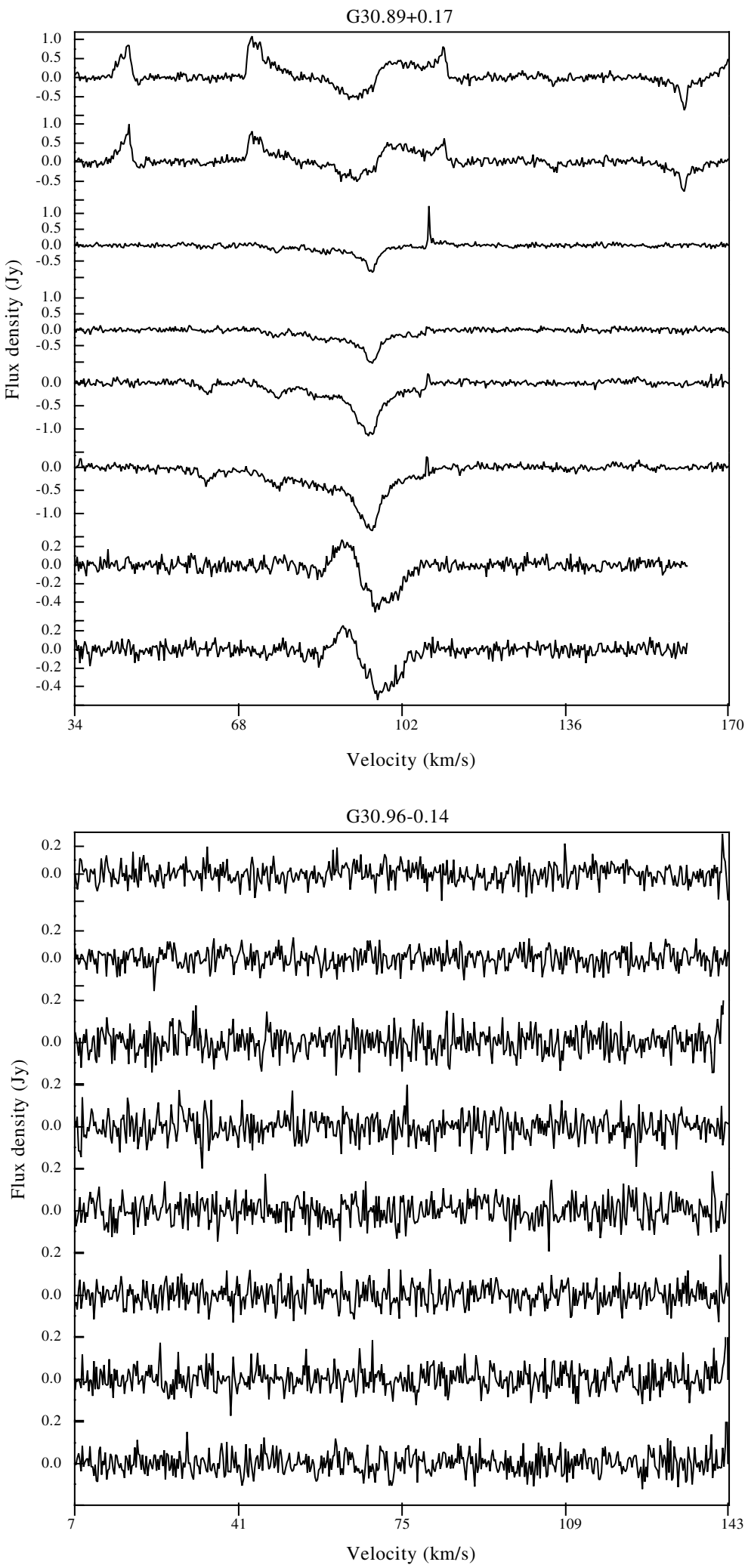

Fig. A.1. continued. 
M. Szymczak and E. Gérard: Hydroxyl ground state transitions in methanol sources, Online Material p 35
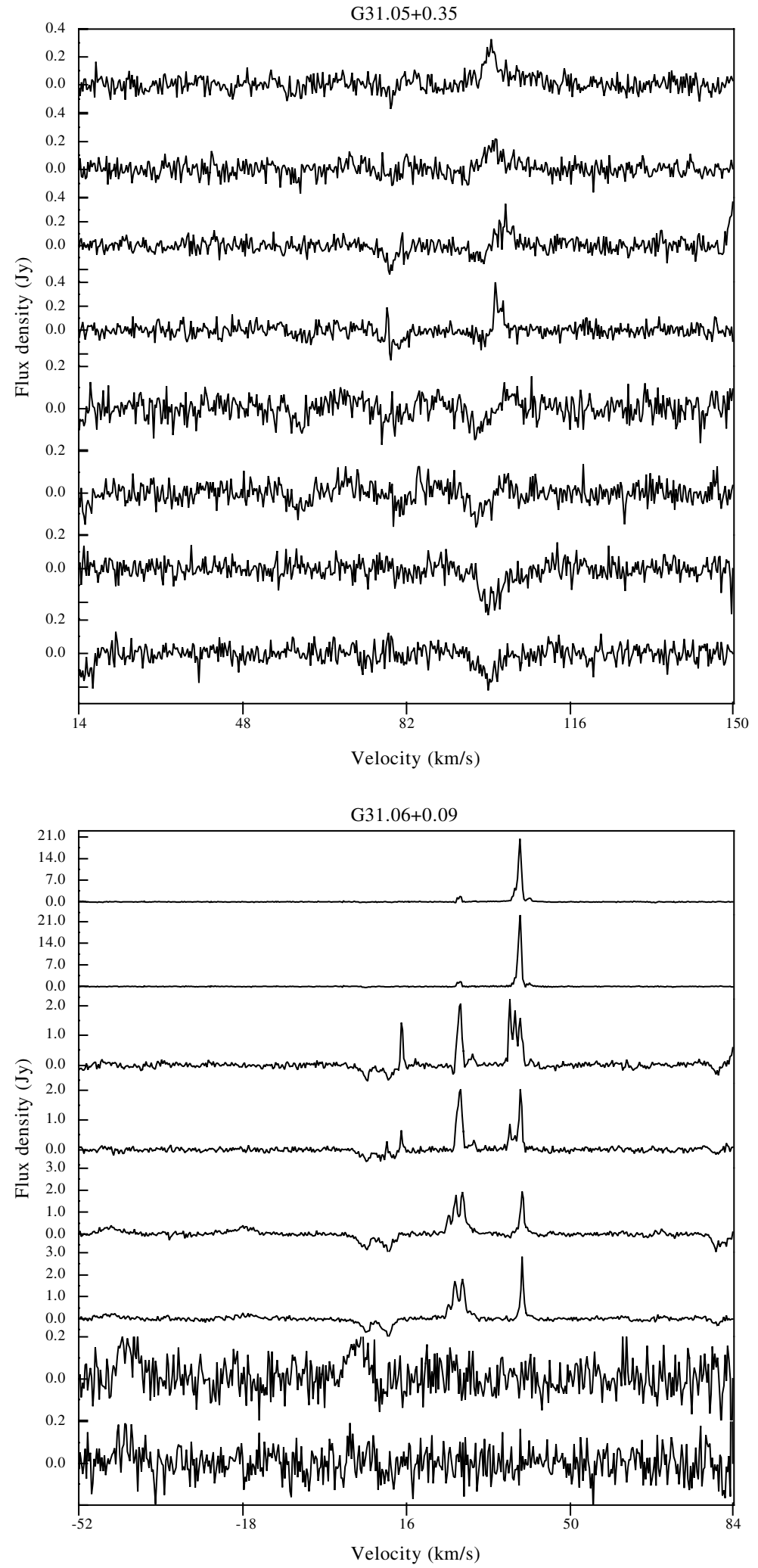

Fig. A.1. continued. 
M. Szymczak and E. Gérard: Hydroxyl ground state transitions in methanol sources, Online Material p 36
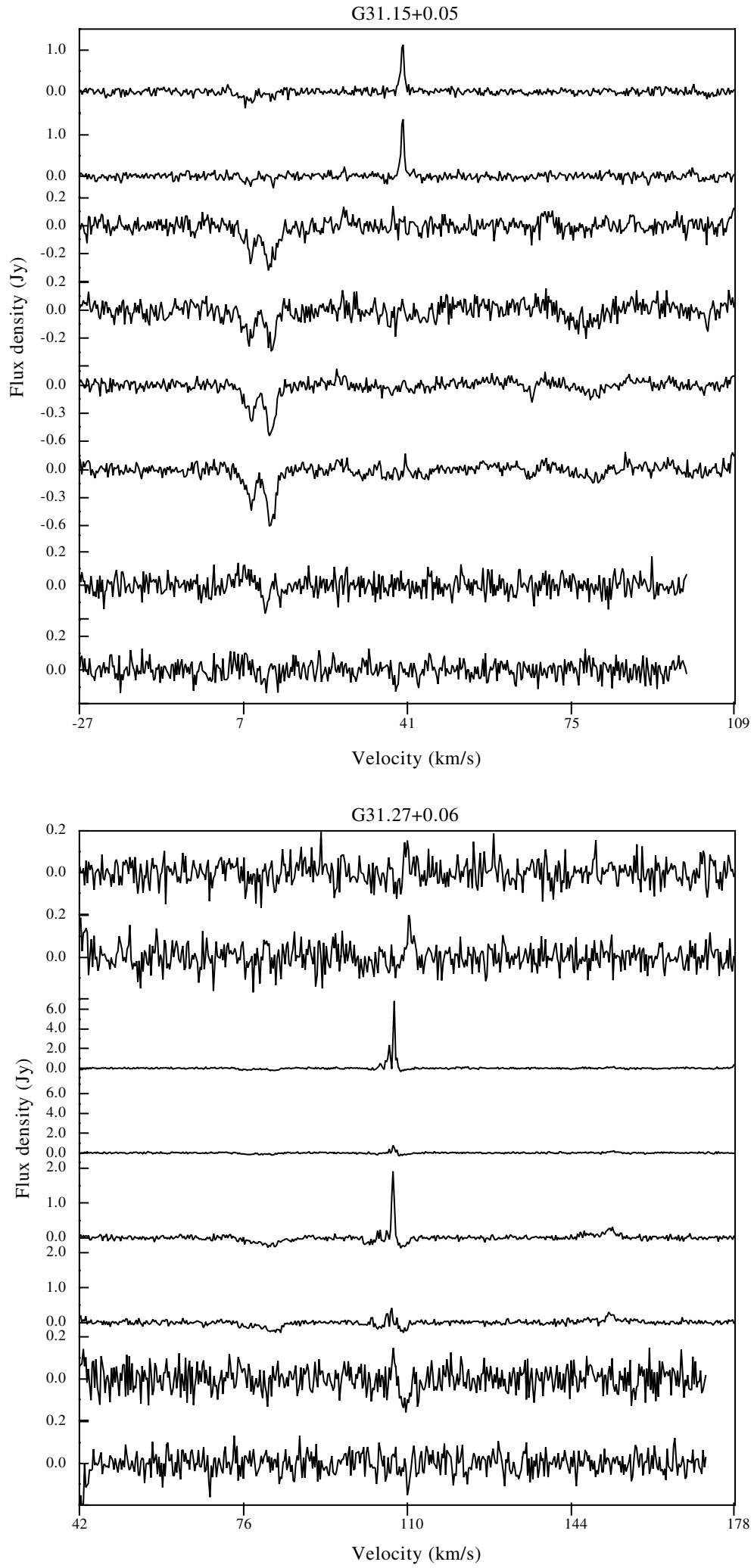

Fig. A.1. continued. 
M. Szymczak and E. Gérard: Hydroxyl ground state transitions in methanol sources, Online Material p 37
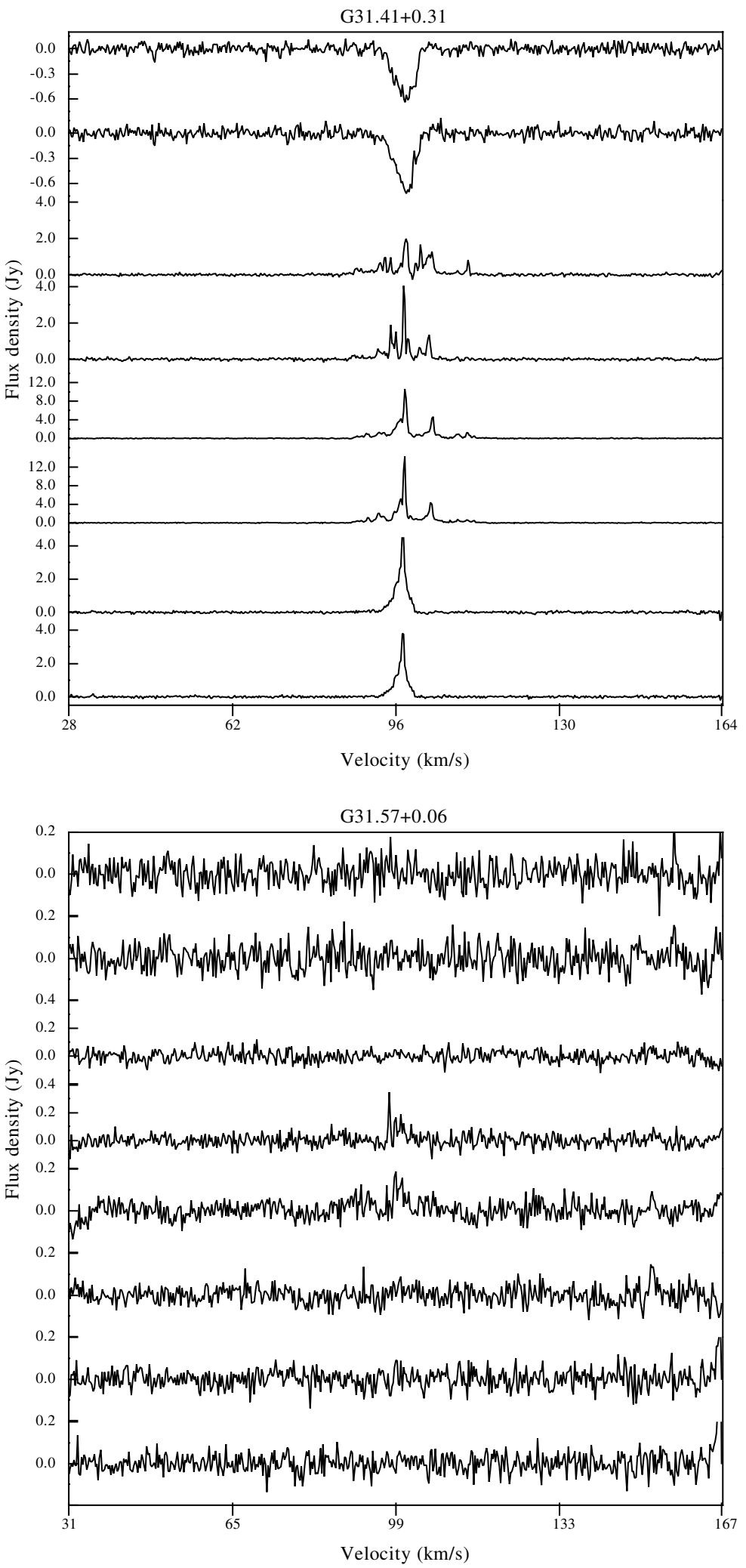

Fig. A.1. continued. 
M. Szymczak and E. Gérard: Hydroxyl ground state transitions in methanol sources, Online Material p 38
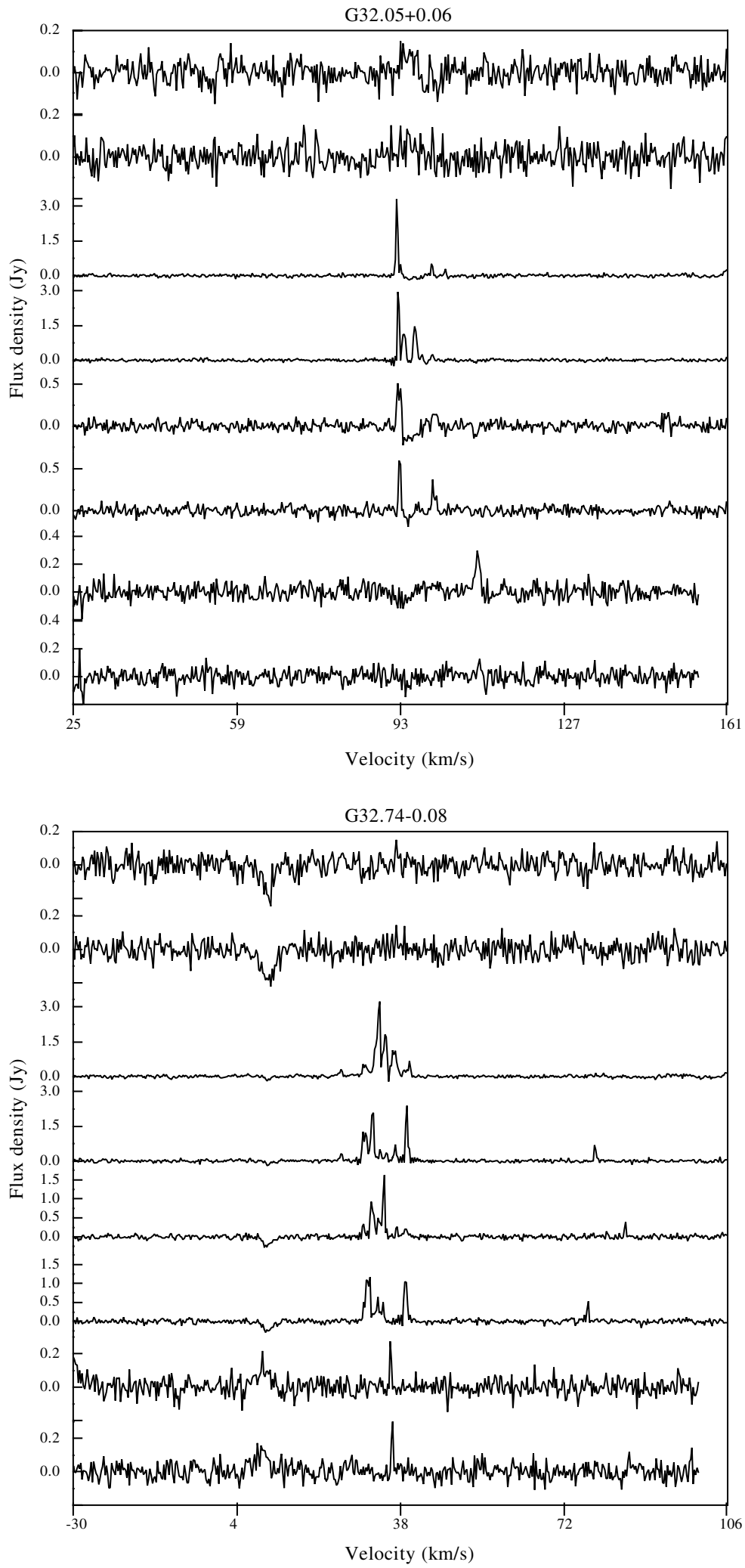

Fig. A.1. continued. 
M. Szymczak and E. Gérard: Hydroxyl ground state transitions in methanol sources, Online Material p 39
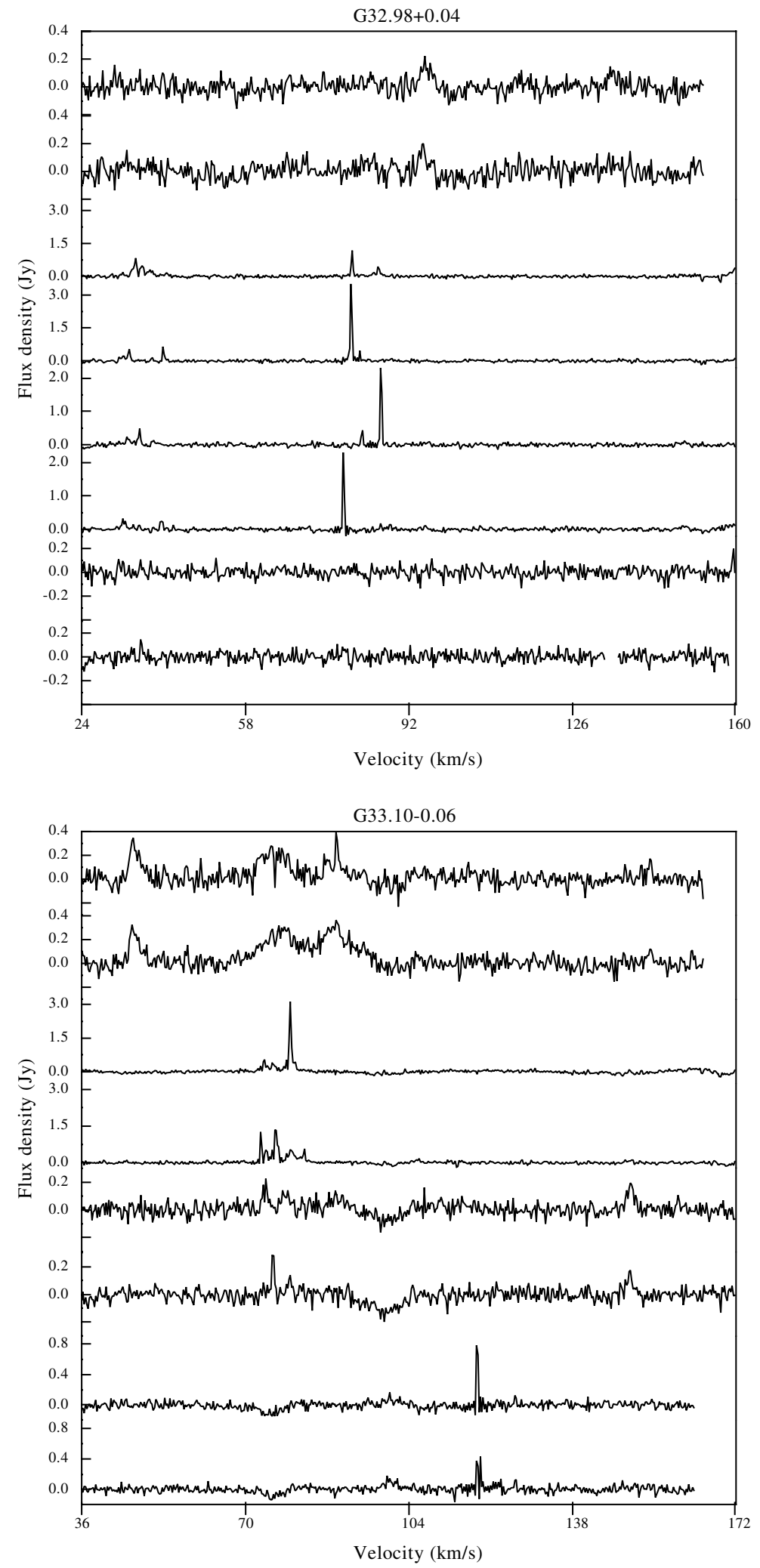

Fig. A.1. continued. 
M. Szymczak and E. Gérard: Hydroxyl ground state transitions in methanol sources, Online Material p 40
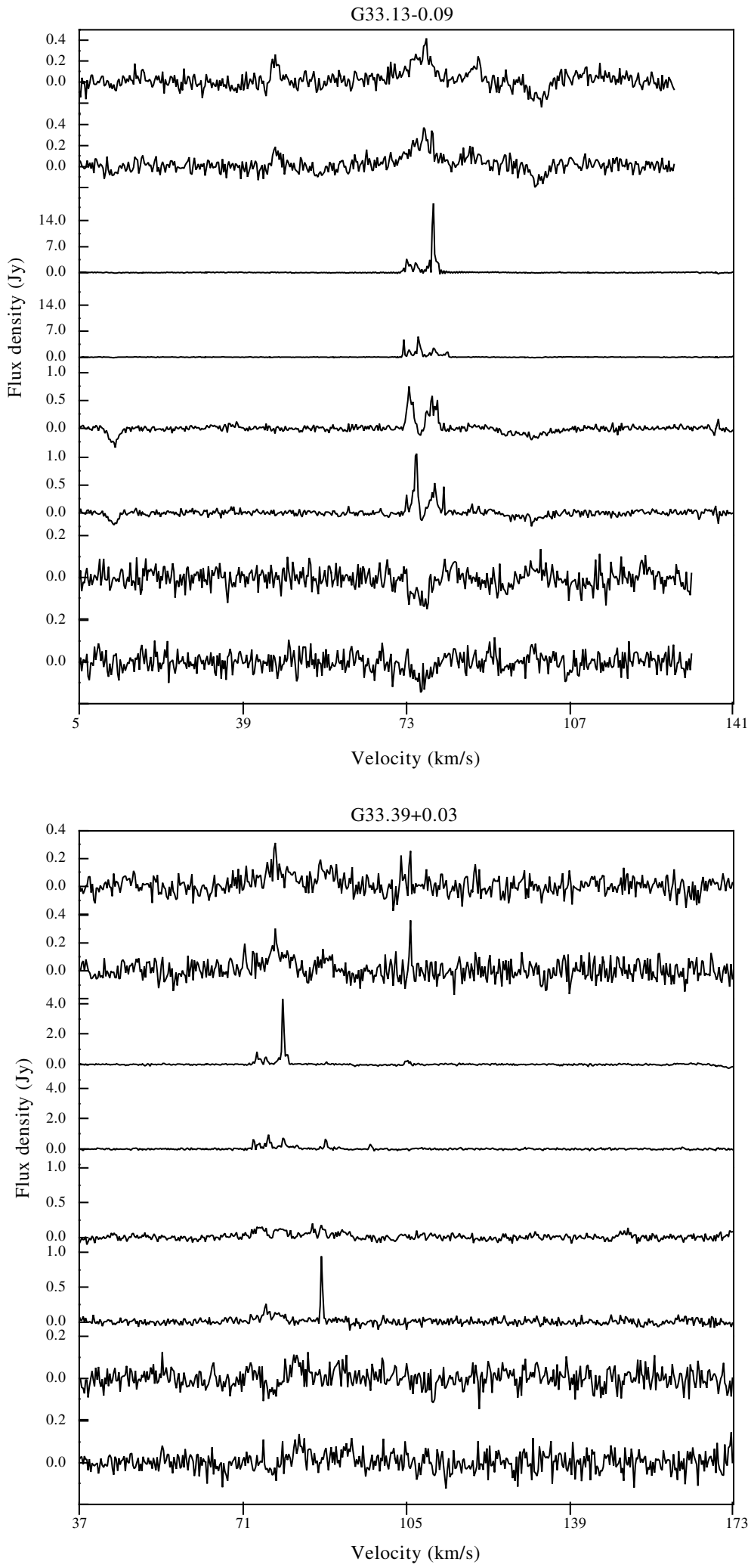

Fig. A.1. continued. 
M. Szymczak and E. Gérard: Hydroxyl ground state transitions in methanol sources, Online Material p 41
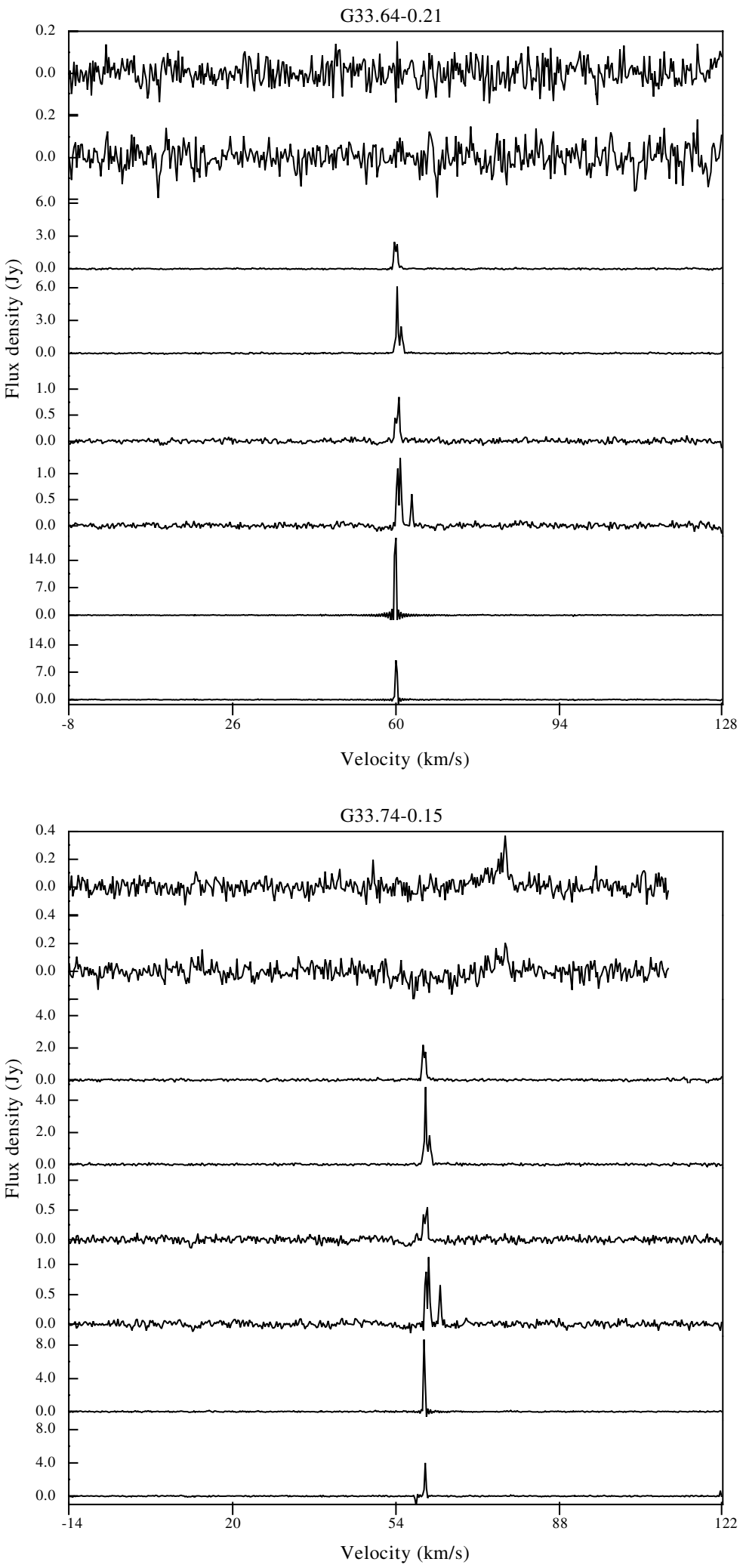

Fig. A.1. continued. 
M. Szymczak and E. Gérard: Hydroxyl ground state transitions in methanol sources, Online Material p 42
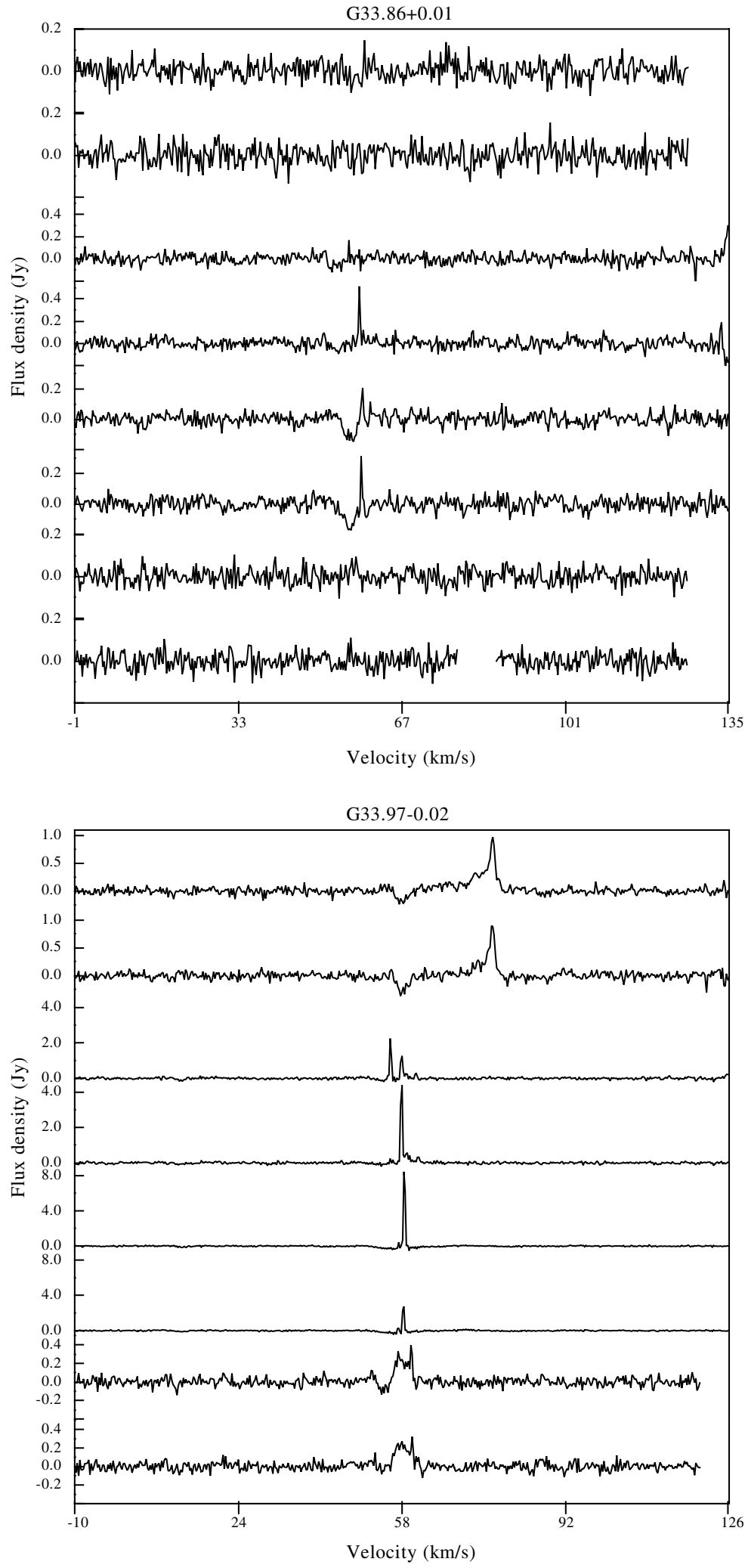

Fig. A.1. continued. 
M. Szymczak and E. Gérard: Hydroxyl ground state transitions in methanol sources, Online Material p 43
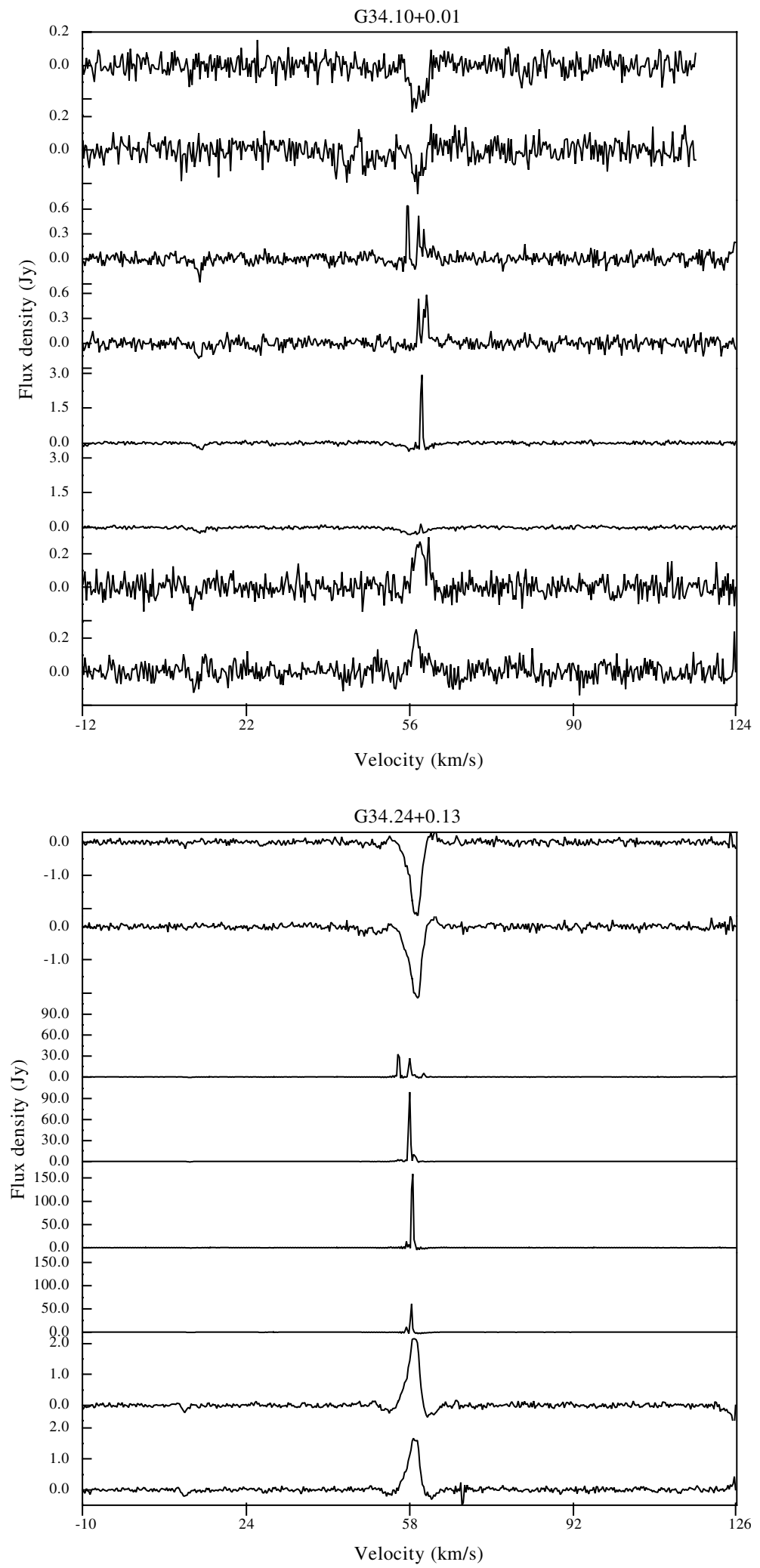

Fig. A.1. continued. 
M. Szymczak and E. Gérard: Hydroxyl ground state transitions in methanol sources, Online Material p 44
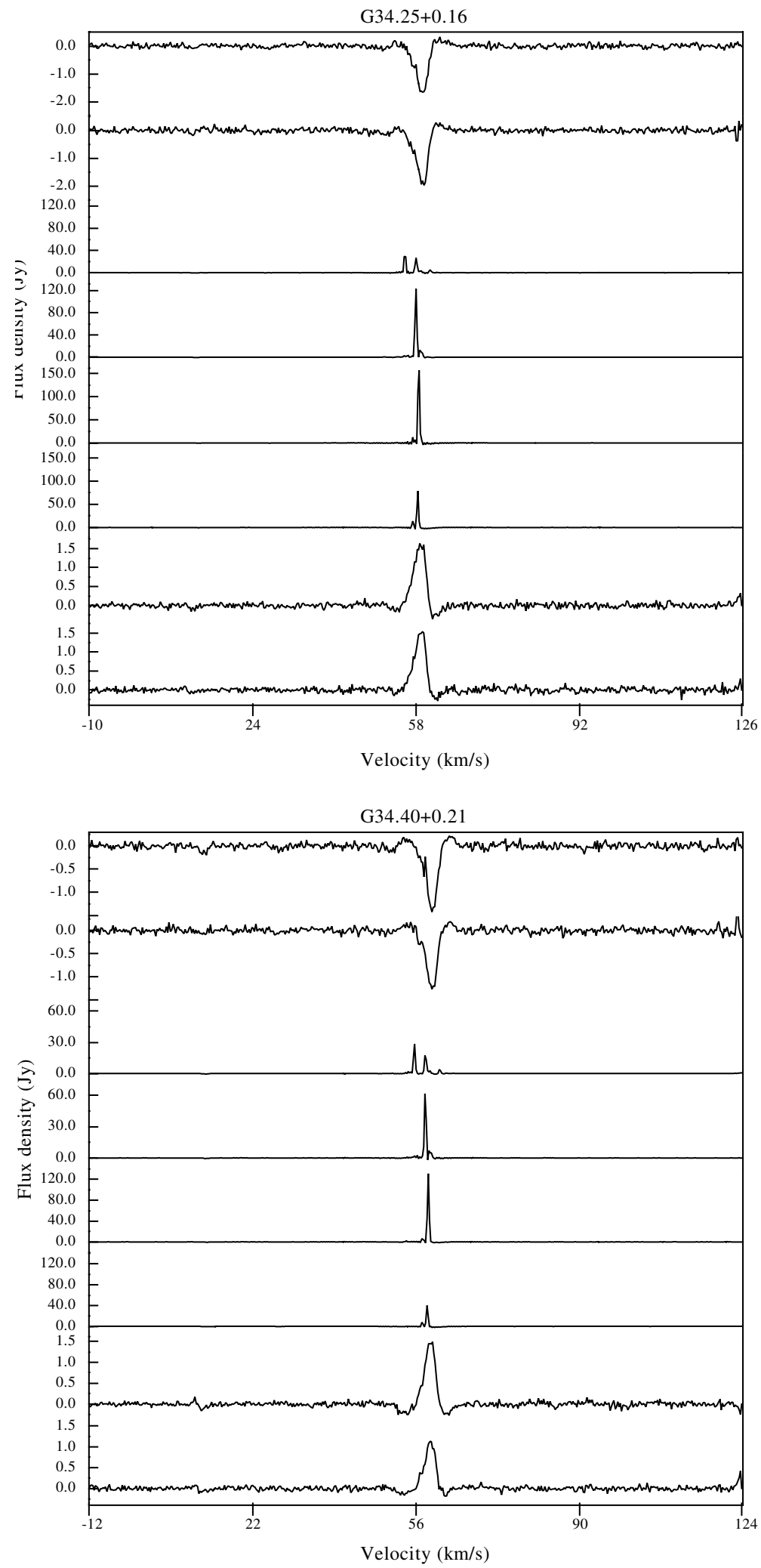

Fig. A.1. continued. 
M. Szymczak and E. Gérard: Hydroxyl ground state transitions in methanol sources, Online Material p 45
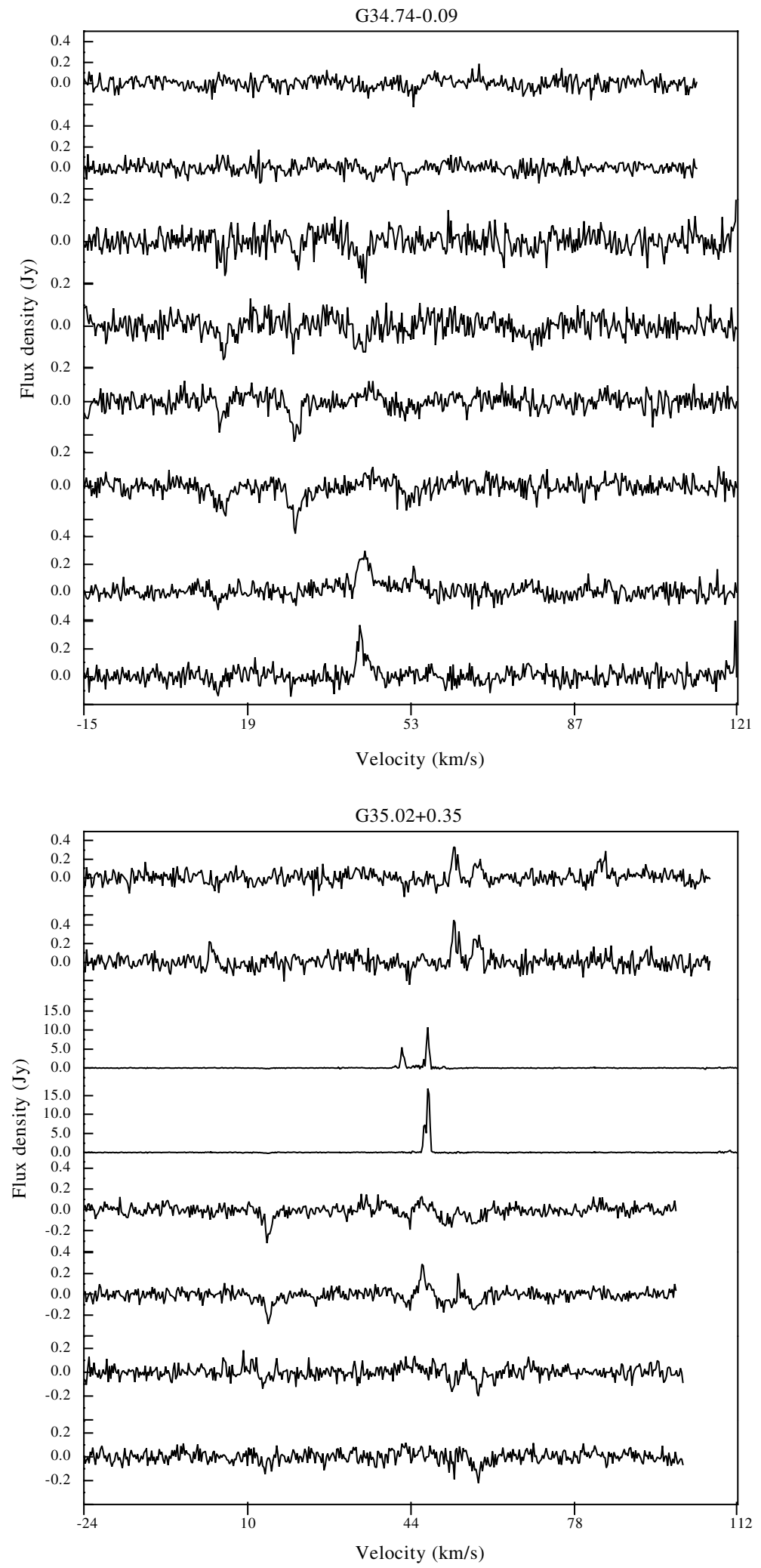

Fig. A.1. continued. 
M. Szymczak and E. Gérard: Hydroxyl ground state transitions in methanol sources, Online Material p 46 G35.79-0.17
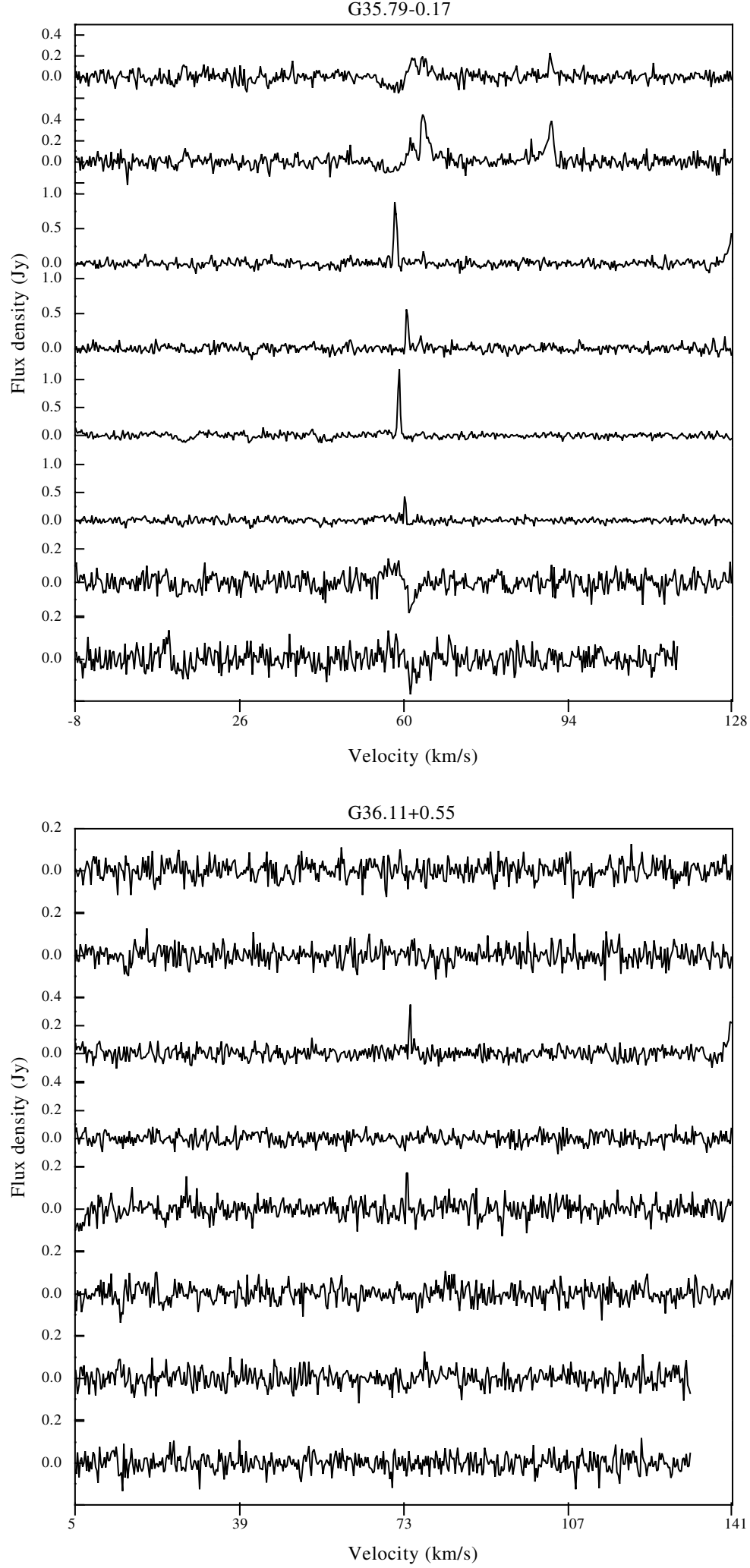

Fig. A.1. continued. 
M. Szymczak and E. Gérard: Hydroxyl ground state transitions in methanol sources, Online Material p 47
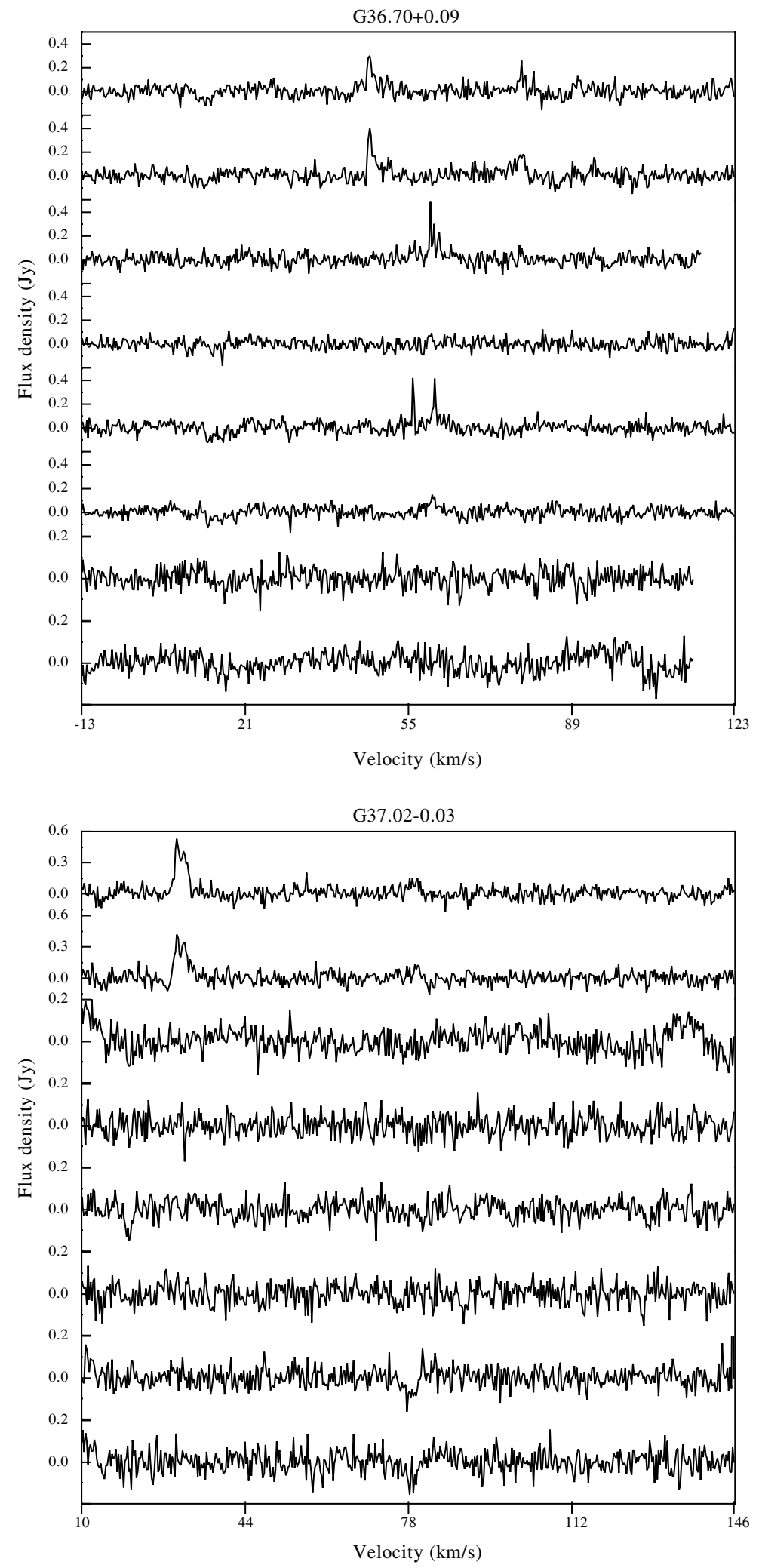

Fig. A.1. continued. 
M. Szymczak and E. Gérard: Hydroxyl ground state transitions in methanol sources, Online Material p 48
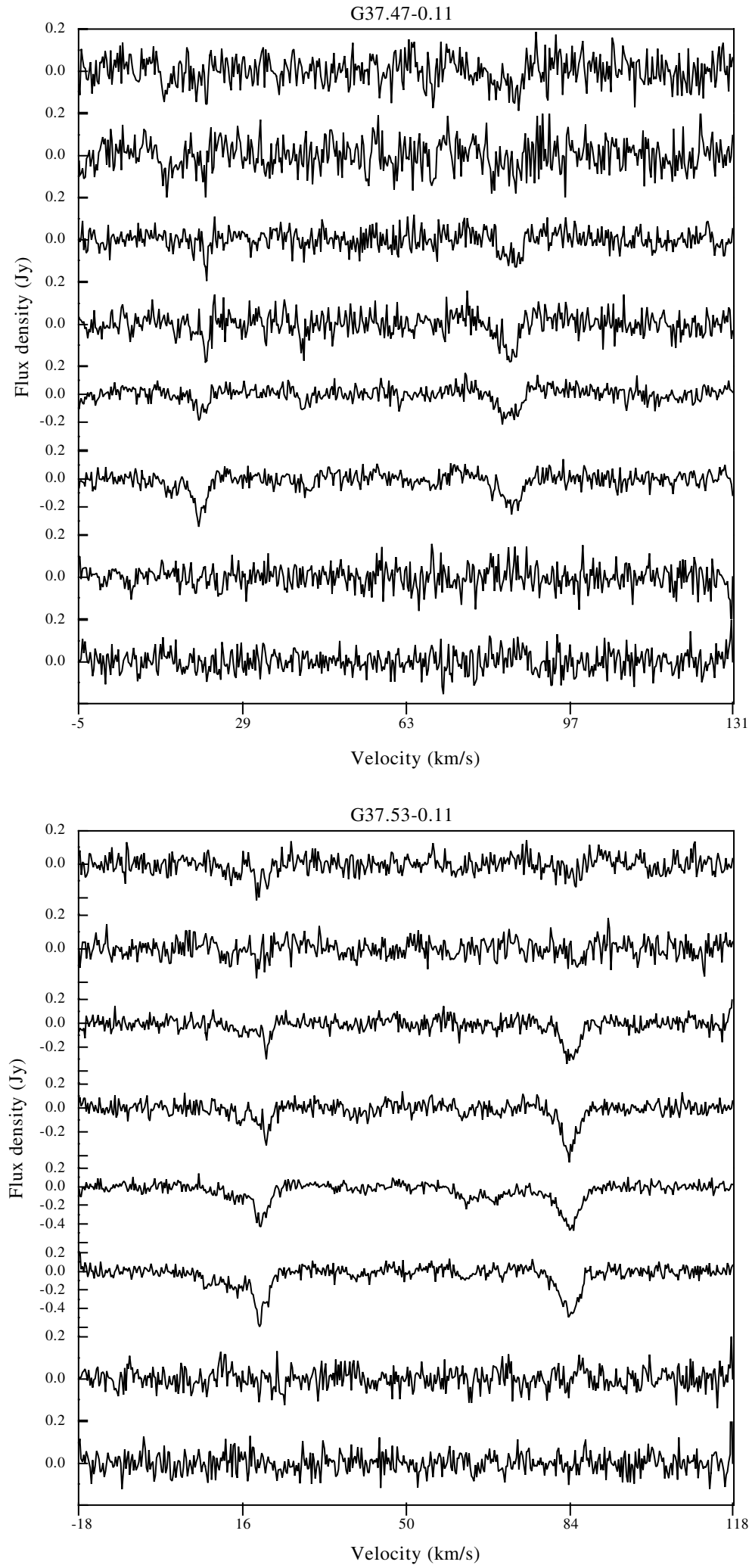

Fig. A.1. continued. 
M. Szymczak and E. Gérard: Hydroxyl ground state transitions in methanol sources, Online Material p 49
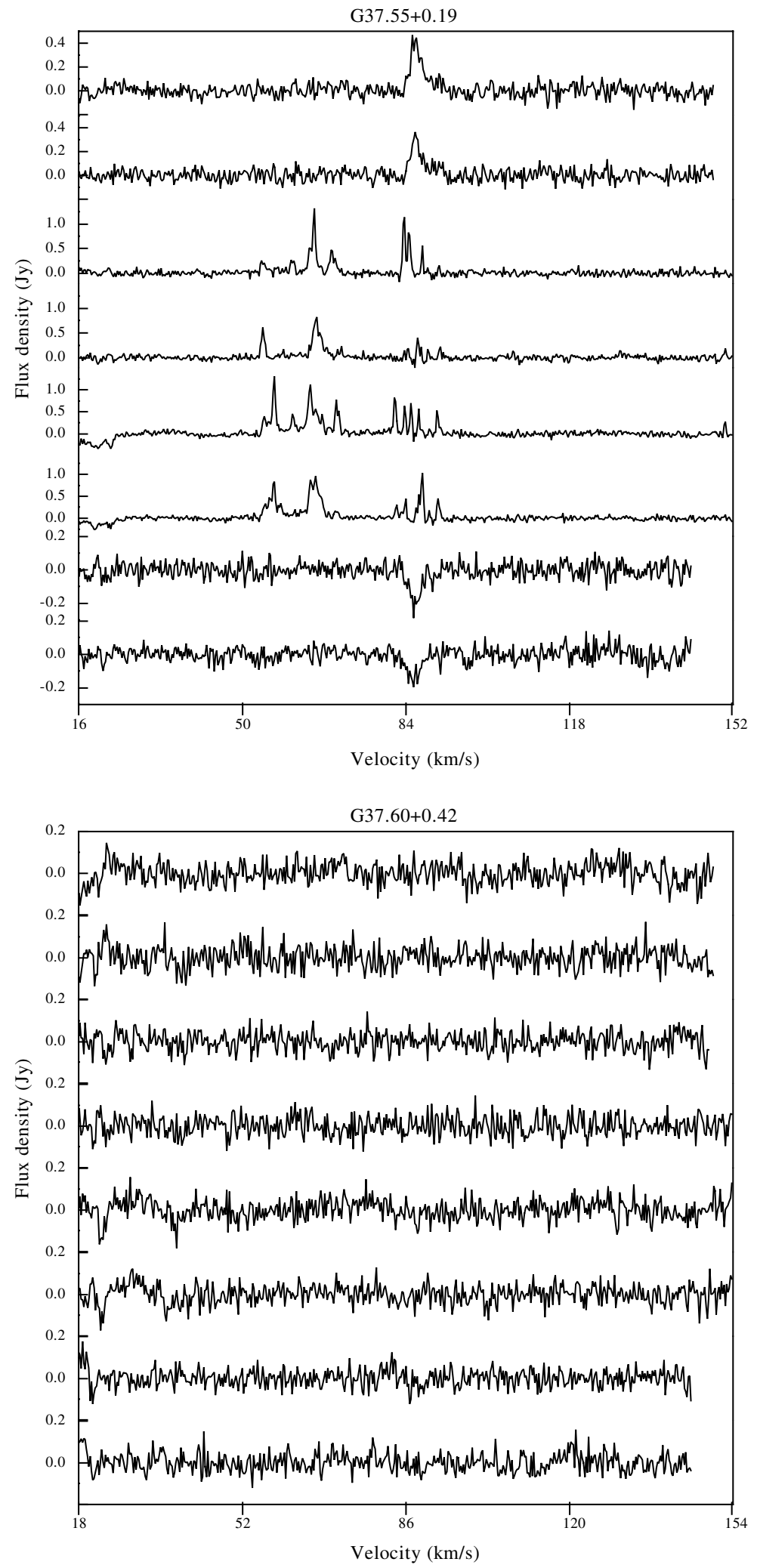

Fig. A.1. continued. 
M. Szymczak and E. Gérard: Hydroxyl ground state transitions in methanol sources, Online Material p 50
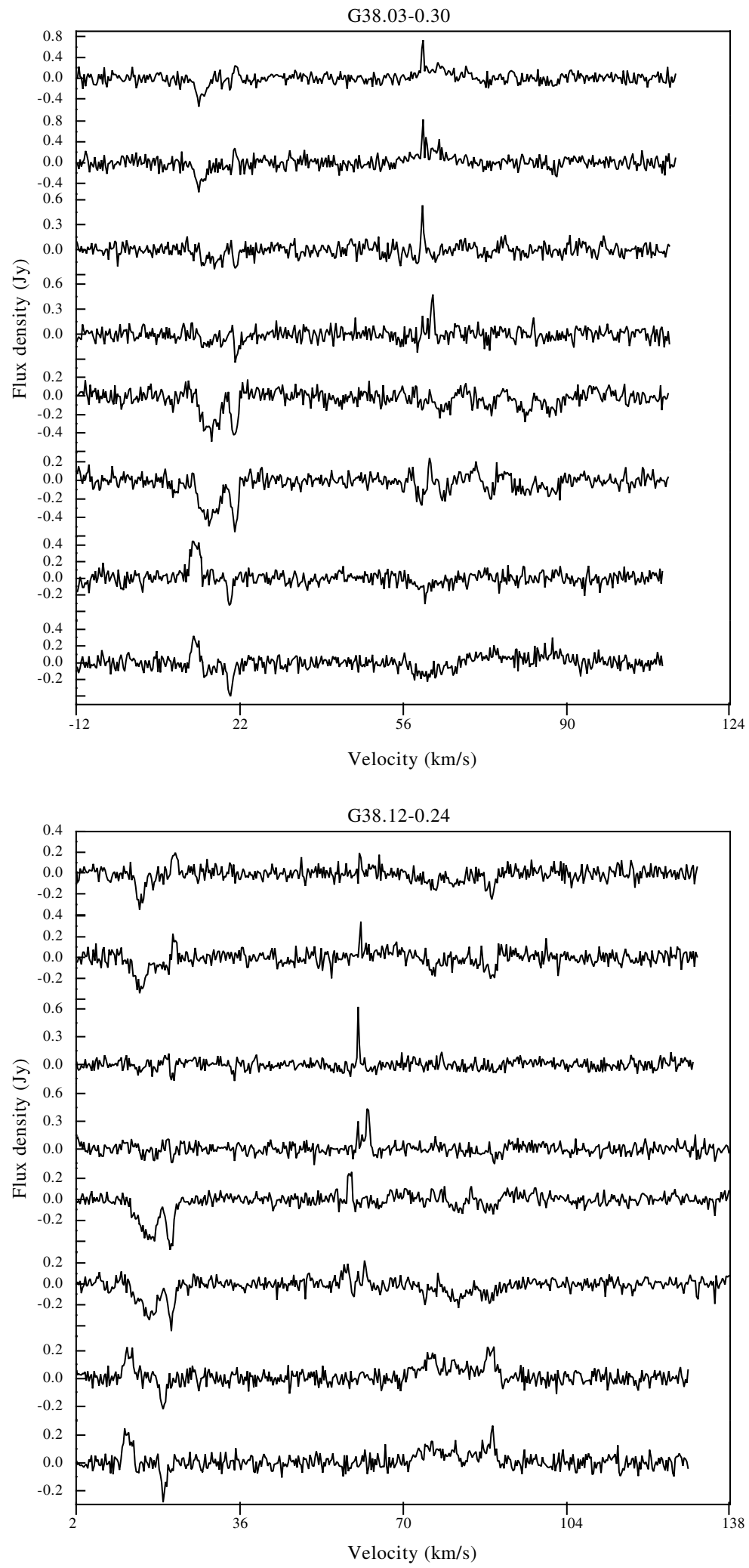

Fig. A.1. continued. 
M. Szymczak and E. Gérard: Hydroxyl ground state transitions in methanol sources, Online Material p 51
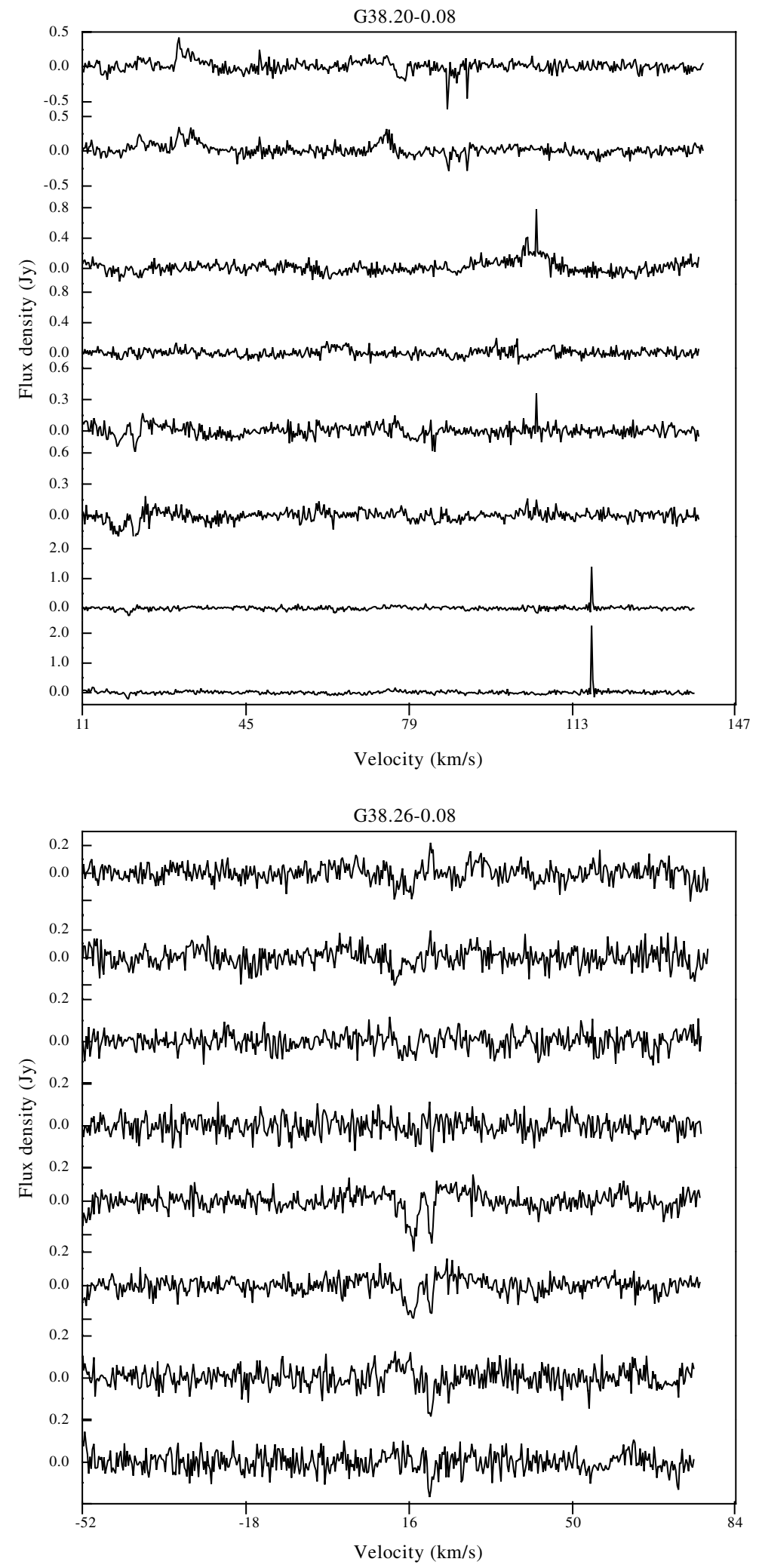

Fig. A.1. continued. 
M. Szymczak and E. Gérard: Hydroxyl ground state transitions in methanol sources, Online Material p 52

G39.10+0.48

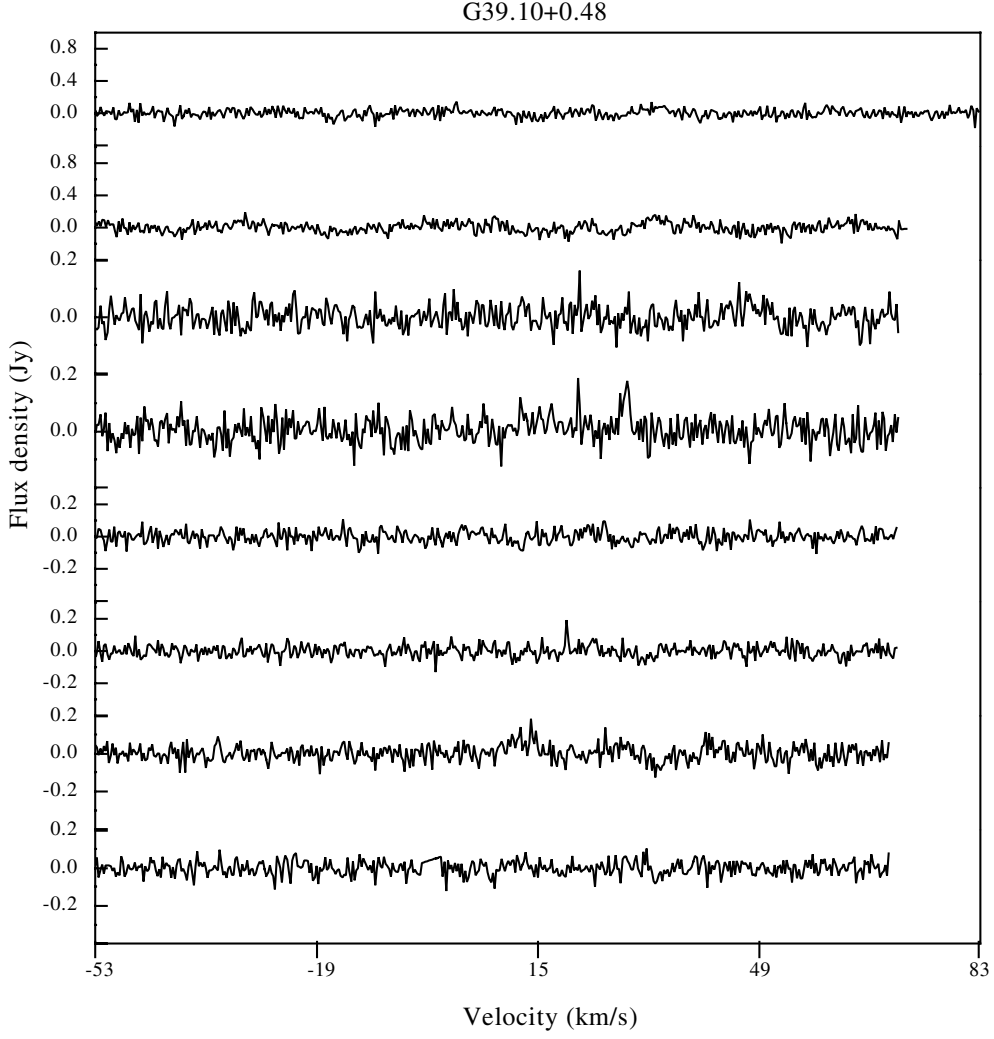

Fig. A.1. continued. 